\title{
SHEAR AND FLEXURAL BEHAVIOUR OF FIBER REINFORCED LIGHTWEIGHT SELF-CONSOLIDATING CONCRETE BEAMS
}

\author{
By \\ Ali Rashidian \\ BEng, Ryerson University, Toronto, Ontario, 2016
}

\author{
A Thesis \\ Presented to Ryerson University \\ in partial fulfillment of the \\ requirements for the degree of \\ Master of Applied Science \\ in the program of \\ Civil Engineering \\ Toronto, Ontario, Canada, 2018 \\ (C) Ali Rashidian 2018
}




\section{AUTHOR'S DECLARATION}

I hereby declare that I am the sole author of this thesis. This is a true copy of the thesis, including any required final revisions, as accepted by my examiners.

I authorize Ryerson University to lend this thesis to other institutions or individuals for the purpose of scholarly research.

I further authorize Ryerson University to reproduce this thesis by photocopying or by other means, in total or in part, at the request of other institutions or individuals for the purpose of scholarly research.

I understand that my thesis may be made electronically available to the public. 


\title{
SHEAR AND FLEXURAL BEHAVIOUR OF FIBER REINFORCED LIGHTWEIGHT SELF-CONSOLIDATING CONCRETE BEAMS
}

\author{
Ali Rashidian, Master of Applied Science, 2018 \\ Department of Civil Engineering \\ Ryerson University, Toronto, Canada
}

\begin{abstract}
This research studied the shear and flexural behaviour of fiber reinforced lightweight selfconsolidating concrete (FRLWSCC) beams made of three different fibers such as: High-Density Poly Ethylene (HDPE), Crumb Rubber (CR) and Polyvinyl Alcohol (PVA) compared with lightweight self-consolidating concrete (LWSCC) beams. The performances of all beams were described based on load-deformation or moment-rotation response, strain developments, crack characterization, failure modes, ductility, stiffness and energy absorbing capacity. All FRLWSCC shear beams showed higher ultimate shear resistance, ductility and energy absorption capacity compared to LWSCC beams. All FRLWSCC flexural beams at failure exhibited higher flexural capacity, more cracks with smaller width, higher ductility, higher energy absorption capacity and lower stiffness compared to their LWSCC counterparts. FRLWSCC beams especially made of HDPE fibers showed better shear and flexural capacities besides satisfactory ductility performance. Experimental shear and flexural capacities of FRLWSCC beams were compared with those predicted from Code based and other existing equations.
\end{abstract}




\section{ACKNOWLEDGEMENTS}

I wish to express my deepest gratitude to my supervisor Professor Dr. Khandaker M. Anwar Hossain whose insight, guidance, meticulous review, and criticism of the work had a significant impact on this thesis. Without his time and countless efforts, this thesis would not have been completed. His inspirational attitude toward research, trust in his graduate students, and insight into the problems left a significant impression on this work. I cannot thank him enough as my life will always bear an imprint of his teachings and vision.

I would also like to thank the examining committee members for their revisions and suggestions. I also thank all my colleagues and lab technicians in the Civil Engineering Department at Ryerson University. Especial thanks to PhD Candidate Ali Ehsani Yeganeh for his great help, support and guidance and also to Farzad Kouroshnezhad (lab assistant) for his helpduring casting and testing in the concrete and structural laboratories. 


\section{DEDICATIONS}

To my parents and brother

Who sacrifice their life for my greatest success

And our technical lab staff, Min Yao

Who passed away during my research 


\section{TABLE OF CONTENTS}

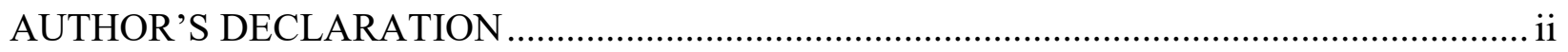

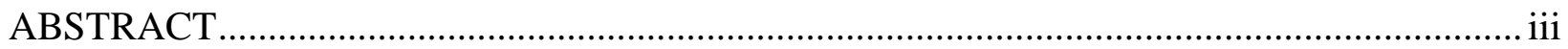

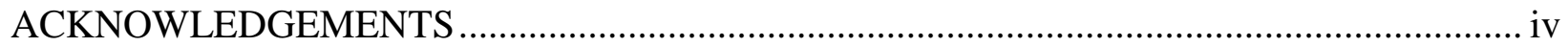

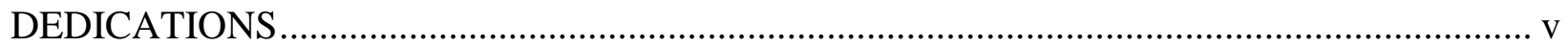

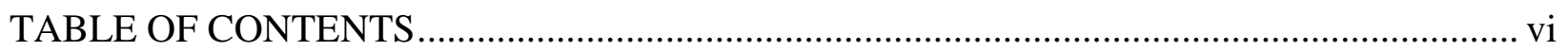

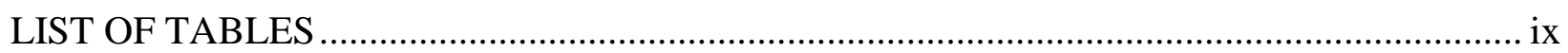

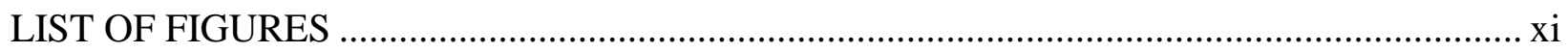

LIST OF SYMBOLS AND ABBREVIATIONS ……….................................................. xiv

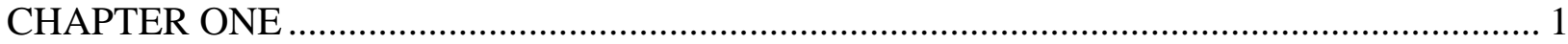

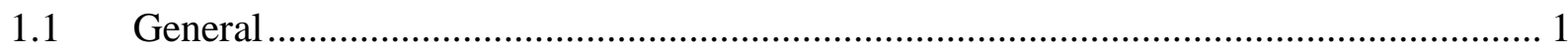

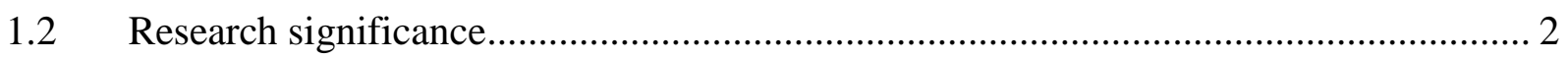

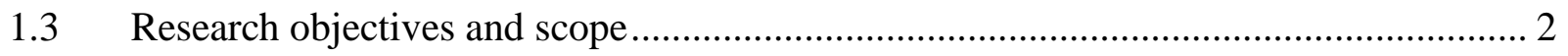

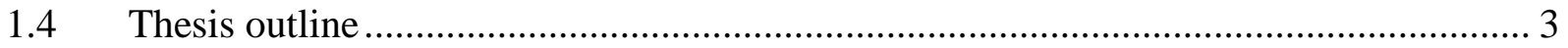

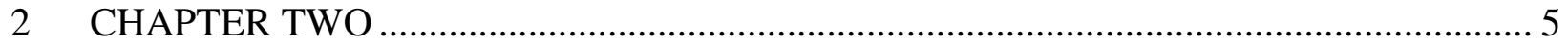

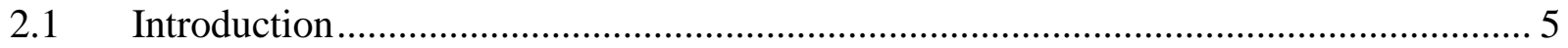

2.2 Lightweight aggregate …………………………............................................. 5

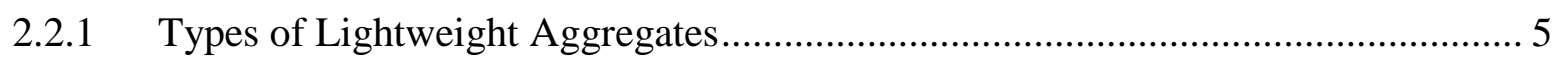

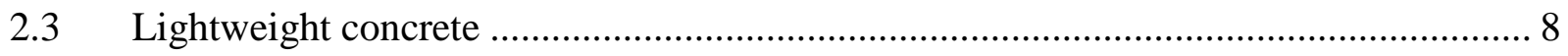

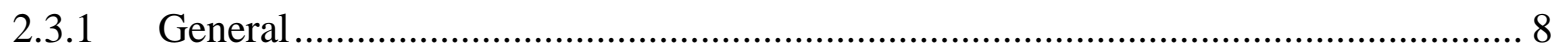

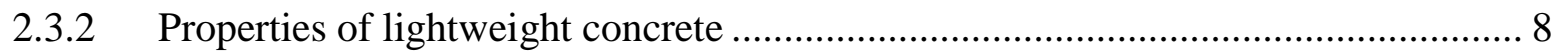

2.3.3 Compressive strength of lightweight concrete....................................................... 9

2.3.4 Modulus of elasticity of lightweight concrete .................................................... 10

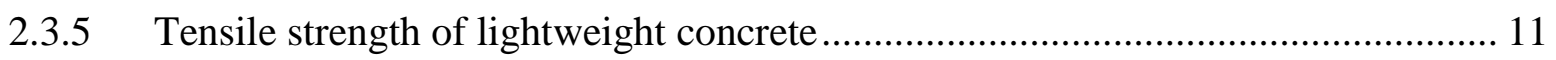

2.3.6 Examples of some studies on lightweight concrete ............................................. 12

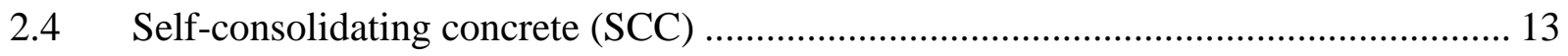

2.5 Lightweight self-consolidating concrete ................................................................. 14

2.5.1 Example of some studies on lightweight self-consolidating concrete .................... 15

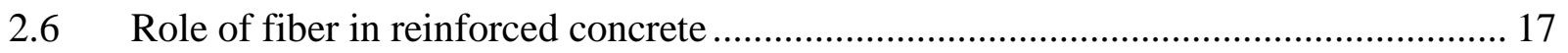

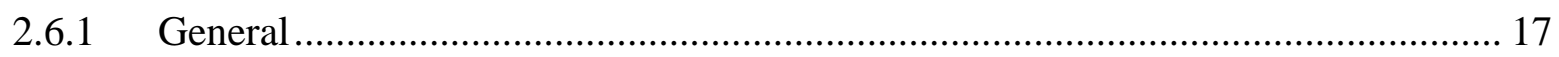

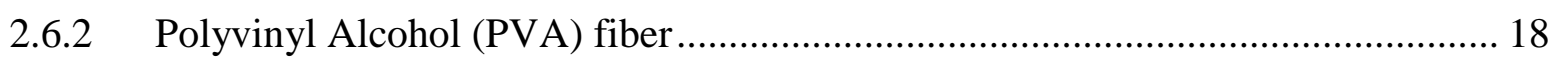




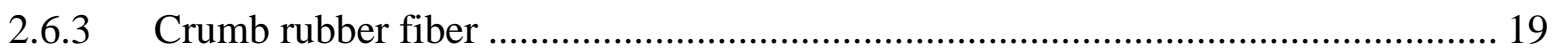

2.6.4 High Density poly ethylene (HDPE) fiber ...................................................... 20

2.7 Fiber reinforced lightweight self-consolidating concrete ……………………............... 21

2.7.1 Studies on fiber reinforced self-consolidating concrete........................................ 22

2.8 Design aspects of lightweight self-consolidating concrete members ........................... 28

2.8.1 Basic shear transfer mechanism for beams without shear reinforcement ............... 28

2.8.2 Shear transfer mechanism for beams with shear reinforcement ............................ 29

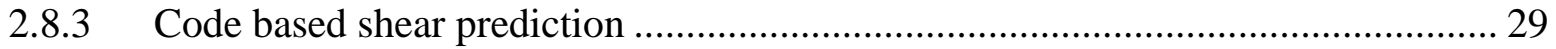

2.8.4 Shear strength of reinforced lightweight concrete members …………………...... 31

2.8.5 Studies on shear behavior of lightweight reinforced concrete beams..................... 32

2.9 Analysis of reinforced concrete member in flexure................................................... 34

2.9.1 Theoretical ultimate moment of the LWSCC flexural beams ................................ 35

2.9.2 Some previous studies of flexural behavior of lightweight concrete beams .......... 36

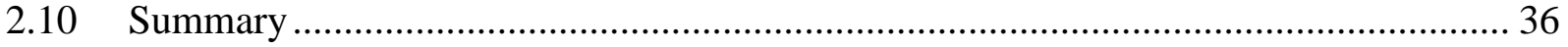

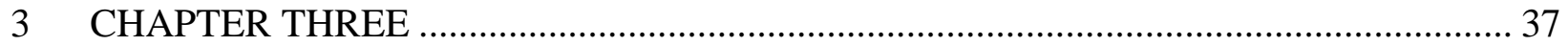

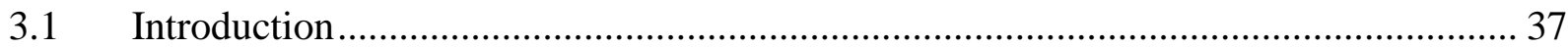

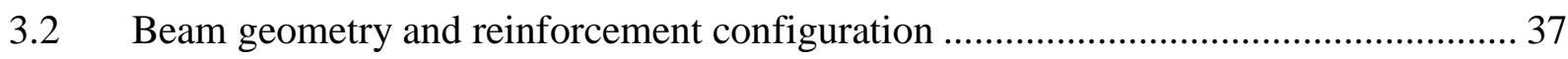

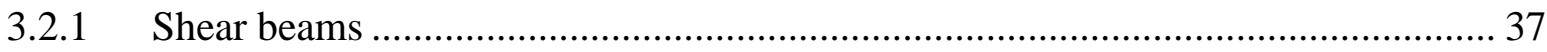

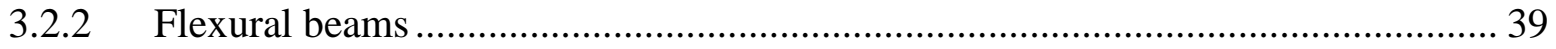

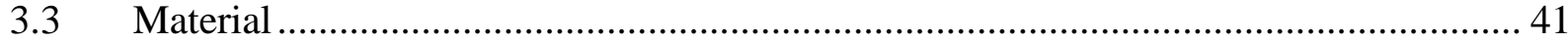

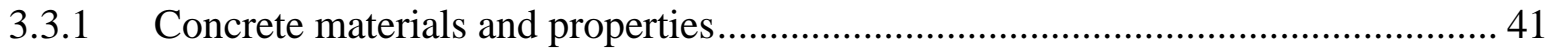

3.3.2 Steel reinforcement properties ......................................................................... 44

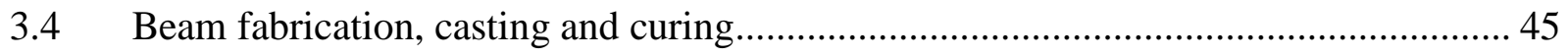

3.5 Experimental set up and instrumentation................................................................... 47

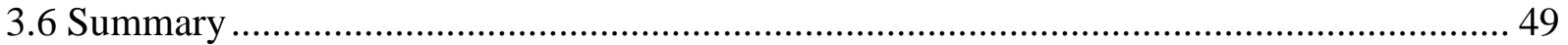

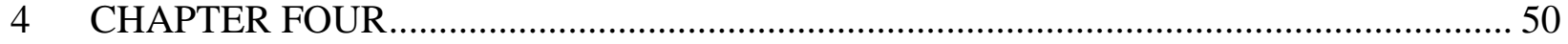

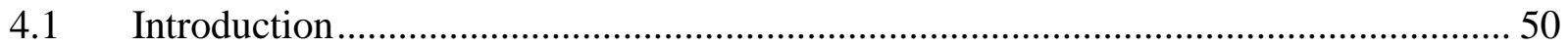

4.2 FRLWSCC and LWSCC shear beams without shear reinforcement........................... 50

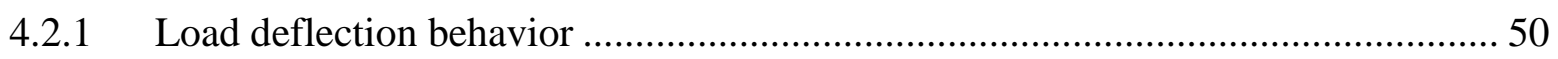

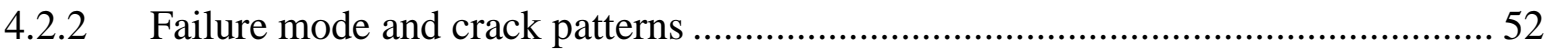

4.2.3 Post cracking shear resistance, ductility and energy absorption ............................. 56

4.3 LWSCC shear beams with shear reinforcement .......................................................... 58 


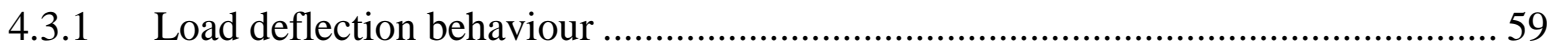

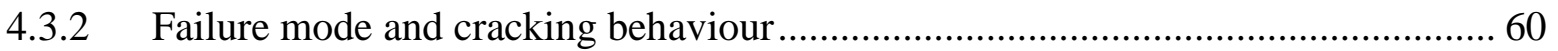

4.3.3 Strain development in the flexural and shear reinforcement ................................ 66

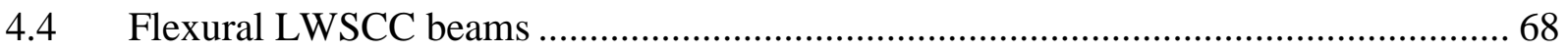

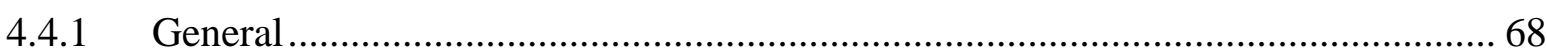

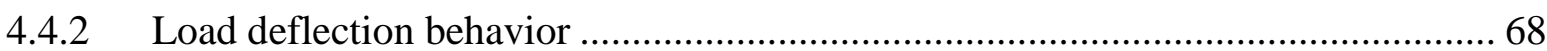

4.4.3 Failure mode, crack pattern and ultimate load capacity ......................................... 69

4.4.4 Strain development in concrete and flexural/shear reinforcements ........................ 73

4.4.5 Bending moment and beam end rotation development.......................................... 74

4.4.6 Ductility behavior, energy absorption capacity and stiffness of FRLWSCC-F beams 75

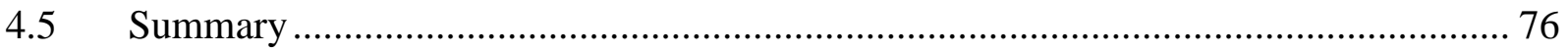

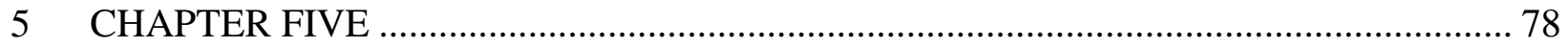

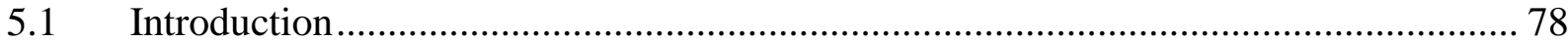

5.2 Codes and the prediction of shear capacity of beams …………………………....... 78

5.3 Shear strength prediction of FRLWSCC beams without shear reinforcement .............. 81

5.4 Shear strength prediction of FRLWSCC-S-S beams based on design codes ............... 82

5.5 Shear strength prediction of FRLWSCC-S and FRLWSCC-S-S beams with existing

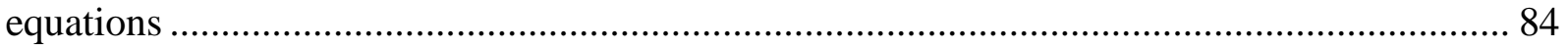

5.6 Code based prediction of flexural capacity of FRLWSCC beams .............................. 85

5.6.1 Theoretical cracking moment of the FRLWSCC flexural beams ........................... 85

5.7 Theoretical ultimate moment of the LWSCC flexural beams ..................................... 86

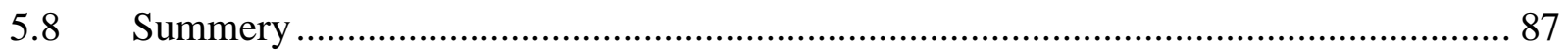

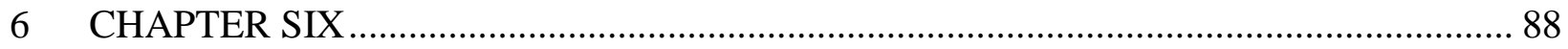

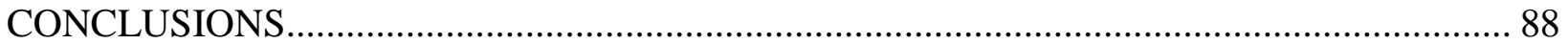

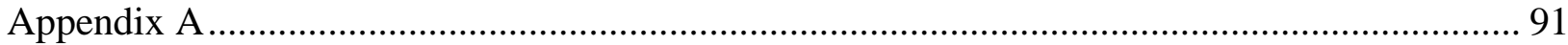

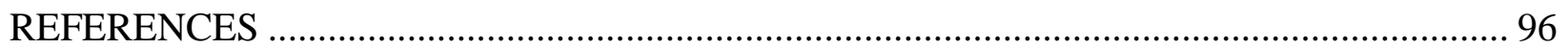




\section{LIST OF TABLES}

Table 2.1: Natural and artificial lightweight aggregates.................................................. 6

Table 2.2: Maximum dry loose bulk density of LWA for Structural Concrete (ASTM C330, 2014)

Table 2.3: Compressive Strength and Splitting Tensile Strength Requirements (ASTM C330,

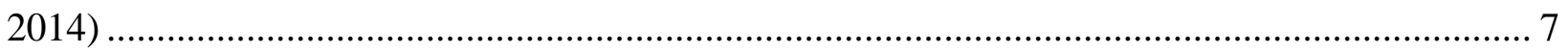

Table 2.4: Compressive strength and modulus of elasticity of aggregates and cement mortar (Gerritse1981) 11

Table 2.5: Geometrical and mechanical properties of PVA fiber........................................ 18

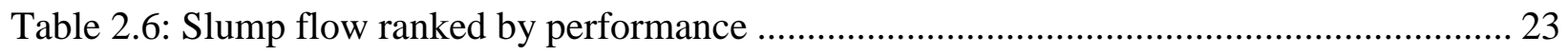

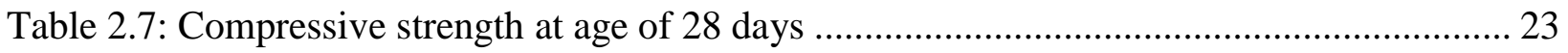

Table 2.8: Details of the experimental POCC beams (Mohammed, Foo, Hossain, Abdullahi, \&

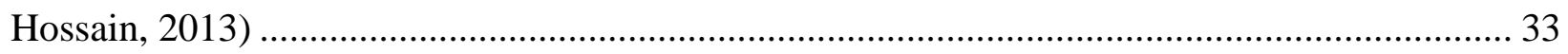

Table 2.9: lightweight concrete beam's details tested (Juan, 2011)...................................... 34

Table 3.1: Geometric dimensions and reinforcement details for shear beams ........................... 39

Table 3.2: Geometric dimensions and reinforcement details for flexural beams ...................... 40

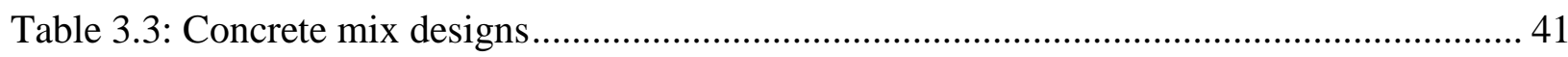

Table 3.4: Properties of cementitious materials .............................................................. 42

Table 3.5: Aggregates gradation and physical properties ............................................... 42

Table 3.6: Geometrical and mechanical properties of fibers ............................................ 44

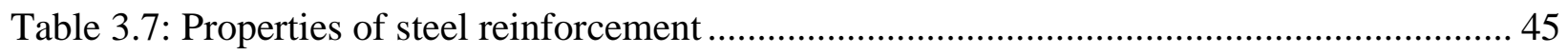

Table 3.8: Concrete compressive strength, flexural strength and density at 28 days ................. 46

Table 4.1: Experimental summary for shear beams without shear reinforcement .................... 53

Table 4.2: Summery of crack width and number of shear beams without shear reinforcement... 55 
Table 4.3: Shear resistance and ductility factor for the shear beams without shear reinforcement 57

Table 4.4: Experimental results summary for tested shear beams with shear reinforcement...... 61 Table 4.5: Summery of ductility factor, energy absorption and stiffness of shear beam with shear

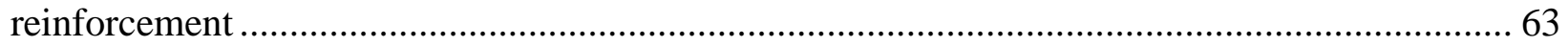

Table 4.6: Summery of crack width and number of shear beams without shear reinforcement... 63

Table 4.7: Summery of load strain performance of tested shear reinforced beams................... 66

Table 4.8: Summary of loads, moment and failure modes of flexural beams .......................... 70

Table 4.9: Summery of crack width and number of flexural beams................................... 71

Table 4.10: Summary of yield load, ultimate load/moment and strain for tested flexural beams 74

Table 4.11: Summery of ductility factor, energy absorption and stiffness of flexural beams ...... 76

Table 5.1: Shear resistance of beams without shear reinforcement from experiment and code based

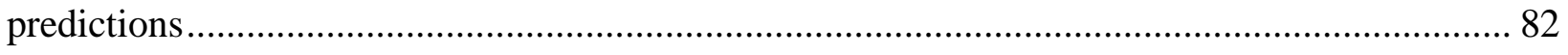

Table 5.2: Shear resistance of beams shear reinforcement from experiment and code based

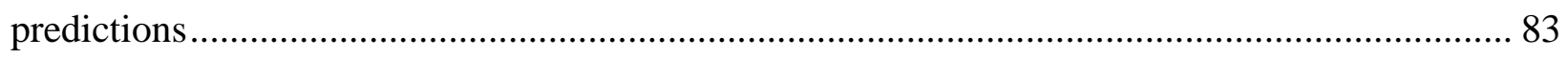

Table 5.3: Experimental and theoretical shear capacity comparison..................................... 84

Table 5.4 Experimental and theoretical cracking moment comparison................................. 86

Table 5.5 Comparison of experimental and theoretical ultimate moments of LWSCC beans ..... 87 


\section{LIST OF FIGURES}

Figure 2.1: Lytage aggregate and internal pore structure (Lotfy, 2012)................................. 6

Figure 2.2: Lightweight concrete crack pattern (Left), Normal weight concrete crack pattern (Right) 10

Figure 2.3: Schematic of split tensile strength test (left) and flexural tensile test (right) (Garg et al. , 2014) 12

Figure 2.4: Self consolidating concrete (SCC) (civilexi 2014) ............................................ 14

Figure 2.5: Load deflection response (Sathiyamoorthy, Hossain, \& Lotfy, 2016).................... 15

Figure 2.6: Failure modes of beams (Sathiyamoorthy et al., 2016)......................................... 16

Figure 2.7: Ultimate tensile strain of ECC for (a) uncoated and (b) coated fiber (Li, et al., 2003)

Figure 2.8: The compressive strength of the concretes (Pelisser et al. 2010) .......................... 19

Figure 2.9: Tensile, compressive and flexural strength of concrete with HDPE fiber ............... 21

Figure 2.10: shear transfer in beam without shear reinforcement .......................................... 29

Figure 2.11: The experimental set-up for the reinforced POCC beams (Mohammed et al., 2013)

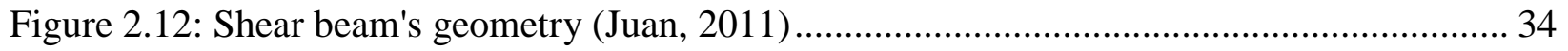

Figure 3.1: Shear beam without shear reinforcement geometry, cross section and loading points. 38

Figure 3.2: Shear beams with stirrups geometry, cross-section and loading points ................... 38

Figure 3.3: Flexural beam's geometry and loading points sketch........................................... 40

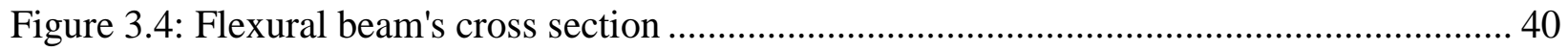

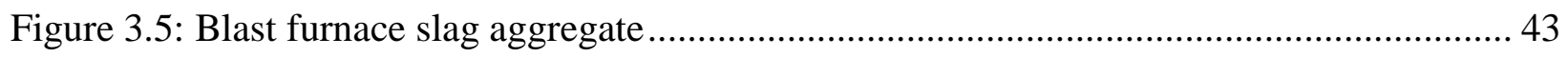

Figure 3.6: Aggregate pre-soaking and Aggregate in SSD condition ................................... 43

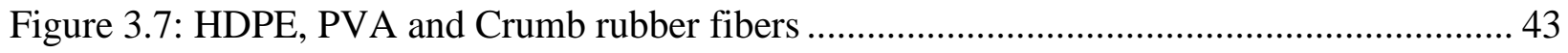


Figure 3.8: Rebar stress-strain/deformation responses of steel rebars.

Figure 3.9: Flexural strength load-deflection curves (a) LWSCC (b) CR-LWSCC (c) HDPE-

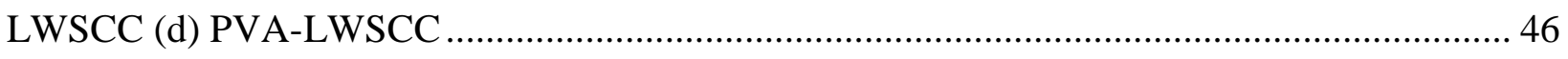

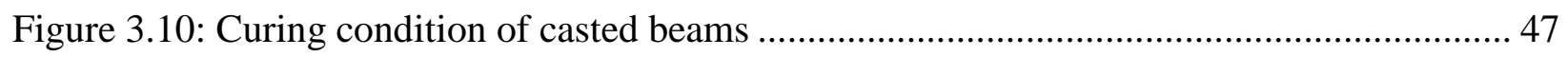

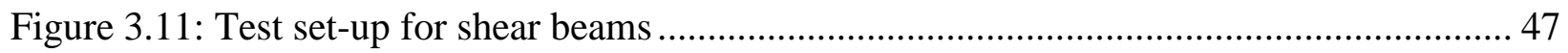

Figure 3.12: Location of strain gauges for shear beams with and without stirrups ................... 48

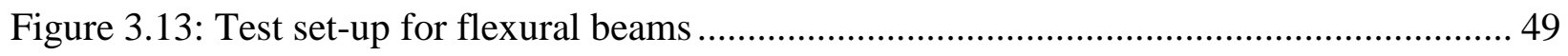

Figure 3.14: Location of strain gauges for flexural beams ............................................. 49

Figure 4.1: Comparative load-deflection curve for shear beams without shear reinforcement.... 51

Figure 4.2: Load-deflection responses of beams (a) HDPE-LWSCC-S (b) CR-LWSCC-S (c) PVA-

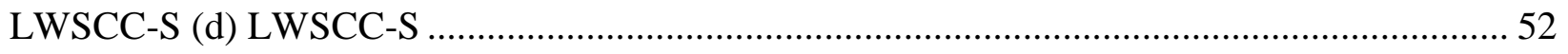

Figure 4.3: (a) Failure modes of tested shear beams without shear reinforcement, (a) HDPELWSCC-S (b) PVA-LWSCC-S (c) CR-LWSCC-S (d) LWSCC-S ....................................... 54

Figure 4.4: Crack width and pattern for shear beans without shear reinforcement, (a) HDPELWSCC-S (b) PVA-LWSCC-S (c) CR-LWSCC-S (d) LWSCC-S ........................................ 56

Figure 4.5: Normalized comparative shear load-deflection responses for all shear beams without

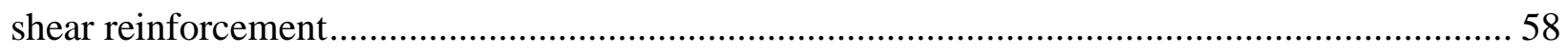

Figure 4.6: Comparative load-mid span deflection curve for beams with shear reinforcement... 59

Figure 4.7: Load-deflection responses (a) HDPE-LWSCC-S-S (b) CR-LWSCC-S-S (c) PVALWSCC-S-S (d) LWSCC-S-S 60

Figure 4.8: Failure modes of tested shear beams with shear reinforcement (a) HDPE-LWSCC-S-S

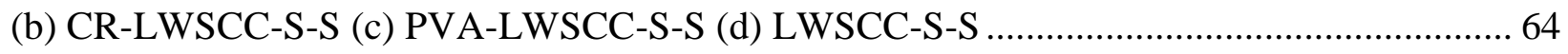

Figure 4.9: Crack width and pattern for shear beans without shear reinforcement (a) HDPELWSCC-S-S (b) CR-LWSCC-S-S (c) PVA-LWSCC-S-S (d) LWSCC-S-S ........................... 65

Figure 4.10(a): Load-strain curves for shear beams with shear reinforcement (a) HDPE-LWSCC-

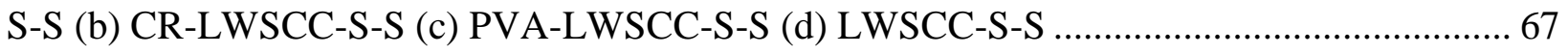


Figure 4.11: Load-deflection curve for tested flexural beams: (a) HDPE-LWSCC-F, (b) CR-

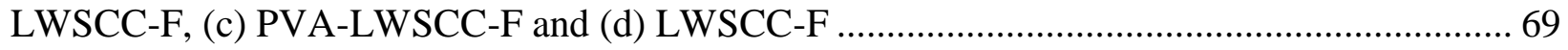

Figure 4.12: Crack patterns at the centre of flexural beams (a) CR-LWSCC-F, (b) LWSCC-F, (c)

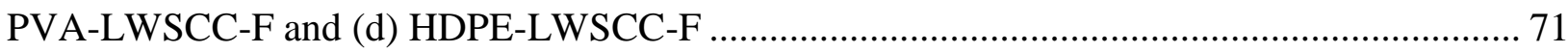

Figure 4.13: Crack pattern and failure modes of flexural beams (a) HDPE-LWSCC-F, (b) CR-

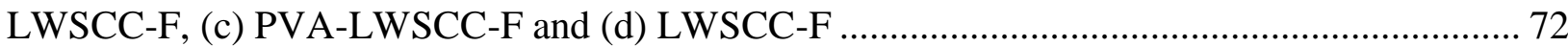

Figure 4.14: Load-strain curves for tested: (a) HDPE-LWSCC-F, (b) CR-LWSCC-F, (c) PVA-

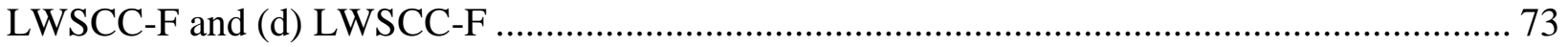

Figure 4.15: Moment-rotation curves for tested flexural beams.......................................... 75 


\section{LIST OF SYMBOLS AND ABBREVIATIONS}

a: Depth of the equivalent compressive block

$a_{g}$ : Maximum size of aggregate in the concrete

$a_{s}:$ Shear span

$a_{b}$ : The balance depth of the compression zone

$A_{f}$ : Cross-sectional area of steel fibers

$A_{v}$ : Area of shear reinforcement

$A_{s}$ : Tension reinforcement area

$\mathrm{A}_{\mathrm{sv}}$ : Area of shear reinforcement

$A_{s, \min }$ : Minimum area of tensile reinforcement

$A_{v, \min }$ : Minimum area of shear reinforcement

b: Width of the cross-section

$b_{t}$ : The width of tension zone

$\mathrm{C}$ : Concrete compressive force

$\mathrm{C}_{\mathrm{s}}$ : Force in the compression steel

$\mathrm{C}_{\mathrm{c}}$ : Compression fore in concrete

c: Depth of neutral axis from the top fiber

d: Effective depth

$\mathrm{d}^{\prime}$ : Distance from extreme compression fibre to centroid of compression reinforcement

$d_{f}$ : Fiber bond factor

$d_{v}$ : Effective depth of concrete block

$D_{c}$ : Deflection at first diagonal crack

$D_{u}$ : Deflection at peak shear load

$D_{y}$ : Deflection at first yielding of steel

$D_{f}$ : Diameter of fiber

DI: Ductility index

$E_{s}$ : Modulus of elasticity of non-prestressed reinforcement

$E_{f}$ : Modulus of elasticity of fibers

$f^{\prime}{ }_{c}$ : Cylinder compressive strength of concrete

$f^{\prime}{ }_{c f}$ : Compressive strength of fibrous concrete

$f_{y}$ : Yield strength of tensile reinforcement bar 
$f_{c u}$ : Cube compressive strength

$f_{y v}$ : Yield strength of shear reinforcement

$f_{s p f c}$ : Split cylinder strength of fiber concrete

$f_{c u f}$ : Cube strength of fiber concrete

$\mathrm{h}$ : Total beam height

$I_{g}$ : Second moment of inertia

$l_{f}$ : Length of fibers

$M_{f}$ : Factored moment

$M_{c r}$ : Cracking moment

$M_{u}$ : Ultimate moment capacity

$M_{r}$ : Resisting moment capacity

$r_{f}$ : Radius of steel fibers

$S_{Z}$ : Crack spacing parameter

$s_{v}$ : Spacing of shear reinforcement

$s$ : Spacing of shear reinforcement

$\mathrm{T}$ : Tensile force in bottom steel.

$\mathrm{V}$ : Shear force in a concrete section

$V_{c}$ : Shear resistance of compression zone

$V_{a}$ : Interlocking action of aggregates

$V_{d}$ : Dowel action

$V_{n}$ : Shear resistance of the beam

$V_{u}$ : Ultimate shear force

$V_{f}$ : Factored shear force

$V_{r}$ : Resisting shear capacity

$V_{f l}$ : Shear at first flexural crack

$V_{n u}$ : Normalized ultimate shear load

$V_{n c}$ : Normalized inclined cracking shear load

$V_{n c z}$ : Normalized shear stress

$w / b$ : Water to binder ratio

$\mathrm{x}$ : Distance

$y_{t}$ : Distance from the extreme tension fiber to the neutral axis 
$\propto_{1}$ : Concrete stress block parameter

$\beta_{1}$ : Concrete stress block parameter

$\varepsilon_{\mathrm{c}}:$ Concrete strain

$\varepsilon_{\mathrm{f}}$ : Fiber tensile strain

$\varepsilon_{\mathrm{y}}:$ Reinforcement strain

$\rho_{\mathrm{s}}$ : Longitudinal reinforcement ratio

$\phi_{\mathrm{c}}:$ Concrete reduction factor

$\phi_{\mathrm{s}}:$ Steel reduction factor

$\lambda$ : Concrete stress block parameter

$\eta_{b}$ : Fiber bond efficiency factor

$\eta_{l}$ : Fiber length efficiency factor

$\eta_{0}$ : Fiber orientation facto

$\theta$ : Cracks angle

$\tau_{f}$ : Bond strength between the fiber and matrix

$\phi$ : Diameter 


\section{CHAPTER ONE}

\section{INTRODUCTION}

\subsection{General}

Concrete can be mentioned as one of the most commonly used construction materials around the world (Sideris \& Savva, 2005). In order to achieve proper quality of construction regardless of adequate consolidation, Self-Consolidating Concrete (SCC) - a new type of high performance concrete which can consolidate under its own weight was developed in Japan (Hassan et al., 2010; Okamura \& Ouchi, 2003). Lots of researches have been dedicated to developing different types of SCC in the last few years to improve fresh state and mechanical properties. Lightweight selfconsolidating concrete (LWSCC) and fiber reinforced lightweight self-consolidating concrete (FRLWSCC) are two of the latest innovations in SCC productions which have combination of flowability of SCC, low dead weight of lightweight concrete (LWC) and improved ductility and mechanical properties of fiber reinforced concrete (FRC) (Khayat \& Roussel 2000; Ding et al., 2008; Aydin, 2007; Nehdi \& Ladanchuk, 2004).

The primary advantage of SCC is that it can consolidate under its own weight and spread through the congested reinforced elements with no external vibration (Yehia et al., 2016). These properties of SCC lead to reduce labour cost, casting time and request of different equipment for compaction. SCC offers ease of placing and transporting which allow its application in different projects such as residential building or large infrastructures especially with congested reinforcements (Yehia et al., 2016).

Lightweight concrete (LWC) has been produced successfully for many years by using lightweight aggregates (LWAs). Replacement of LWAs as a substitute of normal weight aggregates lead to reduction in density of LWC compared to ordinary concrete which is in range of $1400 \mathrm{~kg} / \mathrm{m}^{3}$ to $2000 \mathrm{~kg} / \mathrm{m}^{3}$ (ACI 211.2, 1981; Bamforth, 1987). Lightweight aggregates can be either natural aggregates such as pumice, scoria, diatomite etc. or artificial aggregates which are produced usually by expanding the rocks such as slate, shale, siliceous rock and etc. (ACI 211.2, 1981; Bamforth, 1987; Topcu, 1997; Bai et al., 2004; Hossain \& Lachemi, 2007a; Hossain et al., 2011; Hossain, 2004a-b; Curcio et al., 1998). High porosity structure of lightweight aggregates has the 
potential of reduction in thermal conductivity, dead weight of concrete structures and increase heat and sound insulation (K M A Hossain \& Lachemi, 2007).

Fiber reinforced lightweight self-consolidating concrete (FRLWSCC) is a new type of SCC which has combination of best properties of FRC and LWSCC. Recently some researches have been conducted on the optimization of the performance of using lightweight aggregate and fiber at the same time in SCC to improve its performance in different applications.

\subsection{Research significance}

Although researches have been conducted on the mix design and properties of LWSCC over the recent years (Lotfy et al., 2016a-b; Lotfy et al., 2015a-b; Hossain et al., 2014), very limited number of studies were conducted on the mix design/development of FRLWSCCs and structural performance of FRLWSCC/LWSCC. The proposed research on the shear and flexural performance of FRLWSCC/LWSCC beams is a timely initiative to make significant contributions to the FRLWSCC/LWSCC technology.

Lightweight concrete is being more and more widely used due to its better structural and durability performance. The lack of research studies specifically in Canada requires a detailed investigation

of the structural performance of FRLWSCC/LWSCC mixtures in infrastructure to understand structural behavior and to compare existing design guidelines and specifications. The findings of this research will surely benefit engineers, builders and local authorities when designing and constructing civil infrastructures.

\subsection{Research objectives and scope}

The proposed research on the structural performance of FRLWSCC/LWSCC beams made of blast furnace slag aggregates is an important step towards the design and construction of lightweight infrastructure systems for the $21^{\text {st }}$ century with enhanced workability, durability and economy. The objectives of this experimental and theoretical research are:

- Carry out experimental investigations on the shear and flexure behavior of beams made of developed FRLWSCCs (incorporating different types of fibers such as Polyvinyl Alcohol 'PVA', Crumb Rubber 'CR' and High-Density Poly Ethylene 'HDPE') and LWSCC with and without shear reinforcement. 
- Study the shear behavior of FRLWSCC beams with and without shear reinforcement compared with their LWSCC counterparts based on concrete shear capacity, ultimate shear resistance, post-cracking shear transfer mechanism, post-cracking shear capacity, loaddeflection response, ductility, energy absorbing capacity, strain development in concrete/steel, failure modes, load/deflection at first flexure/inclined crack and number of cracks.

- Carry out experimental tests on the flexure behavior of singly reinforced FRLWSCC beams under four point loading. Analyze the behavior of FRLWSCC beams based on loaddeflection response, ductility, strain development in concrete/and steel, failure modes, load/deflection at first flexure/inclined crack and number of cracks.

- Compare the shear and flexural capacities of experimental FRLWSCC beams with those obtained from existing equations and Code based procedures to analyze their prediction capability.

- Make recommendations on the shear and flexure performance of FRLWSCC beams.

\subsection{Thesis outline}

Chapter 1 introduces FRLWSCC and a summary of advancement in LWSCC technology. It also describes the significance, objectives and scope of this research with a thesis outline.

Chapter 2 presents the comprehensive literature review on lightweight aggregate, lightweight concrete, self-consolidating concrete, lightweight self-consolidating concrete, fiber reinforced lightweight self-consolidating concrete, shear and flexural behavior of reinforced concrete beams and Code based analysis of shear and flexural capacities. Research conducted on the above topics are described and analyzed.

Chapter 3 describes the experimental program including material properties, geometric dimensioning of flexural and shear beams, fabrication/casting/curing of beam specimens, test setup, instrumentation and testing procedures.

Chapter 4 presents the results of the experimental investigations on shear and flexural behavior of FRLWSCC beams in addition to LWSCC beams. The performance is described based on loaddeflection response, strain development in rebar/concrete, moment end rotation behavior, energy absorption, ductility index, and crack formation/propagation and failure modes. Post-cracking 
shear transfer mechanism comparison between FRLWSCC and LWSCC beams is also described in this Chapter.

Chapter 5 compares the experimental shear and flexure capacities of FRLWSCC beams with those obtained from various Code based and other existing equations proposed by various researchers. Chapter 6 summarizes the findings of the research and provides recommendation for future research study. 


\section{CHAPTER TWO}

\section{LITERATURE REVIEW}

\subsection{Introduction}

Fiber reinforced lightweight self-consolidating concrete (FRLWSCC) is a new technology in high performance concrete (HPC) and until to date limited investigations have been dedicated to this technology (Corinaldesi \& Moriconi, 2015; Doukakis, 2013). The aim of this technology is to combine the best properties of LWSCC and FRC in order to take advantage of potential of fibers to improve concrete performance in different aspects (Gonen, 2015). Addition of fiber into concrete matrix tends to reduce the workability. This reduction depends on fiber's geometry, amount of fiber, type and dispersion. On the other hand, it can enhance some mechanical and ductile behaviour of concrete such as: energy absorption, bending capacity, tension capacity and resistance to crack propagation (Gonen, 2015; Yehia et al., 2016). Also over the years, many researches has been done on LWSCC and SCC at Ryerson University (Lachemi et al., 2003; Karahan et al., 2012; Lotfy et al., 2016a, b) with recent focus on FRLWSCC. This chapter provides a literature review of research studies conducted on LWC, LWSCC and FRLWSCC covering various aspects such as mix design/fresh state/mechanical/durability properties and shear/flexural performance of structural elements as well as existing equations and Code based procedures.

\subsection{Lightweight aggregate}

In general, particle's density of normal weight aggregate is in the range of $2400 \mathrm{~kg} / \mathrm{m}^{3}$ to 2800 $\mathrm{kg} / \mathrm{m}^{3}$ which in case of lightweight aggregate (LWA) is between $800 \mathrm{~kg} / \mathrm{m}^{3}$ and $2000 \mathrm{~kg} / \mathrm{m}^{3}$ (Cheeseman et al., 2005). Low density of aggregate particles can be beneficial not only in concrete industry in production of lightweight concrete, also it can be applicable in production of lightweight blocks, lightweight geotechnical fill, insulation products, soil engineering and any other lightweight construction products. The main advantage of LWA in concrete industry is the ability of considerable reduction in the dead weight, enhance insulation and thermal inertia of concrete structures (Hossain, 2008; Cheeseman et al., 2005).

\subsubsection{Types of Lightweight Aggregates}

Generally LWAs are divided into two different categories such as natural and artificial aggregates as it is shown in Table 2.1 ( Hossain, 2008; Cheeseman et al., 2005; Lotfy, 2012). 
Table 2.1: Natural and artificial lightweight aggregates

\begin{tabular}{|l|l|}
\hline Categories & Aggregate types \\
\hline Natural aggregates & Pumice, Scoria, volcanic cinders or Di-atomite \\
\hline $\begin{array}{l}\text { manufactured by } \\
\text { thermally treating }\end{array}$ & $\begin{array}{l}\text { Expanding clays, Shale, Siliceous rock or Slate such as: Liapor, } \\
\text { Optiroc, Buildex, Stalite, Haydite, Perlite, Norlite and Solite }\end{array}$ \\
\hline $\begin{array}{l}\text { manufactured by } \\
\text { industrial by-products }\end{array}$ & $\begin{array}{l}\text { Fly ash, paper mill sludge, Sewage sludge, Clay and Expanded } \\
\text { blast furnace slag }\end{array}$ \\
\hline
\end{tabular}

Formation of LWAs is a natural phenomenon happening during the solidification of lava such as pumice, scoria, volcanic cinders and diatomite. Also, LWAs can be manufactured by either thermal treating or obtained from industrial by-products (Cheeseman et al., 2005). Porous structure of LWA forms when volatile gasses get trapped due to the rapid cooling of volcanic lava (Hossain, 2004, 2008; Sereda \& Litvan, 1980). Although natural lightweight aggregates are less consistent and predictable in their properties compare to manufactured lightweight aggregates, but using them as a construction material can be beneficial to achieve more sustainable construction with lower cost (Hossain et al. 2011). Based on the report of concrete society of United Kingdom, Lytag is the most common LWA in U.K which is processed fly ash with dry density of $770 \mathrm{~kg} / \mathrm{m}^{3}{ }^{3}$ to 960 $\mathrm{kg} / \mathrm{m}$ (Lotfy, 2012). The internal cellular nature of Lytag aggregate has been shown in Figure 2.1 (Lotfy, 2006).
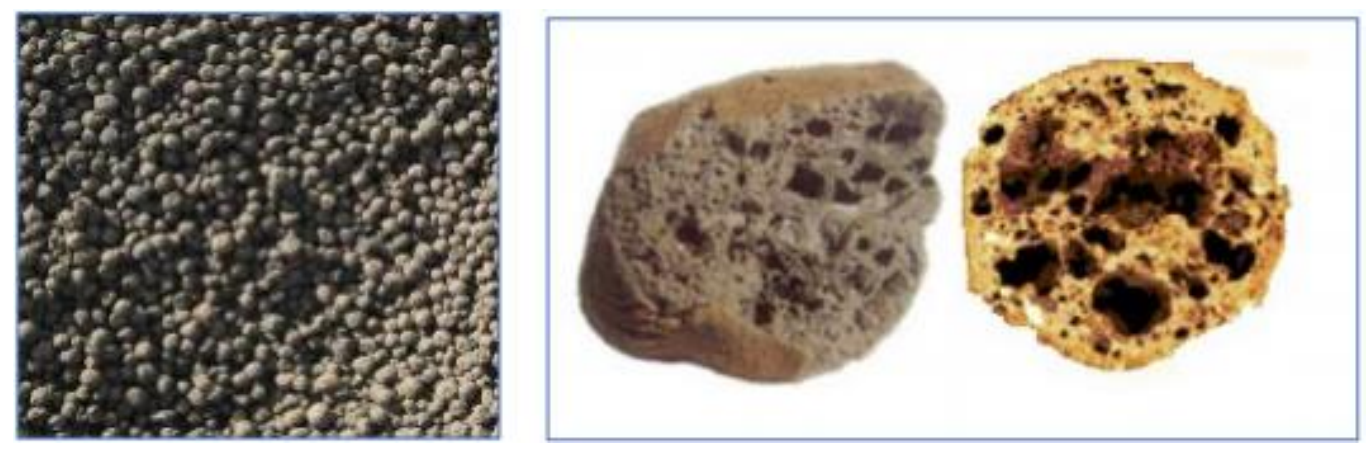

Figure 2.1: Lytag aggregate and internal pore structure (Lotfy, 2012).

Lightweight aggregates must meet the required criteria based on ASTM C330 to be allowable to use in concrete productions. The following Table 2.2 shows the required maximum dry loose bulk density and 
Table 2.3 shows physical properties of lightweight aggregates established by ASTM standard.

Table 2.2: Maximum dry loose bulk density of LWA for Structural Concrete (ASTM C330, 2014)

\begin{tabular}{|l|l|}
\hline Size Designation & Maximum Dry Loose Bulk Density $\frac{\mathrm{Kg}}{\mathrm{m}^{3}}$ \\
\hline Fine aggregates & 1120 \\
\hline Coarse aggregates & 880 \\
\hline Combine fine and coarse aggregates & 1004 \\
\hline
\end{tabular}

Table 2.3: Compressive Strength and Splitting Tensile Strength Requirements (ASTM C330, 2014)

\begin{tabular}{|c|c|c|}
\hline $\begin{array}{c}\text { Maximum } \\
\text { Density } \frac{\mathrm{Kg}}{\mathrm{m}^{3}}\end{array}$ & $\begin{array}{c}\text { Average 28-day Splitting Tensile Strength, } \\
\mathrm{min}, \mathrm{MPa}\end{array}$ & $\begin{array}{c}\text { Average 28-day Compressive Strength, } \\
\mathrm{min}, \mathrm{MPa}\end{array}$ \\
\hline \multicolumn{2}{|c|}{ All Lightweight Aggregate } \\
\hline 1760 & 2.2 & 28 \\
1680 & 2.1 & 21 \\
1600 & 2.0 & 17 \\
\hline \multicolumn{2}{|c|}{} & Combination of Normal Weight and Lightweight Aggregate \\
\hline 1840 & 2.3 & 28 \\
1760 & 2.1 & 21 \\
1680 & 2.1 & 17 \\
\hline
\end{tabular}

Water absorption of lightweight aggregates is much higher than normal aggregates due to their higher porosity. Mostly, water absorption for normal aggregate is less than $2 \%$ while in LWA this number is varied in the range of 5-25\% by mass of dry aggregate. In case of using dry aggregate, free water in matrix will be taken by aggregates to fill the voids and pores which leads to change in the actual water to cement ratio and increase the rate of plastic shrinkage (Lotfy, 2012; ESCSI, 2007). Therefore, LWA must be used in saturated surface dry (SSD) condition and be presoaked in water at least for 48 hours prior to use. It also helps to extend the hydration process of cementitious material by releasing the internal moisture content of aggregates gradually into concrete and decrease the rate of plastic shrinkage (Lotfy, 2012; ESCSI, 2007). 


\subsection{Lightweight concrete}

\subsubsection{General}

Structural lightweight concrete (LWC) can be produced by introducing lightweight aggregates to the ordinary concrete instead of normal weight aggregates. Back in 1990s, almost 20 percent of the produced concrete were LWC in construction industries (Ormal, 1999). Evidences show that during the Roman Empire, LWC has been used with pumice aggregate. Since middle of $20^{\text {th }}$ century use of LWC widely spread across countries in buildings, bridges, pre-stressed and precast elements ( Hossain \& Lachemi, 2007; Sari \& Pasamehmetoglu, 2005). Performance of lightweight concrete could be enhanced by enhancing the physical and chemical interaction between cement paste and aggregates (Doukakis, 2013; Ormal, 1999). Although wide range of lightweight aggregates are available, but overall performance must comply with the requirements based on ACI and ASTM committee. Compressive strength of LWC must be more than 17.2 MPa after 28 days and air-dry density should be less than $1840 \mathrm{~kg} / \mathrm{m}^{3}$ (ASTM C 330; ACI 318R 2005). Compressive behaviour of LWC mainly depends on type and volume of aggregates while in NC compressive strength can be controlled by quality of the cement paste (Bogas et al., 2017). .

\subsubsection{Properties of lightweight concrete}

Lightweight concrete can be divided into two different categories such as: aerated concrete and lightweight aggregate concrete. Aerated concrete requires autoclave process to get specified compressive strength which consume high level of energy. Compare to aerated concrete, LWC shows higher strength and density with lower thermal conductivity (Kim, Jeon, \& Lee, 2012). Thermal conductivity of LWC is about $1.0 \mathrm{~W} / \mathrm{m}^{*} \mathrm{~K}^{-1}$ with density of less than $1840 \mathrm{~kg} / \mathrm{m}^{3}$ which can be implemented as a solution where dead weight is important such as seismic zones (Bogas \& Gomes, 2014; Gonen, 2015a). Seismic loads acting on the structure are proportional to the building's dead load. Using the LWC in the structure resulted in the reduction of the dead weight of the building compared to the using of NC. Also, when LWC was used in the structure lesser effect of earthquake forces was seen due to the reduction in the dead weight of the building. The dead load reduction was resulted in lesser inertial forces which led to less material damage (Gonen, 2015; Kiliç et al., 2003; Kim et al., 2012; Yasar et al., 2003).

Lightweight concrete offers builders lower final cost and more flexibility to designers by reducing the dead load of structures. Furthermore, reduction in the dead load led to reduction in size of 
footing and columns, increase span length, less required steel reinforcement, better performance in case of seismic and ease of transportation ( Hossain, 2004; Kim et al., 2012; Bogas, De Brito, \& Figueiredo, 2015). Also, due to higher porosity of lightweight aggregates, better performance obtained in terms of thermal expansion and heat and sound insulation. Although initial cost of LWC is higher than NC, but the final cost saving is about $10 \%$ to $20 \%$ ( Hossain, 2004; Hossain, 2006).

Lightweight concrete has higher fire resistance compare to normal concrete due to its lower thermal conductivity and density ( Hossain \& Lachemi, 2007; Lotfy, 2012, 2016). Porous cellular characteristic of lightweight aggregates provide extra internal source of water which delay evaporation of water from interlayer of concrete (Wang, 2009). Lower thermal conductivity of LWC can be attributed to rapid rise of temperature in surface layers compare to interior layers which can cause spalling and separation of hot surface layers from cooler interior layers. On the other hand, interior layers can remain cool for longer duration and reserve the strength in spite of surface damage which is the reason of higher fire resistance of LWC compared to normal concrete (Hossain \& Lachemi, 2005; Hossain \& Lachemi, 2007; Hossain, 2006).

\subsubsection{Compressive strength of lightweight concrete}

Compressive strength of LWC can be effected by either mortar or LWA and as indicated in ACI 213, it is limited to features of LWAs ( Bogas \& Gomes, 2014; Gerritse, 1981; Hwang \& Hung, 2005). The concept of strength ceiling in LWC demonstrates when addition of binder has little influence on strength. At this stage, strength of concrete is limited to the strength of lightweight coarse aggregate or quality of interfacial transition zone (ITZ) ( Bogas \& Gomes, 2014; ESCSI, 2007; Hwang \& Hung, 2005). By reduction in the maximum size of coarse particles, concrete strength can significantly improve as this reduction help to reduce stress concentration on aggregates and also increase homogeneity of concrete matrix (ACI 213R-03 2003; Hwang \& Hung, 2005; Lo \& Cui, 2004; Lotfy, 2012). In LWC, component's properties such as deformability, rigidity and internal adherence play an important role in prediction of force transmission behaviour of concrete. Modulus of elasticity of LWA is usually lower than surrounded mortar compared to normal aggregate. Therefore, transmission of internal forces will be more through mortar and crack will propagate through the aggregate particles ( Bogas et al., 2017; Gerritse, 1981). Except in case of less porous or stiffer aggregate, the stress in aggregate 
will increase and failure will occur through ITZ and mortar. Mode of failure for normal concrete and lightweight concrete is shown in Figure 2.2 (Doukakis, 2013; Gerritse, 1981; Lotfy, 2006).
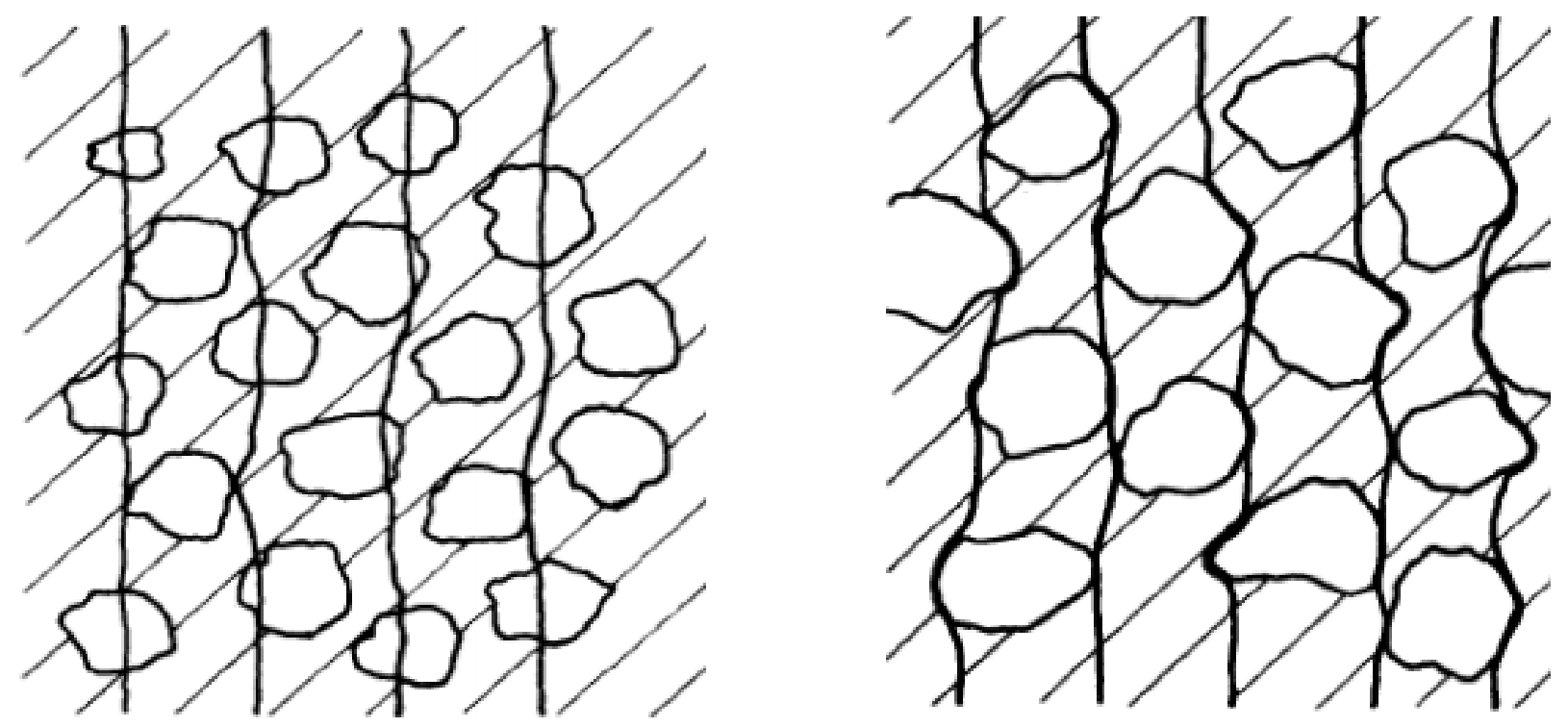

Figure 2.2: Lightweight concrete crack pattern (Left), Normal weight concrete crack pattern (Right) (Doukakis, 2013; Gerritse, 1981; Lotfy, 2006).

\subsubsection{Modulus of elasticity of lightweight concrete}

The modulus of elasticity of concrete is an important factor to determine the axial deformation of concrete structures which is normally stated with reference to compressive strength (dos Santos et al. 2017; Malešev et al., 2014; Nemati, 2015). It describes the stiffness of structure and it depends on the adherence and content ratio between elastic moduli of binders and aggregates (Balendran, 1995; Nemati, 2015). Accurate determination of elastic modulus of concrete is difficult due to the nonlinear behaviour of concrete stress-strain curve under load (Diógenes et al. , 2011; Malešev et al., 2014). In general, the modulus of elasticity of normal weight concrete (NWC) is higher than LWC due to the higher moduli of the normal weight aggregates (Balendran, 1995; dos Santos et al., 2017). Usually the modulus of elasticity of LWC is in range of $50 \%$ to $75 \%$ of NWC in the same strength level (Hossain, 2006; Lotfy, 2012). Table 2.4 shows compressive strength and modulus of elasticity of lightweight and normal weight aggregates and cement mortar. 
Table 2.4: Compressive strength and modulus of elasticity of aggregates and cement mortar (Gerritse1981)

\begin{tabular}{|l|l|l|}
\hline Components & Compressive strength $(\mathrm{MPa})$ & Modulus of elasticity $\left(\mathrm{kN} / \mathrm{mm}^{2}\right)$ \\
\hline Lightweight aggregate & $5-30$ & $5-30$ \\
\hline Cement mortar & $20-60$ & $20-30$ \\
\hline Normal aggregate & $60-100$ & $60-100$ \\
\hline
\end{tabular}

\subsubsection{Tensile strength of lightweight concrete}

Tensile strength of concrete can be defined as a fraction of its compressive strength which has effect on crack resistance, torsion, shear and bond strength behaviour of concrete. This value is dependent on tensile strength of the mortar phase, coarse aggregate as well as the bond strength between these two phases in the matrix (ESCSI, 2007). As the first approximation, tensile strength could be defined as a function of compressive strength. However, the aggregate's strength, surface of aggregate and moisture content of concrete need to be considered to calculate the accurate value (ACI 213R-03 2003). Use of lightweight fine aggregate instead of normal weight fine aggregate can enhance tensile strength of concrete as the hydration of cement can take place inside the pore structure of lightweight aggregates which leads to have better bond between mortar and aggregate phases (Hossain \& Lachemi, 2005). Concrete tensile strength test can be either direct tensile test such as splitting tensile or indirect tensile test which is flexural tensile test and is more preferable and easier due to the weak and brittle behaviour of concrete under tension (Juan, 2011). Figure 2.3 shows both types of tensile tests. Based on ASTM C330, the minimum tensile splitting strength of 2.0 $\mathrm{MPa}$ is required to meet the standard for structural-grade lightweight aggregates (Kockal \& Ozturan, 2011). 

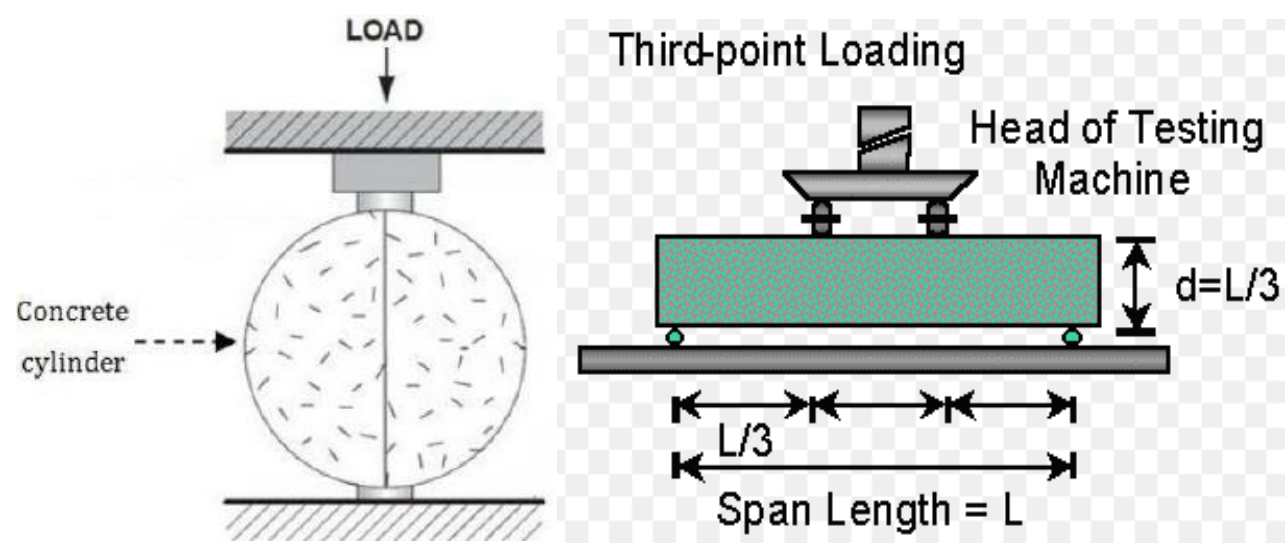

Figure 2.3: Schematic of split tensile strength test (left) and flexural tensile test (right) (Paper, Garg, Pilani, \& Garg, 2014)

\subsubsection{Examples of some studies on lightweight concrete}

Hossain et al.(2011) investigated the performance of lightweight volcanic pumice concrete (VPC) by using pumice-based ASTM type I blended cement (PVPC) which contains both coarse and fine aggregates. The performance of VPC has been evaluated in terms of slump, air content, compressive strength, tensile strength, density, and modulus of elasticity of fresh and hardened concrete as per American Society for Testing and Materials (ASTM). Durability properties of hardened VPC including: drying shrinkage, water permeability, mercury intrusion porosimetry, differential scanning calorimetry and micro hardness tests were also carried out. In this study two different series of concrete mixtures with twenty-four samples were tested. The variable in the series I was the percent replacement of normal weight coarse aggregate by lightweight coarse aggregate and in the series II water to binder ratio was variable. The results showed that all mixtures meet the ASTM requirements as the strength excess $18 \mathrm{MPa}$ with density of less than $1850 \mathrm{~kg} / \mathrm{m}^{3}$ at 28 days. However lower values of density, compressive/tensile strength and modulus of elasticity were observed for VPC compared to NC (with $0 \%$ pumice aggregate). The drying shrinkage also increased - maximum of $34 \%$ more than NC with the increase of pumice aggregate as replacement of normal coarse aggregate. The VPC mixtures showed 32\% lower permeability compared to $\mathrm{NC}$ which is attributed to continued internal curing and higher quality of ITZ which can improve the long term durability of VPCs against corrosion (Hossain et al., 2011). 
Hossain (2008) also studied the difference between bond characteristics of volcanic pumice concrete (VPC) and normal concrete (NC) by considering influence of type of concrete, type of reinforcing bars (plain and deformed reinforcing bars), failure modes, age of concrete and embedment length based on the obtained results of total 112 pullout tests at various ages of 1,7 and 28 days. The plain smooth bars behaved similar for both VPC and NC in terms of failure which was associated with bar pullout with no contribution of compressive strength or type of concrete on the bond strength. However, results showed that relative value of compressive strength, embedment length, age or type of concrete had an influence on load-slip relationship and failure mode of deformed bar specimens where the failure was due to pullout of rebar, splitting of concrete and yielding of steel rebar. It has been demonstrated that the normalized bond strength of deformed bars for NC specimens was about 1.12 times higher than for VPC.

\subsection{Self-consolidating concrete (SCC)}

Self-consolidating concrete (SCC) is one the newest innovations in high performance concrete (HPC) which has some specific performance and uniformity that cannot be achieved by normal concrete such as high flow ability under its own weight without any significant bleeding or segregation as shown in Figure 2.4 (Li, 1995; Khayat et al. 2000; Lachemi et al. 2003; Hossain \& Lachemi, 2007). Tremendous development has been obtained in high-rise building structural designs which leads to the increasing use of heavily reinforced formworks to satisfy the builder's requirements (Hassan et al., 2010). Back in 1983, Japan was faced with steady drop in the number of skilled workers which had an impact on the quality of their constructions. In order to achieve proper quality of construction regardless of adequate consolidation, SCC was first developed in Japan (Hossain \& Lachemi, 2007; Li, 1995; Okamura \& Ouchi, 2003). SCC has lower water to cement ratio compared to ordinary concrete and it has the ability to consolidate under its own weight and spread in every corner of congested formworks with no needs of external vibration (Lotfy et al., 2015; Su et al., 2001). High flowability of SCC arises from increase in the volume of fine particles and use of chemical/mineral admixtures in matrix which leads to have better deformability, resistance to segregation, bleeding and it also has the ability of pumping from bottom or dropped from the top (Lotfy, 2006; Mazaheripour et al., 2011). SCC can reduce the construction time as well as making structures more economical and environmental friendly (Khayat, 2000). 


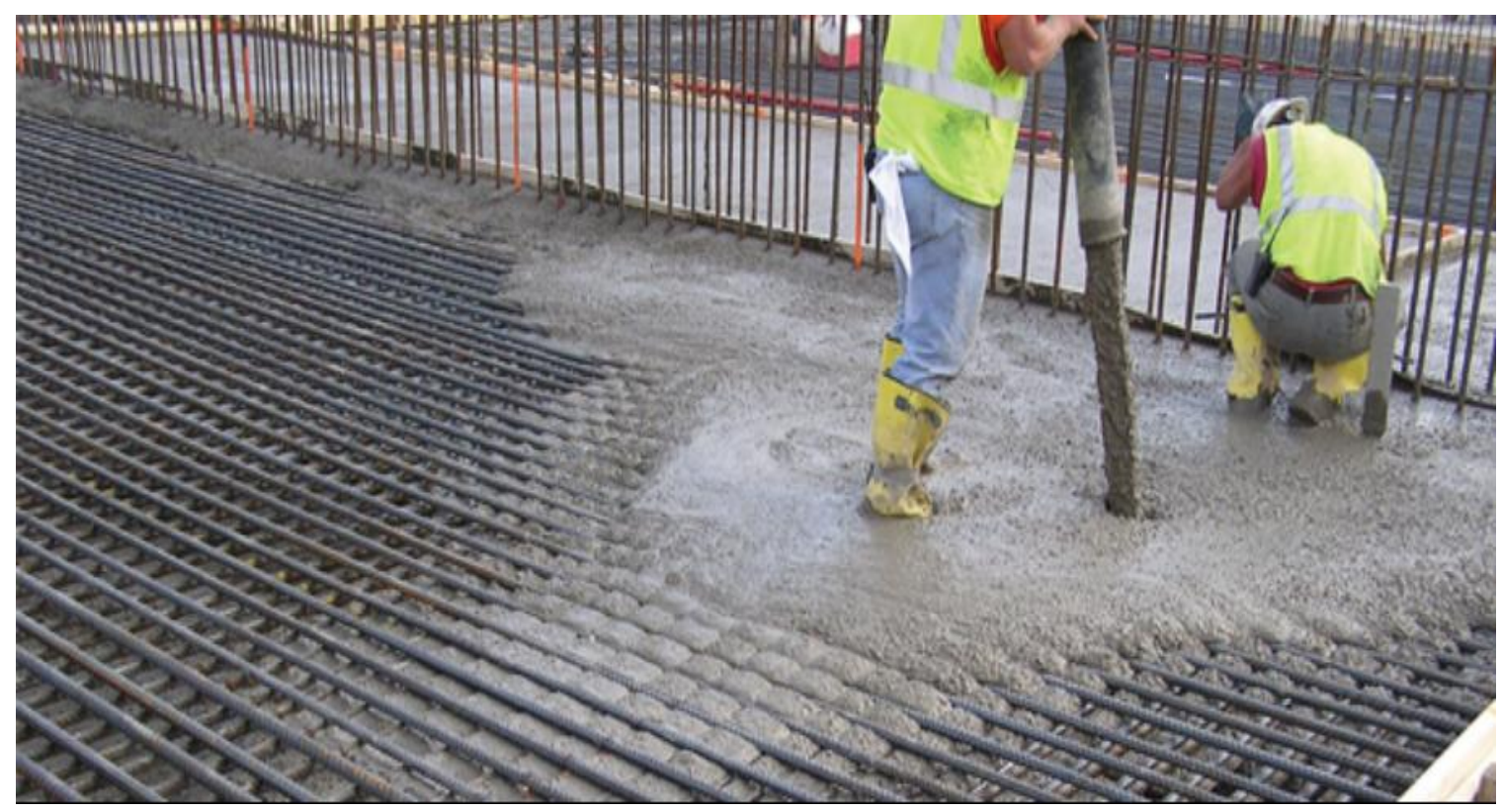

Figure 2.4: Self consolidating concrete (SCC) (civilexi, 2016)

\subsection{Lightweight self-consolidating concrete}

Successes in recent concrete technology have encourage the introduction of lightweight selfconsolidating concrete (LWSCC) which has been made to combine the best properties of LWC and SCC in one package to reduce dead weight of structures and high flowability without segregation (Vakhshouri \& Nejadi, 2016). Production of LWSCC is increasing around the world because of its advantages regarding money-saving and lowering the duration of construction (Hubertova \& Hela, 2007). Regardless of various available codes for mix design of SCC and LWC, there is no specific mix design's code or methodical draft available for LWSCC and its applications (Lotfy et al. 2016a,b). LWSCC is capable to maximize structural efficiency by saving in large portion of total dead load for structural design and foundation due to reduction of gravity load and seismic inertia mass (Corinaldesi \& Moriconi, 2015). LWSCC can reduce concrete cracking and improve hardened properties due to its higher internal curing and higher quality of aggregate-paste contact zone (ITZ) compared to NC (Lotfy et al., 2015). The first application of LWSCC was implemented in Japan back in 1992 as it was used for cable stayed bridge main girder (Lotfy, 2006). Other applications of LWSCC can be mentioned as: bridge decks, strengthening of structural panels and precast stadium benches (Corinaldesi \& Moriconi, 2015). To improve compressive strength and rheological properties of LWSCC, combination of fine normal weight 
aggregates and coarse lightweight aggregates can be used. The best result obtained by combination of using of expanded clay aggregates, slag and natural crushed stone (Maghsoudi, 2011).

\subsubsection{Example of some studies on lightweight self-consolidating concrete}

Sathiyamoorthy et al. (2016) studied the shear behaviour of LWSCC beams without shear reinforcemnet and SCC beams served as control sample. All beams had same width of $100 \mathrm{~mm}$ with three different heights of 150, 200 and $300 \mathrm{~mm}$ to obtain the effect of shear span to depth ratio $(\mathrm{a} / \mathrm{d})$ on shear resistance capacity of concrete. The shear resistance capacity increased with the decrease of shear span to depth ratio (a/d). Although, the ultimate shear capacity of LWSCC beams was lower than SCC beams; LWSCC beams showed higher deflection before failure compared to their SCC counterparts as shown in Figure 2.5.
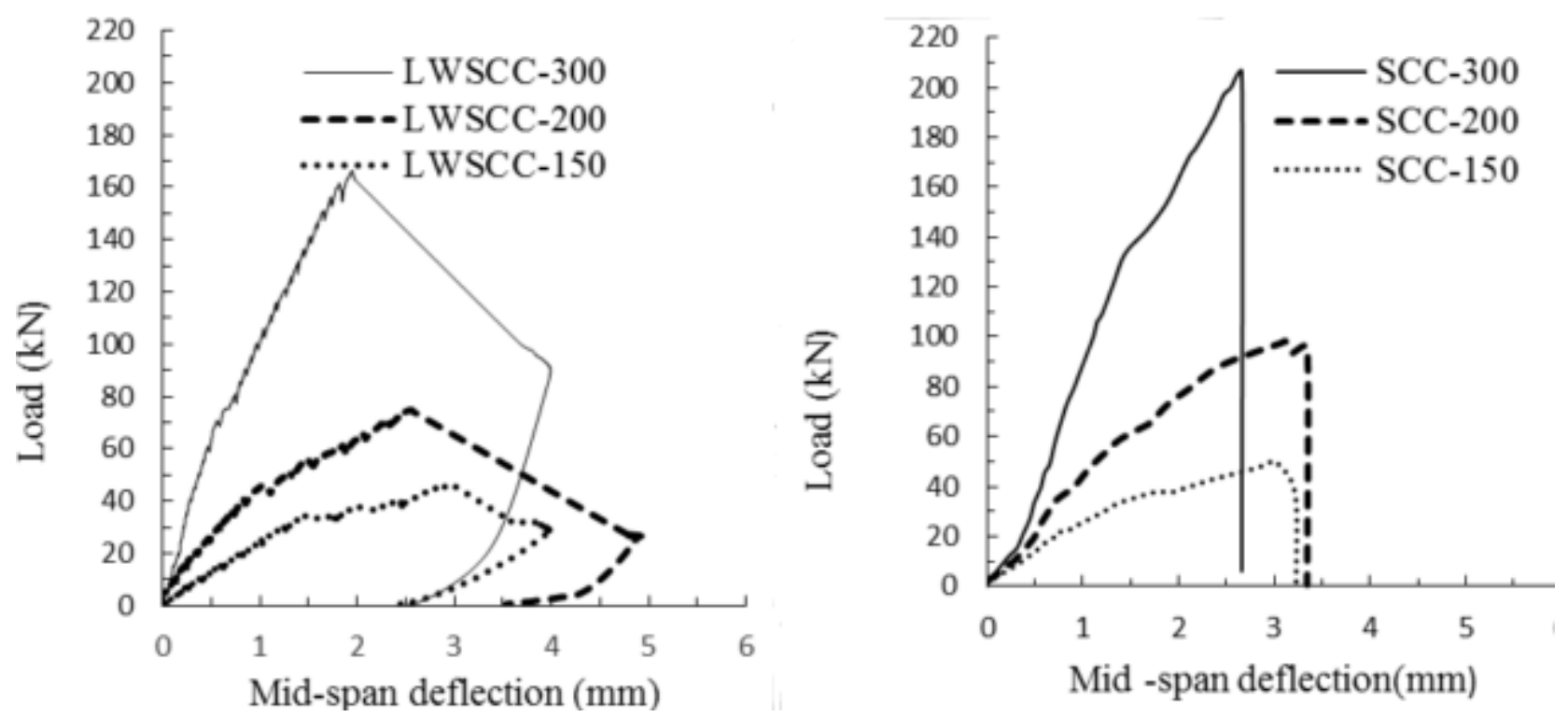

Figure 2.5: Load deflection response (Sathiyamoorthy et al. , 2016)

It was noted that the first flexural crack occurred at higher loads for SCC beams which is an indication of lower flexural capacity of LWSCC. SCC beams also showed higher post-cracking shear resistance compared to LWSCC and it increased with the decrease of a/d for both SCC and LWSCC beams. As it is shown in Figure 2.6, at failure point LWSCC developed more cracks compared to SCC which is approximately 14 to 17 cracks observed on LWSCC and 6 to 9 cracks occurred on SCC beams. Authors suggested that the existing reduction factors based on codes for lightweight concrete can be amplified for the prediction of shear resistance of LWSCC beams. 

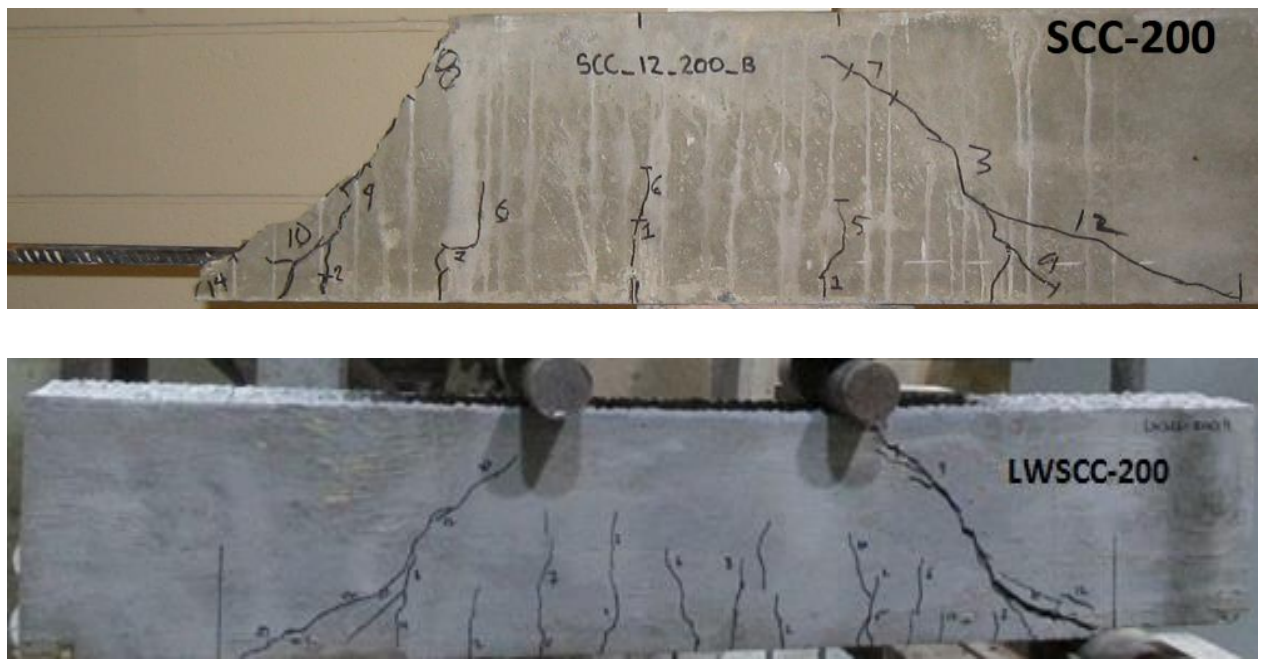

Figure 2.6: Failure modes of beams (Sathiyamoorthy et al., 2016)

Hossain (2015) studied the effect of pumice aggregates and combination of different supplementary cementing materials such as: volcanic ash, pumice powder and metakaolin on durability and mechanical properties of LWSCC mixtures. Fresh concrete properties were determined based on segregation, $\mathrm{V}$-funnel flow time, air content and slump flow tests. Mechanical and durability properties were determined by measuring compressive strength, rapid chloride permeability, ultrasonic pulse velocity, freez-thaw and salt scaling resistance and drying shrinkage. The results showed the developed LWSCC mixtures had satisfactory durability and structural properties. The use of mentioned supplementry cementing materials enhanced durabilty properties in terms of resistance to freezing and thawing, chloride penetration and salt scaling.

Lotfy (2012) investigated the impact of essential factors on properties of LWSCCs developed with three different types of lightweight aggregates such as: furnace slag (FS), expanded caly (EC) and expanded shale $(\mathrm{ESH})$. In this study experimental results were used to develop mathematical models to evaluate fresh and mechanical characteristics of LWSCC mixtures. Fresh LWSCC properties were evaluated by conducting slump flow, V-funnel flow time, J-ring flow diameter, Jring height difference, L-box ratio, filling capacity, bleeding, fresh air content, initial and final set times, sieve segregation and 28-day air dry unit weights. Other tests such as compressive, flexural, split tensile strength, bond strength, drying shrinkage, absorption, porosity, rapid chloride permeability, hardened air void (\%), spacing factor, corrosion resistance, resistance to elevated 
temperature, salt scaling, freeze-thaw resistance, and sulphuric acid resistance tests were also conducted. The total binder content was varied between 410 and $550 \mathrm{~kg} / \mathrm{m}^{3}$ with water to binder ratio between 0.30 and 0.40 and high range water reducing agent (HRWRA) between $0.3 \%$ and $1.2 \%$ by total content of binder. The results showed the type of lightweight aggregates did not have a significant contribution to compressive strength compared to the effect of quality of the paste and ITZ. The suggested optimized LWSCC mixture was corresponded to the one with expanded shale (ESH) aggregate which had the lowest dry density of $1706 \mathrm{~kg} / \mathrm{m}^{3}$ and the highest compressive strength of $46.7 \mathrm{MPa}$ at 28 days. High aggregate packing density and low coarse to total aggregate volume ratio increased the compressive strength of this mixture. The mixtures with high dry density and high water to binder ratio of 0.4 are more susceptible to lower compressive strength and lower segregation resistance. The flexural strength was affected by quality, size and volume of coarse aggregate and the low flexural strength value of expanded clay LWSCC could be attribiuted to the low quality of the coarse expanded clay aggregates. The fresh properties of mixtures made with expanded shale aggregate showed the best results in terms of workability, passing ability, filling capacity and segrigation resistance compared to the other mixtures and the lowest results was corresponded to expanded clay aggregate mixtures. In the pullout bond strength test, the highest result obtained by ESH-LWSCC was due to better quality of the lightweight aggregates and the paste as well as higher compressive strength. The pullout bond test value for mixes made with furnace slag and expanded caly aggregates were almost $40 \%$ and $51 \%$ lower than ESH-LWSCC, respectivly. A correlation between bond strength $\left(f_{b}\right)$ and compressive strength $\left(\mathrm{f}^{\prime} \mathrm{c}\right)$ with a correlation coefficient of $\left(R^{2}\right)$ of 0.92 based on the experimental results was derived in the form: $f_{b}=0.0004\left(f^{\prime}{ }_{c}\right)^{2.5386}$.

\subsection{Role of fiber in reinforced concrete}

\subsubsection{General}

In general, contribution of fiber into concrete mixture has the ability to decrease concrete workability. Amount and type of fiber have influence on properties of concrete. Some types of fibers have tendency to clump together and get surrounded by paste. This can be contributed to lower slump and non- homogeneity (Ferrara, Park, \& Shah, 2007). On the other hand, high flow ability and low viscosity of concrete can sink the fibers to the bottom of formwork and rise segregation (Corinaldesi \& Moriconi, 2015). Addition of fiber can also have influence on other 
properties such as: compressive strength, tensile strength, flexural strength, modulus of elasticity, crack control, ductility, fatigue and shrinkage resistance (Doukakis, 2013; Gencel et al., 2011).

\subsubsection{Polyvinyl Alcohol (PVA) fiber}

Polyvinyl Alcohol (PVA) fiber can be considered as one of the most common type of fibers in engineered cementitious composites (ECC) productions. Table 2.5 shows geometric and mechanical properties of PVAfibers.

Table 2.5: Geometrical and mechanical properties of PVA fiber

\begin{tabular}{|c|c|c|c|}
\hline Diameter $(\mu \mathrm{m})$ & Length $(\mathrm{mm})$ & Nominal strength $(\mathrm{MPa})$ & Modulus of elasticity $(\mathrm{GPa})$ \\
\hline 39 & 12 & 1620 & 2.8 \\
\hline
\end{tabular}

Structural integrity of concrete enhances in the presence of fiber in matrix. Allocation of fiber in concrete needs to be uniform. Ductile behaviour of concrete after the formation of first crack through fibers is enhanced by bridging characteristic of fiber and their capacity to carry tensile stress due to their high tensile strength and modulus of elasticity (JCI-DFRCC Committee, 2003). Fibers are either coated or uncoated. As it's shown in the Figure 2.7, coated fibers have more tensile capacity in ECC mixes compared to uncoated. Consequently, in existence of tensile stresses, by the interfacial bonding between matrix and fiber, oil coated fibers tend to tear rather than pull out. PVA fiber is oil coated by twenty percent of its mass (Li et al., 2000).
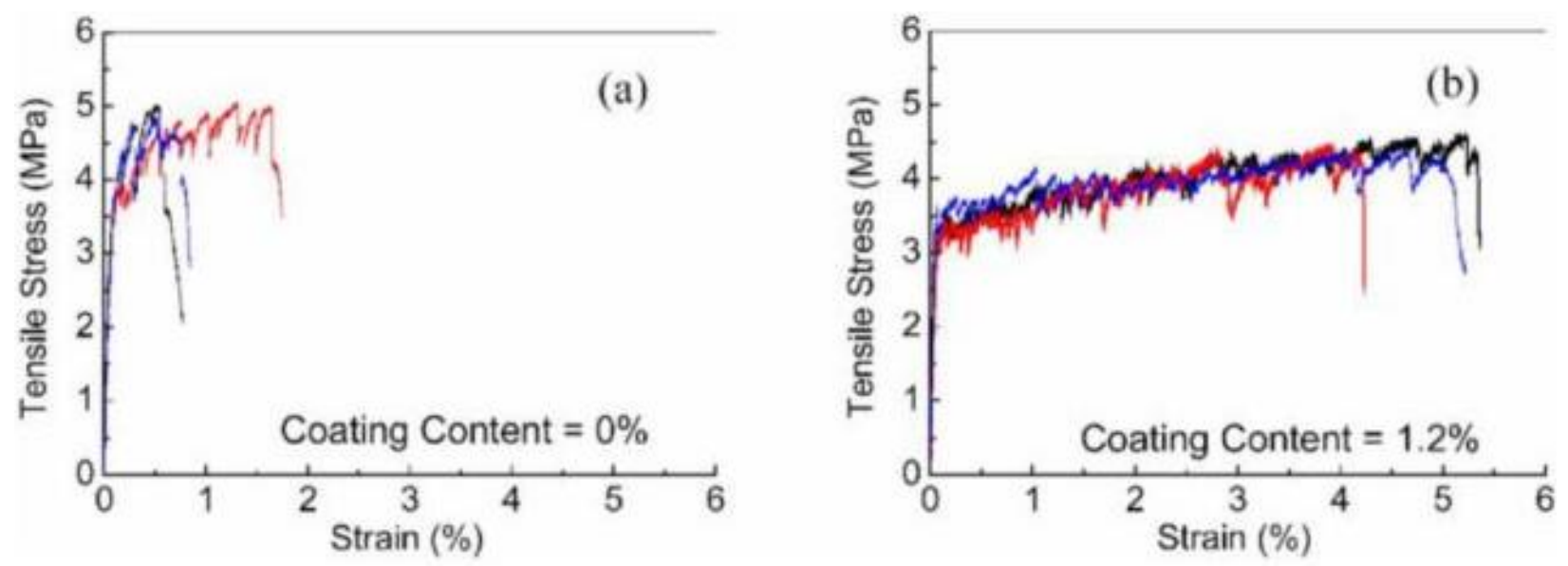

Figure 2.7: Ultimate tensile strain of ECC for (a) uncoated and (b) coated fiber (Li et al., 2000) 


\subsubsection{Crumb rubber fiber}

To support sustainable construction and decrease threat to the environment, more research has been dedicated to use waste materials as fibers in concrete structures such as: old tires, plastic and pet bottles (Batayneh, Marie, \& Asi, 2008). Crumb rubber is made of millions of recycled tires by grinding as an alternative to reduce the consumption of natural conventional aggregates (Batayneh et al., 2008; Pelisser et al., 2011). Sukontasukkul (2008) reported that the use of crumb rubber as a replacement of fine aggregates in range of $10 \%$ to $30 \%$ by weight lead to reduction in unit-weight of concrete from $14 \%$ to $28 \%$. Many scholars have confirmed superior performance of rubberized concrete in terms of reduction in thermal conductivity coefficient $(k)$ and increase in sound absorption coefficient $(\propto)$ (Batayneh et al., 2008; Issa \& Salem, 2013; Sukontasukkul \& Wiwatpattanapong, 2009). Pelisser et al., (2010) investigated the effect of replacement of fine aggregate with modified crumb rubber with addition of alkaline activation and silica fume addition on concrete. The performance of concrete evaluated based on the results of compressive strength, elastic modulus, density and microstructure (by scanning electron microscopy "SEM"). The experimental investigation at $10 \%$ replacement of fine aggregate with modified crumb rubber leads to reduction of compressive strength by $14 \%$ compared to conventional concrete at 28 days as shown in Figure 2.8.
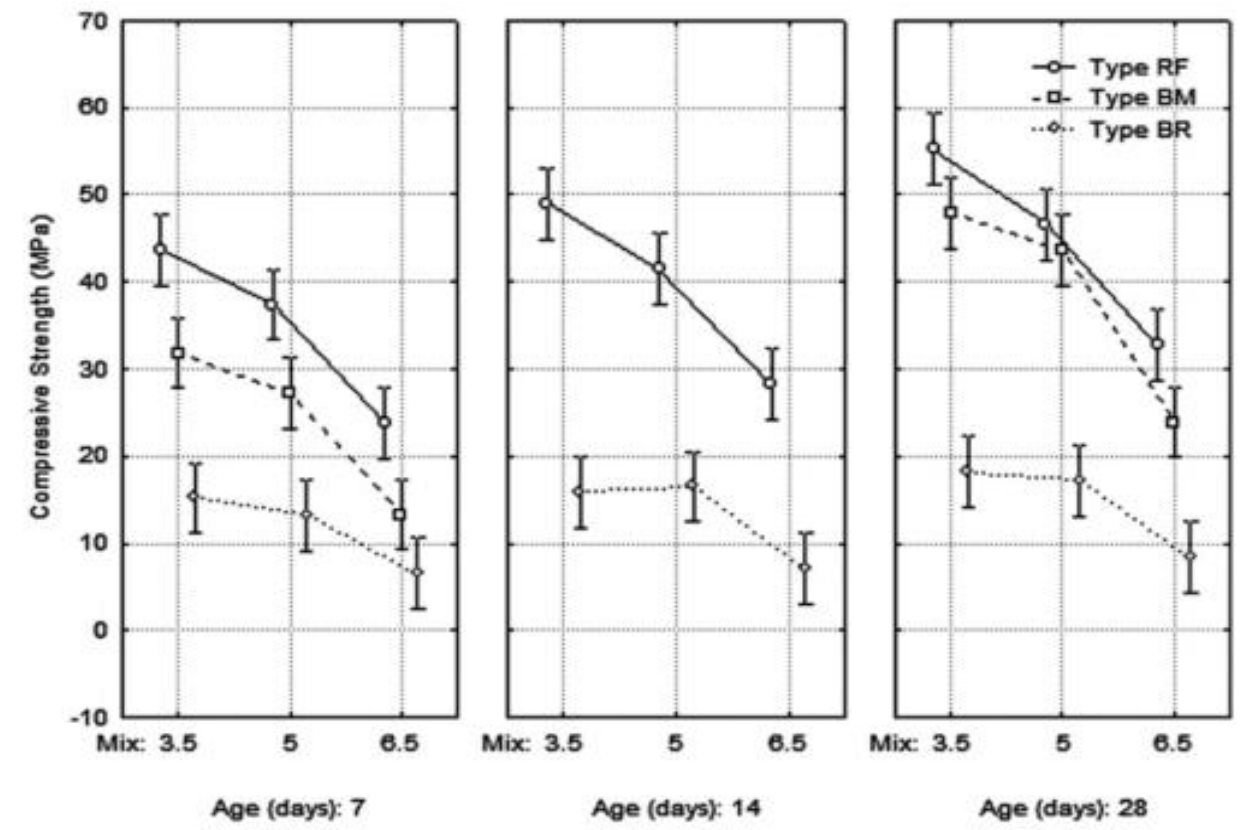

Figure 2.8: The compressive strength of the concretes (Pelisser et al. 2010) 


\subsubsection{High Density poly ethylene (HDPE) fiber}

High Density Polyethylene (HDPE) fibers are made of flexible polymers (Sengupta et al., 2007). HDPE fiber is a plastic element that has been used as food's container in market and household chemicals. In recent years, many research studies were conducted to evaluate the potential use of post-consumer materials in concrete structures. Addition of fibre to concrete has several advantages such as: reduced shrinkage, increased flexural ductility, improved tensile fatigue strength and increased fracture energy (Sengupta et al., 2007). HDPE fiber has the ability to behave as its room temperature properties even at elevated temperatures of about $80^{\circ} \mathrm{C}$ as well as it has favorable creep properties compared to other fibers (Soroushian et al., 1992). An experimental study by Malagavali (2011) found improvement in workability of concrete mixture in presence of up to $2 \%$ of HDPE fiber and reduction in workability when more fiber was added. The study also evaluated the effect of HDPE fiber content of $0 \%$ to $6 \%$ and found improvement in compressive strength, split tensile strength and flexural strength at tested age of 28 days by $7.69 \%, 14 \%$ and $17.47 \%$ respectively, compared to normal concrete with 3.5\% of HDPE fiber by volume. Bhavi et al. (2012) investigated the potential use of HDPE fiber as additives to concrete from $0 \%$ to $1 \%$ and the performance was evaluated based on different tests including: compressive strength, tensile strength and flexural strength. The results showed good mechanical performance up to 0.6 percentage of HDPE and performance decreased as fiber volume fraction was increased. As shown Figure 2.9, the improvement in terms of compressive strength, tensile strength and flexural strength by $15 \%, 23 \%$ and $22 \%$ respectively was observed when $0.6 \%$ HDPE fiber was used and as decreasing trend was observed in case of addition of fiber (Bhavi et al., 2012). It was also noted that the workability of fiber reinforced concrete decreased by the addition HDPE fiber which can be resolved by taking higher amount of superplasticizer. 

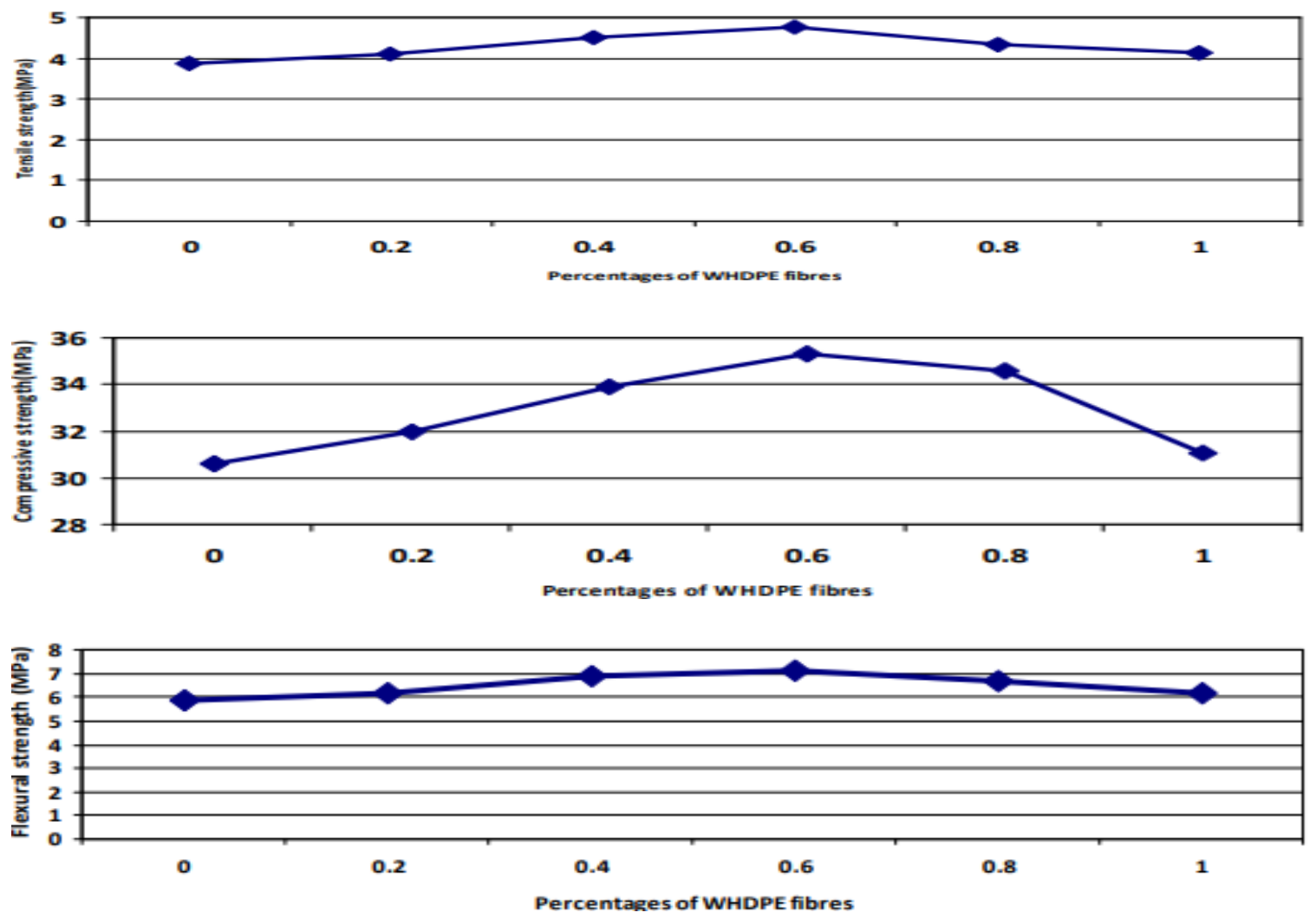

Figure 2.9: Tensile, compressive and flexural strength of concrete with HDPE fiber (Bhavi et al., 2012)

\subsection{Fiber reinforced lightweight self-consolidating concrete}

Use of FRC is one of the most effective methods to improve performance under direct tensile/ bending load, crack propagation resistance, energy absorption, shrinkage and strain capacity of concrete structures (Gonen, 2015). Plain concrete is a brittle material with low ductility and as the compressive strength of concrete increase, concrete acts more brittle and less ductile. Thereby, it is essential to use materials that are able to enhance its ductility properties (Nehme et al., 2017). Presence of fiber in concrete mixture can raise the ability of more deformation and deflection before failure and reduce brittleness of the concrete considerably under tensile loads (Sobhan \& Mashnad, 2002). Numerous structural uses of FRC have been stated including bridges, slabs, road pavements and buildings. FRC carries short discrete fibres such as steel, glass, synthetic and natural fibers and each type of fiber resulting in different properties of concrete. Synthetic fibres which included organic fibres and inorganic fibers such as: polyvinyl alcohol, polyethylene, polypropylene, alkali resistant glass and carbon fibres can be mentioned as the most used fibers. Fibers are available in different sizes and shapes. They can be flat, deformed or rounded as some 
of steel fibers have hooked end to increase pullout resistance. Polypropylene fiber is one the most popular synthetic fibers that are made through an extrusion process (Garg et al., 2014). Back in 1960 s, effect of polypropylene fiber $(0.5 \%$ by total volume) was investigated on concrete performance for a blast-resistance structures by Goldfein, which showed improvement in the ductility and impact resistance of the concrete (Soroushian et al., 1992). FRC is valuable due to its improved flexural performance and its improved capability under tensile stress.

\subsubsection{Studies on fiber reinforced self-consolidating concrete}

Gonen (2015) studied the effect of two different steel fibers such as low carbon (macro fibers) and high carbon content (micro fibers) on workability and mechanical properties of LWSCC. In this study pumice aggregate were used as coarse and fine aggregates. The performance was evaluated based on eight different mixes with $25 \mathrm{~kg} / \mathrm{m}^{3}$ and $50 \mathrm{~kg} / \mathrm{m}^{3}$ of steel fiber content with three mixes had combination of both fibers. Improvement in compressive strength at presence of combination of $50 \mathrm{~kg} / \mathrm{m}^{3}$ f steel fiber content (75\% high carbon and $25 \%$ low carbon) was by $29 \%$ compared to control sample. The results showed that macro fibers had better performance in terms of flexural strength compared to micro fibers. It was seen that flexural strength improved by $43 \%$ higher than control sample in the presence of $50 \mathrm{~kg} / \mathrm{m}^{3}$ of steel fiber (75\% low carbon and $25 \%$ high carbon) with compressive strength of $21 \%$ more than control sample. The workability of all the mixes were found in acceptable range, however compared to control sample, workability decreased with the increase of low carbon steel fibers which could be due to its long length, while addition of short fibers did not have much negative effect on workability of the fresh concrete.

Doukakis (2013) investigated the effects of steel and polypropylene fibers on the fresh and mechanical properties of LWSCC such as: workability, density, compressive strength, flexural strength and splitting tensile strength. Two different fiber concentrations were designed for each type of fibers as $18 \mathrm{~kg} / \mathrm{m}^{3}$ and $36 \mathrm{~kg} / \mathrm{m}^{3}$ for steel fiber and $12 \mathrm{~kg} / \mathrm{m}^{3}$ and $24 \mathrm{~kg} / \mathrm{m}^{3}$ for polypropylene fiber addition to a control sample. All the specimens were tested in accordance with ASTM testing procedures. As it is shown in Table 2.6, addition of fiber had negative effects on workability as the highest workability (slump flow value of $50.8 \mathrm{~cm}$ ) was exhibited by control $\operatorname{mix.}$ 
Table 2.6: Slump flow ranked by performance

\begin{tabular}{|c|c|c|}
\hline Rank & Mix & Slump Flow $(\mathrm{cm})$ \\
\hline 1 & Control & 50.8 \\
\hline 2 & Steel $18 \frac{\mathrm{kg}}{\mathrm{m} 3}$ & 50.2 \\
\hline 3 & Polypropylene $12 \frac{\mathrm{kg}}{\mathrm{m} 3}$ & 46.7 \\
\hline 4 & Polypropylene $24 \frac{\mathrm{kg}}{\mathrm{m} 3}$ & 44.5 \\
\hline 5 & Steel $36 \frac{\mathrm{kg}}{\mathrm{m} 3}$ & 41.9 \\
\hline
\end{tabular}

Equilibrium density of all specimens were in the acceptable range, but the results showed increase in density by addition of fibers. The test results in Table 2.7 showed $6.5 \%$ improvement in compressive strength from 42.9 MPa to 45.9 MPa for control mix with $18 \mathrm{~kg} / \mathrm{m}^{3}$ of steel fiber.

Table 2.7: Compressive strength at age of 28 days

\begin{tabular}{|c|c|c|}
\hline Rank & Mix & Compressive strength (MPa) \\
\hline 1 & Steel $18 \frac{\mathrm{kg}}{\mathrm{m} 3}$ & 45.9 \\
\hline 2 & Polypropylene $24 \frac{\mathrm{kg}}{\mathrm{m} 3}$ & 44.8 \\
\hline 3 & Steel $36 \frac{\mathrm{kg}}{\mathrm{m} 3}$ & 44.5 \\
\hline 4 & Control & 42.9 \\
\hline 5 & Polypropylene $12 \frac{\mathrm{kg}}{\mathrm{m} 3}$ & 41.7 \\
\hline
\end{tabular}

The modulus of rupture for control mix was $1 \mathrm{MPa}$ and the highest modulus of rupture of 1.4 MPa was obtained by steel fiber of $36 \mathrm{~kg} / \mathrm{m}^{3}$. All samples made of fiber mixes were held together by the fibers except the control sample which was split in two separate sections.

Lisantono et al. (2017) studied the flexural behaviour and strength of fiber reinforced FRSCC beams incorporating polypropylene fiber. In this research four beams were casted and tested - two of them contained polypropylene fiber by $0.9 \mathrm{~kg} / \mathrm{m}^{3}$ of concrete weight and two of them were casted as pure SCC with no fiber as the control samples. All beams had width, height and total length of 180, 260 and $2000 \mathrm{~mm}$, respectively. Total of five longitudinal $10 \mathrm{~mm}$ reinforcement were used, two for compression zone and three for tension zone. Shear reinforcement spacing of $100 \mathrm{~mm}$ were used with $8 \mathrm{~mm}$ stirrups. The obtained results shown that the load carrying capacity of the FRSCC beams was higher than the tested control SCC beams. When the concrete was in 
fresh stage, the slump flow and the passing ability decreased by adding the fiber to the mix. The results showed that the FRSCC beams containing polypropylene fiber obtained higher splitting tensile strength and modulus of rupture compared to the tested control SCC beam by $2.64 \%$ and $3.63 \%$, respectively. The average load carrying capacity of polypropylene fiber reinforced concrete beams was also found to be $2.6 \%$ higher than non-fiber reinforced concrete. As shown in Figure 2.10 and Figure 2.11, in the both FRSCC and non-fiber reinforced concrete beams, the first flexural crack occurred in the middle span at load of $24 \mathrm{kN}$ and $25 \mathrm{kN}$, respectively. Generally, the crack patterns of polypropylene FRSCC beams were similar to the non-fiber reinforced SCC beam.

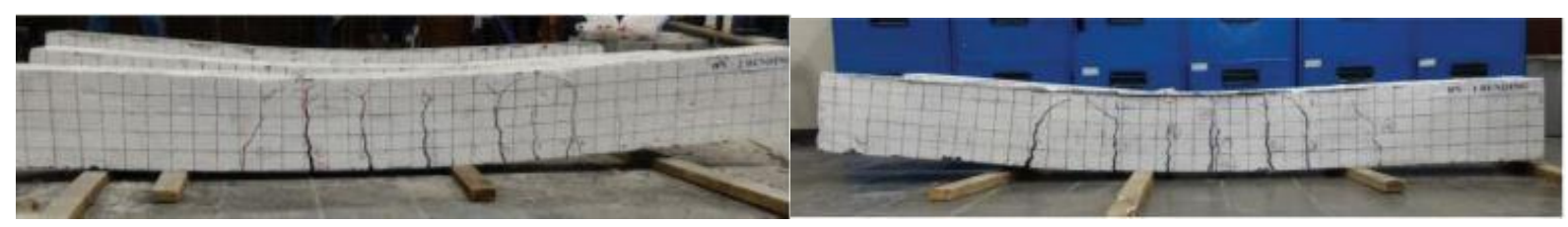

Figure 2.10: Crack pattern of the tested self-consolidating concrete beams

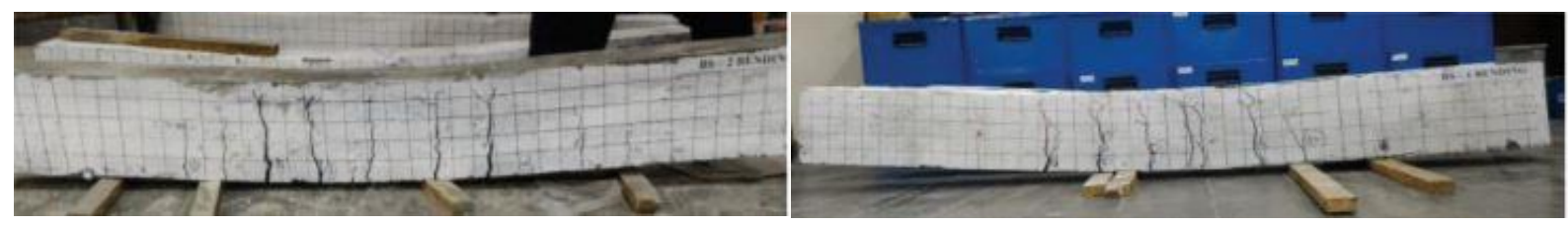

Figure 2.11: Crack pattern of the tested fiber reinforced self-consolidating concrete beams

Campione (2013) proposed an analytical model to determine the shear resistance of lightweight streel fiber reinforced concrete beams. The model was verified based on the available experimental data and is able to include the following variables in the resistance provision: diameter and number of steel bars, depth to shear span ratio, fiber characteristics, crack spacing, tensile stress in main bars, residual bond resistance, post cracking tensile resistance and size effects. The obtained experimental results were compared with various shear resistance expressions of normal weight FRC beams and lightweight plain and FRC beams. The analytical model presented allows to assess the contributions of the arch action and the shear resistance of a beam. The proposed analytical expressions considered the presence of fibers has a further increase in shear strength compared with normal lightweight concrete beams. In the beam effect, the presence of fibers ensures higher shear strength due to the increase in the internal arm of the beam and better bond conditions of longitudinal bars. Referring to the arch effect, an improvement in shear contribution is also 
observed compared with ordinary lightweight RC beams because of the post cracking resistance of FRC and the increase in crack spacing in the main bars. The proposed shear resistance $\left(\mathrm{v}_{\mathrm{u}}\right)$ expressions by Campione (2013) and Al-Taan et al. (1990) for lightweight plain concrete and FRC beams are mentioned in equation 2.1 and 2.2 , respectively.

$v_{\mathrm{u}}=0.125\left(1+\frac{\mathrm{c}}{\mathrm{D}} \cdot \mathrm{F}\right) \cdot \sqrt{\mathrm{f}^{\prime}{ }_{\mathrm{c}}}+21 \cdot \rho \cdot \frac{\mathrm{d}}{\mathrm{a}}+0.15 \cdot \mathrm{F} \cdot \frac{\mathrm{d}}{\mathrm{a}} \cdot \sqrt{\mathrm{f}^{\prime}{ }_{\mathrm{c}}}$

$v_{\mathrm{u}}=\mathrm{e}\left[0.17 \sqrt{\mathrm{f}_{\mathrm{c}}^{\prime}}+10.6 \rho\left(\frac{\mathrm{d}}{\mathrm{a}}\right)\right]+1.128 \mathrm{~F}$

where $\mathrm{c}=$ cover of the longitudinal bars, $\mathrm{D}=$ diameter of the ith bar belonging to the main reinforcements, fiber factor $F=\left(L_{f} / D_{f}\right) V_{f} d_{f}, d_{f}=$ bond factor $(0.5$ for round, 0.75 for crimped, and 1.0 for independent fiber $), L_{f}=$ fiber length $(\mathrm{mm}), D_{f}=$ fiber diameter $(\mathrm{mm}), V_{f}=$ volume fraction of steel fiber, $\rho=$ flexural reinforcement ratio, $a=$ shear span length, $d=$ effective depth, $\mathrm{f}^{\prime}{ }_{\mathrm{c}}=$ cylinders compressive strength, $\tau=$ average fiber-matrix interfacial bond stress (assumed to be 4.15 MPa), e = arch action factor $(1.0$ for $\mathrm{a} / \mathrm{d}>2.5$ and $2.5 \mathrm{~d} / \mathrm{a}$ for $\mathrm{a} / \mathrm{d} \leq 2.5)$.

Hamoush et al. (2010) conducted experimental and theoretical investigations on the stress-strain and load-deflection behavior of PVA microfiber reinforced concrete composites. The actual stress-strain relationships in both compression and tension were established by performing a series of compression and tension tests on PVA micro-fibers reinforced concrete specimens. The proposed deflection model was developed by using moment-curvature and conjugate beam methods. The addition of micro-fibers did not influence the compressive strength of concrete, it enhanced the ductile property of the materials, increased toughness, and prevented the sudden brittle failure of the material. The deflection of microfiber reinforced concrete beams had ductile behavior and also had a post-peak failure point. PVA fiber is very suitable to be used as reinforcement of the concrete materials, though very strong fiber-matrix bond resulting from high chemical bonding caused the micro-fibers to rupture instead of being pulled out. Larger ductility achieved by fiber pullout rather than rupture. It is therefore, recommended to conduct experimental program using coated PVA microfiber with less interface bond. It is also, necessary to develop fiber coating technology to control the fiber-matrix interfacial bonding and produce fiber pullout characteristics which are designed to increase energy dissipation without causing fiber rupture. 
In a research done by Narayanan \& Darwish (1998) to investigate effect of replacement of stirrups and cement with steel fibers and pulverized fuel ash (PFA) in conventional concrete. Total of 24 beams were casted with different combination of steel fibers and conventional stirrups. All the samples loaded with a four-point bending test. The experiments demonstrated partial replacement of conventional shear reinforcements with steel fiber showed no reduction in shear capacity of mortar beams. The reduction and replacement of the stirrups with steel fiber could be done up to $40 \%$ of the stirrups without resulting any significant drops in shear capacity of the beam. Also, beams reinforced with fibers had the advantage of negligible spalling and higher first crack strength compared to the conventionally reinforced concrete. The comparison between the partial replaced stirrups with steel fiber concrete and normal concrete showed an improvement in ductility and smaller failure cracks with higher number of cracks. In fact, fiber reinforced concretes showed ability to sustain greater loads and slower failure than normal reinforced concrete. Concrete containing steel fiber showed reduction in workability which was reversed by partial replacement of cement with PFAwhich also resulted in higher long-term strength. In addition to the mentioned characteristics, replacement of PFA enhanced the shrinkage. The usage of PFA containing mix exhibited easier surface finish ability and was proven to be economical compare to the normal concrete mix. Narayanan R \& Darwish (1998) did experiments on 24 beams containing 3 mix combination of fiber reinforced, PFA and normal reinforced concrete. The shear strength $\left(\mathrm{V}_{\mathrm{u}}\right)$ of the tested samples was calculated from the following proposed equation 2.3:

$V_{u}=e\left[0.24 f_{\text {spfc }}+80 \rho\left(\frac{d}{a}\right)\right]+0.41 \tau F$

where $\rho=$ flexural reinforcement ratio, $\mathrm{e}=$ arch action factor $(1.0$ for $\mathrm{a} / \mathrm{d}>2.8$ and $2.8 \mathrm{~d} / \mathrm{a}$ for $\mathrm{a} / \mathrm{d} \leq 2.8), \mathrm{f}_{\mathrm{spfc}}=$ split cylinder strength $(\mathrm{MPa}), \mathrm{f}_{\mathrm{spfc}}=\mathrm{f}_{\text {cuf }} /((20-\sqrt{\mathrm{F}}))+0.7+\sqrt{\mathrm{F}}, \mathrm{f}_{\text {cuf }}=$ cube strength of fiber concrete (MPa), fiber factor $F=\left(L_{f} / D_{f}\right) V_{f} d_{f}, d_{f}=$ bond factor $(0.5$ for round, 0.75 for crimped, and 1.0 for independent fiber), $\mathrm{L}_{\mathrm{f}}=$ fiber length $(\mathrm{mm}), \mathrm{D}_{\mathrm{f}}=$ fiber diameter $(\mathrm{mm}), \mathrm{V}_{\mathrm{f}}=$ volume fraction of steel fiber, and $\tau=$ average fiber-matrix interfacial bond stress (assumed to be 4.15 MPa). The experimental results compare to the calculated results from the theoretical equation were exceptionally close. Also, the theoretical equation applied on mixes without fiber yielded close values to the results obtained from the experiments.

Hossain et al. (2017) did a vast study on reliability validation of artificial neural network (ANN) modeling in prediction of shear strength of steel fiber reinforced concrete (SFRC) beams. The used 
data pool contained 173 SFRC beams without stirrups but containing various type of steel fiber such as hooked, crimped and straight. The compressive strength of the studied samples ranged from 20.6 MPa to 175 MPa, categorized as medium strength to ultra-high strength concrete beams. First the experimental strengths were compared with ANN modeling results and the results showed prediction of the ANN model could be used as a good feasible design tool. In addition to the original beams built for the experiment, 36 more SFRC beams were used to farther approve the ANN model . After validating the ANN modeling accuracy in predicting the shear strength of the SFRC beams, a new comparison between different sets of empirical equations and ANN modeling were done. The used equations proposed by various researchers as follows:

Ashour et al., (1992):

$\mathrm{V}_{\mathrm{u}}=\left(0.7 \sqrt{\mathrm{f}_{\mathrm{c}}^{\prime}}+7 \mathrm{~F}\right) \frac{\mathrm{d}}{\mathrm{a}}+17.20 \rho \frac{\mathrm{d}}{\mathrm{a}}$

Where $d=$ effective depth, $a=$ shear span, $f_{c}{ }_{c}$ is the compressive strength of concrete, $\rho$ is the flexural reinforcement ratio and $\mathrm{F}$ is the fiber factor.

Sharma (1986):

$\mathrm{V}_{\mathrm{u}}=\mathrm{kf}_{\mathrm{t}}^{\prime}\left(\frac{\mathrm{d}}{\mathrm{a}}\right)^{0.25}$

Where $\mathrm{k}=1$ if $\mathrm{f}_{\mathrm{t}}{ }_{\mathrm{t}}$ is obtained by direct tension test; $\mathrm{k}=2 / 3$ if $\mathrm{f}_{\mathrm{t}}{ }_{\mathrm{t}}$ is obtained by indirect tension test; $\mathrm{k}=4 / 9$ if $\mathrm{f}_{\mathrm{t}}{ }_{\mathrm{t}}$ is obtained using modulus of rupture. $\mathrm{f}_{\mathrm{t}}$ is the tensile strength of steel fiber reinforced concrete to be calculated as $9.5 \mathrm{f}_{\mathrm{c}}{ }^{\prime} 0.5$. Even though Sharma used $\mathrm{f}_{\mathrm{t}}{ }_{\mathrm{t}}$ in the equation, it is indirectly based on the cylinder compressive strength of concrete $\left(\mathrm{f}^{\prime}{ }_{\mathrm{c}}\right)$.

Khuntia, et al. (1999):

$\left.\mathrm{V}_{\mathrm{u}}=(0.167 \propto+0.25 \mathrm{~F}) \sqrt{\mathrm{f}_{\mathrm{c}}^{\prime}}\right)$

Where $\alpha=1$ for $\mathrm{a} / \mathrm{d} \geq 2.5$ and $\alpha=2.5 \mathrm{~d} / \mathrm{a}$ for $\mathrm{a} / \mathrm{d}<2.5$.

Shin et al., (1994):

$\mathrm{V}_{\mathrm{u}}=0.22 \mathrm{f}_{\text {spfc }}+217 \rho \frac{\mathrm{d}}{\mathrm{a}}+0.834 \mathrm{~F}$, if $\frac{\mathrm{a}}{\mathrm{d}}<3$ if $\mathrm{a} / \mathrm{d}<3$

$V_{u}=0.19 f_{\text {spfc }}+93 \rho \frac{d}{a}+0.834 F$, if $\frac{a}{d} \geq 3$ if $a / d \geq 3$ 
Total of 209 samples were used in the research and good consistency observed between the ANN modeling and proposed empirical equations for medium strength (compressive strength: 20-65 $\mathrm{MPa}$ ) and high strength (compressive strength: 66-100 MPa) SFRC beams. The most effective parameter in the shear strength of the SFRC beams were observed to be the shear span to depth ratio.

\subsection{Design aspects of lightweight self-consolidating concrete members}

Researches have been devoted to evaluating shear and flexural behaviour of lightweight selfconsolidating reinforced concrete elements. During the last decades, reasonable performance of lightweight aggregates into concrete have improved the design of structures in terms of functionality and efficiency (Juan, 2011). However, the design of lightweight concrete used to be based on design of normal weight concrete without sufficient guideline, but nowadays, all the international codes are agreed to take lightweight aggregate concrete as a structural medium with general guidelines (ACI 318M-08 2008; CSA A23.3-04 2004). In general, fundamental behaviour of lightweight and normal weight concrete members is imilar except some differences in terms of properties and failure modes which raised the requirement of design modification in codes of practice (Gerritse, 1981). Since lightweight concrete has lower tensile strength capacity compared to normal weight concrete at equal compressive strength, the ACI 318 (2005) applied a reduction factor of 0.75 to normal weight concrete shear equations for all lightweight concretes.

Design of reinforced concrete shear members are classified as either with transverse reinforcements or without transverse reinforcement (Wight and Macgregor 1997; Gastebled and May 2001).

\subsubsection{Basic shear transfer mechanism for beams without shear reinforcement}

In rectangular and slender shear beams, after formation of first inclined crack the applied shear force will be carried out by different mechanisms such as compression zone $\left(\mathrm{V}_{\mathrm{c}}\right)$, aggregate interlocking action $\left(\mathrm{V}_{\mathrm{a}}\right)$ and dowel action $\left(\mathrm{V}_{\mathrm{d}}\right)$ due to the drop in shear strength of beams as it has been shown in Figure 2.12. In short beams load will be transfered directly from the loading point to the support due to arch action. After formation of inclined crack in beam's tension zone, $30 \%$ to $50 \%$ of the shear force mostly is taken through the cracks by interlocking force and its contribution is dependent on crack width and strength of concrete. Dowel action of longitudinal 
bars also can support $15 \%$ to $25 \%$ of the applied shear force relying on the flexural stiffness of bars and the strength of concrete and $20 \%$ to $40 \%$ of the force will be taken by compression zone (Taylor 1970).

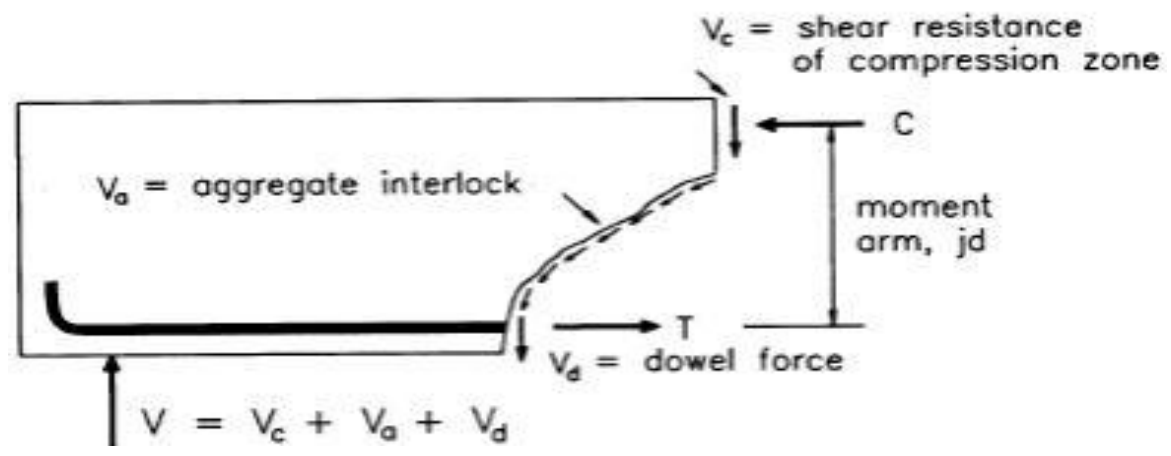

Figure 2.12: shear transfer in beam without shear reinforcement

\subsubsection{Shear transfer mechanism for beams with shear reinforcement}

Shear reinforcements are provided in the forms of stirrups or lateral ties to hold the main tensile and compression reinforcement in place and prevent mitigation of diagonal shear crack. Transverse Shear reinforcement does not prevent formation of crack, but when crack tries to open, the transverse reinforcement tries to resist the expansion of crack and confirm the full flexural capacity can progress (Wight and Macgregor1997).

\subsubsection{Code based shear prediction}

Shear resistance capacity of concrete beams can be calculated by empirical equations based on different available design codes. The ultimate shear capacity of plain concrete $\left(V_{c}\right)$ with no shear reinforcement considered the moment of formation of diagonal cracks in tension zone from support to the point of force. In shear reinforced concrete beams, summation of contribution of transverse shear reinforcement $\left(V_{s}\right)$ and plain concrete shear resistance $\left(V_{c}\right)$ is considered as the ultimate shear capacity (ACI 318M-08 2008; CSA A23.3-04 2004; BS8110-part1 1997). Ultimate shear capacity of shear reinforced concrete beam $\left(\mathrm{V}_{\mathrm{u}}\right)$ can be calculated based on Equation 2.9:

$\mathrm{V}_{\mathrm{u}}=\mathrm{V}_{\mathrm{s}}+\mathrm{V}_{\mathrm{c}}$ 
Concrete shear resistance and shear reinforcement capacity can be calculated according to ACI 318M-08 (2008) from equation 2.10 and 2.11 in SI unit as follows:

$\mathrm{V}_{\mathrm{c}}=\left(0.16 \lambda \sqrt{\mathrm{f}_{\mathrm{c}}^{\prime}}+17 \rho_{\mathrm{w}} \frac{\mathrm{V}_{\mathrm{u}} \mathrm{d}}{\mathrm{M}_{\mathrm{u}}}\right)\left(\mathrm{b}_{\mathrm{w}} \mathrm{d}\right)$

when: $\sqrt{\mathrm{f}_{\mathrm{c}}^{\prime}} \leq 8.3 \mathrm{Mpa}, \mathrm{V}_{\mathrm{c}} \leq 0.29 \lambda \sqrt{\mathrm{f}_{\mathrm{c}}^{\prime}} \mathrm{b}_{\mathrm{w}} \mathrm{d}$ and $\frac{\mathrm{V}_{\mathrm{u}} \mathrm{d}}{\mathrm{M}_{\mathrm{u}}} \leq 1.0$

Where $\lambda$ is the reduction factor of 0.75 for low density concrete with an air dry density of less than $1850 \mathrm{~kg} / \mathrm{m} 3, \mathrm{f}^{\prime}{ }_{\mathrm{c}}$ is the concrete compressive strength, $\rho_{\mathrm{w}}$ is the flexural reinforcement ratio, $\mathrm{V}_{\mathrm{u}}$ and $M_{u}$ are the ultimate shear and moment capacity of the segment, $d$ and $b_{w}$ are the effective depth and width of the beam, respectively.

Contribution of shear reinforcement shall be obtained from equating 2.12:

$V_{s}=\frac{A_{v} f_{y} d_{v}}{s}$

Where $A_{v}\left(\mathrm{~mm}^{2}\right)$ is the area of a vertical shear reinforcement or stirrup, $f_{y t}(\mathrm{MPa})$ is the yield strength of tensile reinforcement bars, $\mathrm{S}(\mathrm{mm})$ is the spacing between transverse reinforcements and $d_{v}$ is the effective shear depth which is the greater of either is: $0.9 \times d$ or $0.72 \times h$.

The following proposed equations is based on modified compression field theory by Canadian code CSA A23.3-04 (2004) and can be used to obtain $V_{c}$ and $V_{s}$ :

$\mathrm{V}_{\mathrm{c}}=\lambda \beta \sqrt{\mathrm{f}_{\mathrm{c}}^{\prime}} \mathrm{b}_{\mathrm{w}} \mathrm{d}$ when $\sqrt{\mathrm{f}_{\mathrm{c}}^{\prime}} \leq 8 \mathrm{Mpa}$

Based on simplified method the value of $\beta$ is 0.18

Based on general method the value of $\beta$ can be obtained from:

$\beta=\frac{0.4}{1+1500 \varepsilon_{\mathrm{x}}} * \frac{1300}{1000+\mathrm{S}_{\mathrm{ze}}}$

where the $\varepsilon_{\mathrm{X}}$ and $\mathrm{S}_{\mathrm{ze}}$ can be calculated from equations (2.15) and (2.16):

$\varepsilon_{\mathrm{x}}=\frac{\frac{\mathrm{M}_{\mathrm{f}}}{\mathrm{d}_{\mathrm{v}}}+\mathrm{V}_{\mathrm{f}}}{2 \mathrm{E}_{\mathrm{s}} A_{\mathrm{s}}}:$ where $\mathrm{M}_{\mathrm{f}} \geq \mathrm{V}_{\mathrm{f}} * \mathrm{~d}_{\mathrm{v}}$

where $M_{f}$ is the moment due to factored loads, $V_{f}$ is the shear force due to factored load, $E_{s}$ is the modulus of elasticity of steel and $A_{s}$ is the area of provided stirrups. 
$\mathrm{S}_{\mathrm{ze}}=\left\{\begin{array}{c}300 \mathrm{~mm} \text { for sections with provided minimum amount } \mathrm{A}_{\mathrm{vmin}} \\ \frac{35 \mathrm{~S}_{\mathrm{z}}}{15+\mathrm{ag}_{\mathrm{g}}} \geq 0.85 \mathrm{~S}_{\mathrm{z}}\end{array}\right.$

Where $a_{g}$ is the maximum aggregate size, $S_{z}$ is the minimum of $\left(d_{v}: d_{l}\right)$ while $d_{l}$ is the distance between two layers of longitudinal reinforcement and $A_{v m i n}$ is the minimum area of shear reinforcement required within a distance s and can be obtained from equation (2.17):

$\mathrm{A}_{\mathrm{vmin}}=0.06 \sqrt{\mathrm{f}_{\mathrm{c}}^{\prime}} \frac{\mathrm{b}_{\mathrm{w}} \mathrm{s}}{\mathrm{f}_{\mathrm{y}}}$

Stirrups contribution can be calculated from equations (2.18) and (2.19) based on the general method and simplified method, respectively.

Contribution of stirrups using general method:

$V_{s}=\frac{A_{v}}{S} f_{y} d_{v} \cot \theta$, where $\theta=29^{\circ}+7000 \varepsilon_{x}$

Contribution of stirrups using simplified method:

$$
\mathrm{V}_{\mathrm{s}}=1.43 \frac{\mathrm{A}_{\mathrm{v}}}{\mathrm{S}} \mathrm{f}_{\mathrm{y}} \mathrm{d}_{\mathrm{v}}
$$

Shear reinforced capacity also can be calculated based on British standards BS8110-part1 (1997) as follow:

$\mathrm{V}_{\mathrm{c}}=0.79 *\left(\left(\frac{100 * \mathrm{~A}_{\mathrm{s}}}{\mathrm{b}_{\mathrm{w}} \mathrm{d}}\right)^{1 / 3} *\left(\frac{400}{\mathrm{~d}}\right)^{1 / 4} *\left(\mathrm{~b}_{\mathrm{w}} \mathrm{d}\right) *\left(\frac{\mathrm{f}_{\mathrm{cu}}}{25}\right)^{1 / 3}\right.$

Shear resistance provided by stirrups, $\mathrm{V}_{\mathrm{s}}$ can be calculated from equation 2.21 :

$\mathrm{V}_{\mathrm{S}}=\frac{\mathrm{A}_{\mathrm{sv}}}{\mathrm{S}_{\mathrm{v}}} 0.95 \mathrm{f}_{\mathrm{yv}} \mathrm{d}$

Where in Equation 2.13, $\mathrm{A}_{\mathrm{sv}}$ is the area of each stirrup in $\mathrm{mm}^{2}, \mathrm{~S}_{\mathrm{v}}$ is the spacing between stirrups in $\mathrm{mm}$ and $\mathrm{f}_{\mathrm{yv}}$ is the yielding strength of stirrups in MPa.

\subsubsection{Shear strength of reinforced lightweight concrete members}

As the lightweight concrete has lower tensile strength compared to normal weight concrete, the ACI 318-05 (2005) code applies a reduction factor of 0.75 for all lightweight concrete, 0.85 for sand lightweight concrete and 1.0 for normal weight concrete. Similarly, in Canadian standard CSA A23.3-04 (2004) code reduction factor of 0.75 applies to low density concrete such as 
lightweight concrete which has an air-dry density of less than $1850 \mathrm{~kg} / \mathrm{m}^{3}, 0.85$ for semi lightweight concrete which has dry density of $1850 \mathrm{~kg} / \mathrm{m}^{3}$ to $2140 \mathrm{~kg} / \mathrm{m}^{3}$ and 1.0 for normal weight concrete; while, the BS8110 (1997) code uses factor of 0.8 for lightweight concrete and 1.0 for normal concrete.

\subsubsection{Studies on shear behavior of lightweight reinforced concrete beams}

Mohammed et al. (2013) presented an experimental result about shear behavior of reinforced palm oil clinker concrete (POCC) which has been classified as a structural lightweight concrete in accordance to ASTM:C330 and BS8110. The results have been evaluated based on seven reinforced POCC shear beams without shear reinforcement with rectangular cross section of 150 $\times 300 \mathrm{~mm}$ and length of $2400 \mathrm{~mm}$, air dry density of less than $1850 \mathrm{~kg} / \mathrm{m}^{3}$ and compressive strength of above $20 \mathrm{MPa}$ at age of 28-day. In this study the variables are the compressive strength of POCC, shear span to depth ratio $(\mathrm{a} / \mathrm{d})$ and tensile reinforcement ratio $(\rho)$. All the variables and details of the beams are presented in Table 2.8 which have been tested under two-point loading as it has been shown in Figure 2.13.

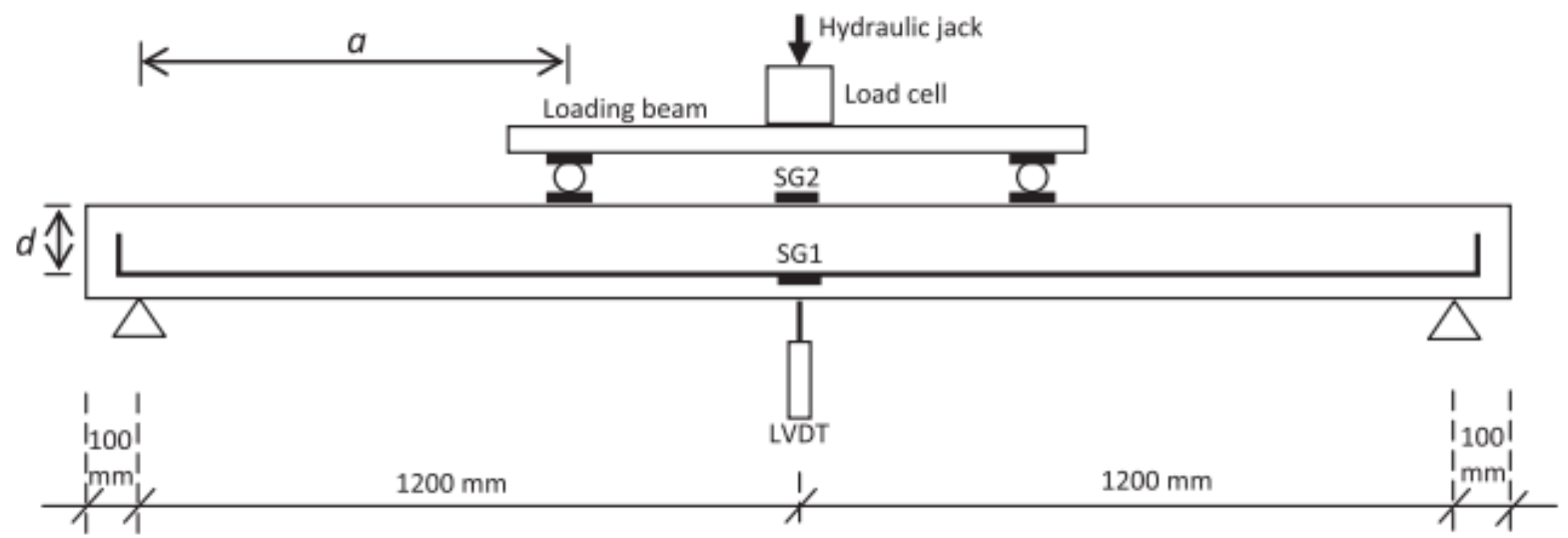

Figure 2.13: The experimental set-up for the reinforced POCC beams (Mohammed et al., 2013) 
Table 2.8: Details of the experimental POCC beams (Mohammed et al., 2013)

\begin{tabular}{|c|c|c|c|c|c|c|c|c|}
\hline $\begin{array}{l}\text { Beam } \\
\text { reference }\end{array}$ & $\begin{array}{c}\mathrm{f}_{\mathrm{cu}} \\
(\mathrm{MPa})\end{array}$ & $\begin{array}{c}\mathrm{f}_{\mathrm{y}} \\
(\mathrm{MPa})\end{array}$ & $\begin{array}{c}\mathrm{b} \\
(\mathrm{mm})\end{array}$ & $\begin{array}{c}\mathrm{d} \\
(\mathrm{mm})\end{array}$ & $\begin{array}{c}\mathrm{h} \\
(\mathrm{mm})\end{array}$ & $\mathrm{a} / \mathrm{d}$ & $\rho \%=\mathrm{A}_{\mathrm{s}} / \mathrm{b}_{\mathrm{d}} * 100$ & Ultimate shear force $V_{u}(K N)$ \\
\hline $\mathrm{AD}-3$ & 31.5 & 590 & 150 & 262 & 300 & 3 & 1.0 & 27.5 \\
\hline AD-1 & 31.5 & 590 & 150 & 262 & 300 & 1 & 1.0 & 19.5 \\
\hline WC-1 & 20.3 & 590 & 150 & 262 & 300 & 2 & 1.0 & 21.5 \\
\hline WC-3 & 39.8 & 590 & 150 & 262 & 300 & 2 & 1.0 & 25.0 \\
\hline SR-1 & 31.5 & 590 & 150 & 250 & 300 & 2 & 3.4 & 30.5 \\
\hline SR-3 & 31.5 & 590 & 150 & 266 & 300 & 2 & 0.3 & 12.5 \\
\hline
\end{tabular}

The result of the experiment has shown same and comparable shear behaviour performance and failure mode compared to normal reinforced concrete beams. Although, it has been noted that the shear capacity of POCC beams with reinforcement ratio of equal or greater than $1(\rho \geq 1)$ can be predicted based on proposed shear design equation of Canadian Standard Association (CSA A23.3 2004) with consideration of adequate safety and for POCC beams with reinforcement ratio of less than 1 , safety factor of 0.5 should be applied in the CSA formula.

Juan (2011) conducted research on the cracking mode and shear behaviour of lightweight concrete beams. In this study three types of lightweight concrete which contained normal weight sand aggregate and expanded clay aggregate casted such as: lightweight aggregate concrete, lightweight aggregate foamed concrete, foamed concrete and normal weight concrete as control sample. The experimental program involved testing of 15 beams with rectangular cross section of $125 \mathrm{~mm}$ width and $200 \mathrm{~mm}$ depth and length of $1350 \mathrm{~mm}$. Details of lightweight concrete beam's design and beam's geometry have been shown in Table 2.9 and Figure 2.14, respectively. Minimum amount of transverse reinforcement was added as per design codes of practice. 
Table 2.9: lightweight concrete beam's details tested (Juan, 2011)

\begin{tabular}{|c|c|c|c|c|c|}
\hline Beam & $\mathrm{f}_{\mathrm{cu}}(\mathrm{MPa})$ & $\mathrm{f}_{\mathrm{y}}(\mathrm{MPa})$ & $a / d$ & $\rho \%$ & $\mathrm{~V}_{\mathrm{u}}(\mathrm{KN})$ \\
\hline S.B 1.5 & 42.6 & 590 & 1.5 & 0.63 & 37.5 \\
\hline S.B 2 & 42.6 & 590 & 2.0 & 0.63 & 33.5 \\
\hline S.B 3 & 42.6 & 590 & 3.0 & 0.63 & 34.3 \\
\hline S.B 3.5 & 42.6 & 590 & 3.5 & 0.63 & 27.5 \\
\hline S.B C50 1.5 & 43.8 & 590 & 1.5 & 0.63 & 65.0 \\
\hline S.B C50 2.0 & 43.8 & 590 & 2.0 & 0.63 & 37.0 \\
\hline S.B C50 3 & 43.8 & 590 & 3.0 & 0.63 & 30.0 \\
\hline S.B C50 3.5 & 43.8 & 590 & 3.5 & 0.63 & 31.5 \\
\hline S.B C50 P0.78 & 46.9 & 590 & 3.0 & 0.63 & 30.0 \\
\hline S.A C50 3.0 & 49.6 & 590 & 3.0 & 0.63 & 32.5 \\
\hline S.G C50 3.0 & 53.0 & 590 & 3.0 & 0.63 & 35.0 \\
\hline S.B C70 2.0 & 64.9 & 590 & 1.5 & 0.63 & 67.0 \\
\hline S.B C70 3.0 & 69.8 & 590 & 3.0 & 0.63 & 40.0 \\
\hline S.B C70 3.5 & 69.8 & 590 & 3.5 & 0.63 & 33.0 \\
\hline
\end{tabular}

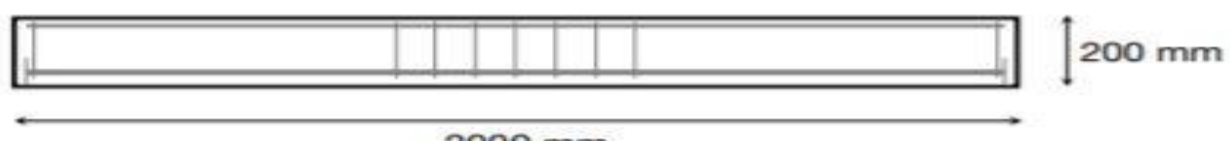

$2000 \mathrm{~mm}$

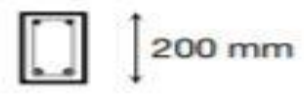

$\overleftrightarrow{25 \mathrm{~mm}}$

Figure 2.14: Shear beam's geometry (Juan, 2011)

The results showed similar behaviour of the lightweight and normal weight concrete beams till beginning of diagonal cracks. Although the normal concrete showed a flexure mode of failure, the lightweight concrete beams with normal weight sand failed in a fragile shear mode and could not exhibit satisfactory resistance. On the other hand, foamed concrete and lightweight coarse aggregate-foamed concrete resisted significant shear load before failure.

\subsection{Analysis of reinforced concrete member in flexure}

Flexure analysis of reinforced concrete beam is based on a theory which has three basic assumptions to be able to calculate the moment resistance which are: the perpendicular section to the axis of bending will remain plane after bending, the strain in the reinforcement is equal to the strain in the concrete at the same level and from the strain by using stress-strain curves for concrete 
and steel, the amount of stresses in the concrete and reinforcement can be calculated (Wight and Macgregor 1997). The linearity of the moment-curvature relationship will remain until the flexural tension cracks occur in the section. It occurs as soon as the stress in the extreme tension fiber is equivalent to the concrete's modulus of rupture. Up to this point the section is in at un-cracked elastic range behaviour.

The moment of first flexural crack is defined as the theoretical cracking moment $\left(\mathrm{M}_{\mathrm{cr}}\right)$ of the beam. According to ACI 318M-08 2008 and CSA A23.3 (2004), the theoretical cracking moment can be calculated from:

$\mathrm{M}_{\mathrm{cr}}=\frac{\mathrm{f}_{\mathrm{r}} \mathrm{I}_{\mathrm{g}}}{y_{t}}$

In which $f_{r}$ is the modulus of rupture of concrete, $I_{g}$ represents the gross concrete section about neutral axis by neglecting the reinforcements and $y_{t}$ represents the distance from neutral axis to the tensile stress location.

\subsubsection{Theoretical ultimate moment of the LWSCC flexural beams}

The ultimate flexural capacity of a beam is when the concrete reaches to its maximum compressive strain at its ultimate stage. At this point, the compressive strain of concrete is equal to 0.0035 based on code of practice of CSA A23.3-04 (2004). It is desirable to get steel-controlled failure which happens when the beam is designed as under reinforced. The streel reinforcement provided in tensile zone will be yielded and the nature of failure will be ductile. If the failure was by crushing of concrete and brittle, the section is over reinforced and undesirable. Singly reinforced beam ultimate moment capacity of $\left(\mathrm{M}_{\mathrm{u}}\right)$ can be obtained from equation 2.23 as per CSA A23.3 (2004):

$M_{u}=f_{y} A_{s}\left(d-\frac{a}{2}\right)$

Where a can be found from equation (2.24) and (2.25)

$a=\frac{f_{y} A_{s}}{\alpha_{1} f_{c}^{\prime} b}$
$\propto_{1}=0.85-0.0015 f_{c}^{\prime}>0.67$ 


\subsubsection{Some previous studies of flexural behavior of lightweight concrete beams}

Sathiyamoorthy (2016) studied the flexural behaviour of LWSCC) with reference to normal weight concrete. The beams were tested under four-point monotonic loading to failure were the flexural reinforcement ratios for beams are $0.66 \%, 1 \%$ and $1.7 \%$. The prediction of cracking moment and ultimate moment capacity of LWSCC according to Canadian Code CSA A23.3-04 was good. All LWSCC flexure beams had similar performance compared to NC. Since all beams were underreinforced, the provided reinforcement in tension zone were yielded before crushing of concrete in pure bending zones as well as significant deformation and ductility were obtained from all LWSCC beams prior to failure.

Lime et al. (2006) investigated the overall flexure response of twenty-one lightweight aggregate reinforced concrete (LWAC) beams by considering normal weight concrete (NWC) beams for reference. All the beams were evaluated based on their flexure capacity, ductility, strength, deflection, stiffness, cracking and crack width. The results have shown that the overall flexural behaviour of LWAC beams were close to NWC. The structural design requirements incorporated in the codes of practice are analyzed and appropriate recommendations are made for the confident flexural design of LWAC beams.

\subsection{Summary}

Numerous research has been devoted to material properties of NC, LWC, SCC, and LWSCC for improved performance. Although the structural performance of FRC, LWC and SCC were the subject matter of earlier studies, literature review confirmed that limited investigations have been directed to durability and mechanical performance of LWSCC and FRLWSCC with little research on their structural performance. This warrants researches on the appraisal of the structural behaviour of FRLWSCC beams and to assess current design guidelines. The proposed research on the shear and flexural performance of FRLWSCC beams made of slag aggregate will contribute to the existing knowledge of such technology. 


\section{CHAPTER THREE \\ EXPERIMENTAL PROGRAM}

\subsection{Introduction}

The experimental program has been devoted to investigating structural shear and flexural performance of fiber reinforced lightweight self-consolidating concrete (FRLWSCC) beams made of slag aggregates incorporating with three different fibers such as High-Density Poly Ethylene (HDPE), Crumb Rubber (CR), Polyvinyl Alcohol (PVA) compared to those made with LWSCC with no fiber (tested as control specimens). In total twelve beams were tested. Four flexure beams were cast and coded by HDPE-LWSCC-F, CR-LWSCC-F, PVA-LWSCC-F and LWSCC-F (as the control). The letter "F" specified the flexural beams. Four shear beams with stirrup were also casted and coded by HDPE-LWSCC-S-S, CR-LWSCC-S-S, PVA-LWSCC-S-S and LWSCC-S-S (as the control). The first and second letter " $\mathrm{S}$ " represent shear beam and stirrup, respectively. The next four shear beams without stirrup were named as HDPE-LWSCC-S, CR-LWSCC-S, PVALWSCC-S and LWSCC-S (as the control). The letter "S" represents shear beam. All beams were tested under four-point loading to failure. In this chapter beam geometries, beam types, material properties, experimental setup and test procedure will be discussed.

\subsection{Beam geometry and reinforcement configuration}

\subsubsection{Shear beams}

The experimental study had been conducted to study the behaviour of FRLWSCC beams compared to their SCC counterparts and estimate fiber and concrete contributions to overall shear resistance $\left(\mathrm{V}_{\mathrm{r}}\right)$. Table 3.1 shows geometric dimensions and reinforcement details for shear beams. Total of eight shear beams were casted and tested with the width and depth of $100 \mathrm{~mm}$ and 200 $\mathrm{mm}$ and length of $1100 \mathrm{~mm}$. Four of them designed to be provided with the minimum amount of longitudinal reinforcements with no stirrup to evaluate the concrete shear resistance capacity as shown in Figure 3.1. 


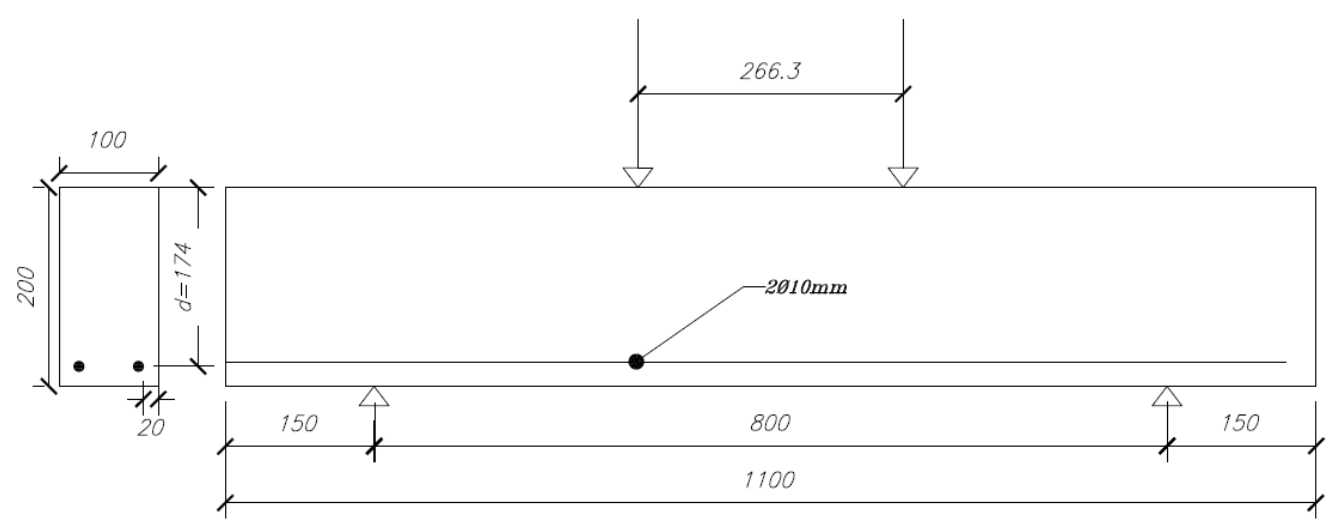

Figure 3.1: Shear beam without shear reinforcement geometry, cross section and loading points.

The next set of four shear beams were provided with minimum longitudinal reinforcement in addition to eight transverse stirrups at spacing of $133 \mathrm{~mm}$ center to center as it shown in Figure 3.2 .

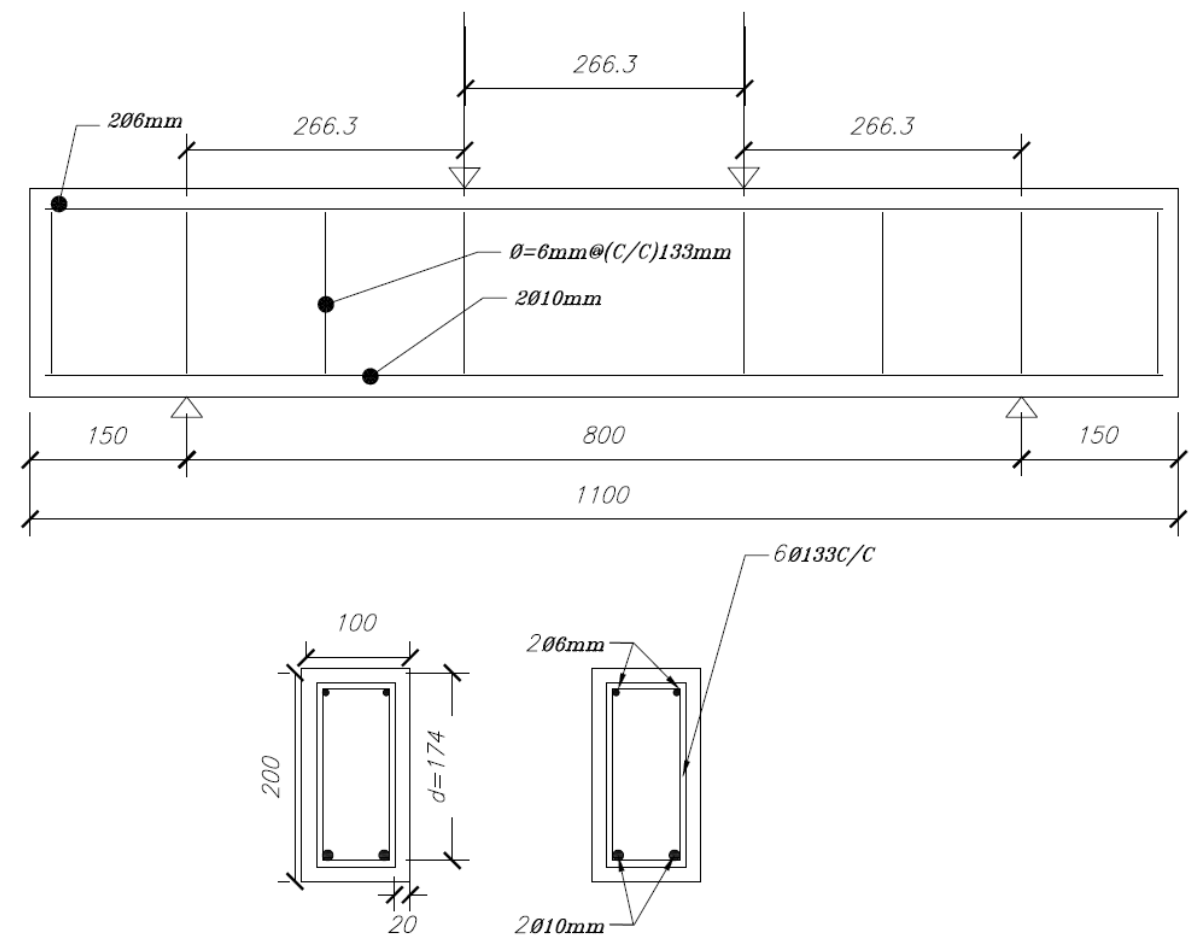

Figure 3.2: Shear beams with stirrups geometry, cross-section and loading points 
Table 3.1: Geometric dimensions and reinforcement details for shear beams

\begin{tabular}{|c|c|c|c|c|}
\hline Beam code & $\begin{array}{l}\text { Effective } \\
\text { depth }(\mathrm{d}) \\
(\mathrm{mm})\end{array}$ & $\begin{array}{c}\text { Shear span (a) to } \\
\text { depth (d) ratio } \\
\text { a/d }\end{array}$ & $\begin{array}{c}\text { longitudinal } \\
\text { reinforcement ratio, } \\
\rho \%=A_{s} / b * 100\end{array}$ & $\begin{array}{c}\text { Shear reinforcement } \\
\text { spacing } \\
(\mathrm{mm})\end{array}$ \\
\hline \multicolumn{5}{|c|}{$\begin{array}{l}\text { width }(\mathrm{b})=100 \mathrm{~mm} \text {, effective span }(\mathrm{S})=800 \mathrm{~mm} \text {, length }=1100 \mathrm{~mm} \text {, Total height }(\mathrm{H})=200 \mathrm{~mm} \text { Shear span } \\
\text { (a) to depth }(\mathrm{d}) \text { ratio } \mathrm{a} / \mathrm{d}=1.53\end{array}$} \\
\hline \multicolumn{5}{|c|}{ Beams without shear reinforcement } \\
\hline HDPE-LWSCC-S & 174 & 1.53 & 1.15 & - \\
\hline CR-LWSCC-S & 174 & 1.53 & 1.15 & - \\
\hline PVA-LWSCC-S & 174 & 1.53 & 1.15 & - \\
\hline LWSCC-S & 174 & 1.53 & 1.15 & - \\
\hline \multicolumn{5}{|c|}{ Beams with shear reinforcement } \\
\hline HDPE-LWSCC-S-S & 174 & 1.53 & 1.15 & 133 \\
\hline CR-LWSCC-S-S & 174 & 1.53 & 1.15 & 133 \\
\hline PVA-LWSCC-S-S & 174 & 1.53 & 1.15 & 133 \\
\hline LWSCC-S-S & 174 & 1.53 & 1.15 & 133 \\
\hline
\end{tabular}

\subsubsection{Flexural beams}

The experimental study had been conducted to analyze flexural behaviour of FRLWSCC beams and evaluate their ultimate flexural moment capacity $\left(\mathrm{M}_{\mathrm{u}}\right)$. A total of four singly reinforced flexural beams were designed based on CSA A23.3-04 (2004) and two $6 \mathrm{~mm}$ provided at top hold the stirrups, casted and tested with the width and depth of $150 \mathrm{~mm}$ and $230 \mathrm{~mm}$ and length of 3300 $\mathrm{mm}$ as it shown in Figure 3.3 and Figure 3.4. All beams were designed as under-reinforced and provided with adequate shear reinforcement at spacing of $60 \mathrm{~mm}$. Same flexural reinforcement arrangement were used for all four beams which are shown in Table 3.2, to compare the contribution of PVA fiber, HDPE fiber and CR fiber to LWSCC (without fiber). 
Table 3.2: Geometric dimensions and reinforcement details for flexural beams

\begin{tabular}{|c|c|c|c|}
\hline $\begin{array}{c}\text { Beam } \\
\text { code }\end{array}$ & $\begin{array}{c}\text { Effective } \\
\text { depth mm }\end{array}$ & $\begin{array}{c}\text { Bottom flexural } \\
\text { reinforcement }\end{array}$ & $\begin{array}{c}\text { Flexural reinforcement } \\
\text { ratio \% }\end{array}$ \\
\hline LWSCC-F & 200 & $3, \# 10 \mathrm{M}$ & 1.00 \\
\hline CR-LWSCC-F & 200 & $3, \# 10 \mathrm{M}$ & 1.00 \\
\hline PVA-LWSCC-F & 200 & $3, \# 10 \mathrm{M}$ & 1.00 \\
\hline HDPE-LWSCC-F & 200 & $3, \# 10 \mathrm{M}$ & 1.00 \\
\hline
\end{tabular}

Width: 150 mm, Depth: 230 mm, Length: 3300 mm, Span length: 3000 mm. All beams had a clear cover of 20 mm,6 mm plain steel bar @ $60 \mathrm{~mm}$ c/c was used as shear reinforcement and $2 \# 6 \mathrm{M}$ hanger bars were provided in the compression zone

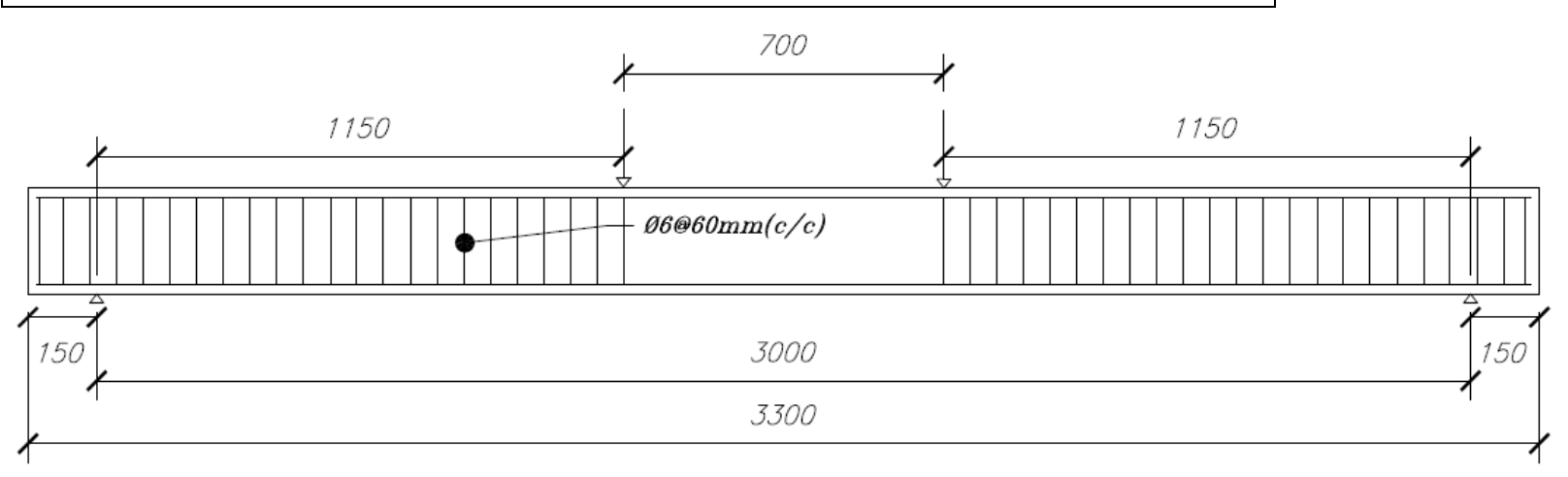

Figure 3.3: Flexural beam's geometry and loading points sketch

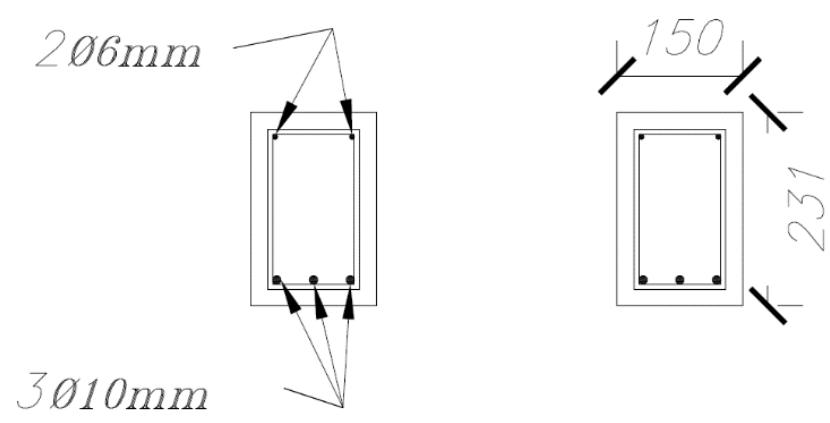

Figure 3.4: Flexural beam's cross section 


\subsection{Material}

This section presents the properties, mix design and mixing sequences for LWSCC and FRLWSCCs as well as casting and construction sequences of the specimens.

\subsubsection{Concrete materials and properties}

Mainly two types of concrete such as LWSCC and FRLWSCC (with PVA, CR and HDPE fiber) were used. Water to cementitious material $(\mathrm{w} / \mathrm{b}$ ) ratio of all mixes was 0.30 (all the mixes were developed at Ryerson) as per Table 3.3. The fiber content of CR-FRLWSCC, PVA-FRLWSCC and HDPE-FRLWSCC mixes were $1 \%, 0.5 \%$ and $1 \%$ of fibers $/ \mathrm{kg}$ of dry material, respectively. All mixes consist of CSA type 10 or ASTM type 1 Portland cement with specific gravity of 3.17, fly ash (class C) and dry-densified silica fume (SF) as the cementing material, water, coarse and fine slag aggregates with nominal size of $10 \mathrm{~mm}$ and $4.75 \mathrm{~mm}$, respectively and polycarboxylatebased high range water reducer (HRWR). Mix designs of LWSCC and all three FRLWSCC are presented in Table 3.3.

Table 3.3: Concrete mix designs

\begin{tabular}{|c|c|c|c|c|c|c|c|c|c|}
\hline $\begin{array}{c}\text { Concrete } \\
\text { Mix }\end{array}$ & w/b & cement & $\begin{array}{c}\text { Fly Ash } \\
\text { (Class C) }\end{array}$ & $\begin{array}{c}\text { Silica } \\
\text { fume }\end{array}$ & Water & $\begin{array}{c}\text { Coarse } \\
\text { Aggregate } \\
\text { (SSD) }\end{array}$ & $\begin{array}{c}\text { Fine } \\
\text { Aggregate } \\
\text { (SSD) }\end{array}$ & $\begin{array}{c}\text { HRWR } \\
\mathrm{kg} / \mathrm{m}^{3}\end{array}$ & $\begin{array}{c}\text { Fiber } \\
\mathrm{kg} / \mathrm{m}^{3}\end{array}$ \\
\hline $\begin{array}{c}\text { LWSCC and FRLWSCC mixtures: } \text {-water; b-binder; HRWRA- High Range Water Reducing } \\
\text { Admixture; Ratio of ingredient for the mixes are by mass; Ingredients per 1 part of cement }\end{array}$ \\
\hline $\begin{array}{c}1 \% \text { HDPE- } \\
\text { FRLWSCC }\end{array}$ & 0.30 & 1.00 & 0.16 & 0.09 & 0.38 & 0.99 & 1.61 & 4.75 & 9.2 \\
\hline $\begin{array}{c}1 \% \text { CR- } \\
\text { FRLWSCC }\end{array}$ & 0.30 & 1.00 & 0.16 & 0.09 & 0.38 & 0.99 & 1.61 & 4.75 & 9.2 \\
\hline $\begin{array}{c}0.5 \% \text { PVA- } \\
\text { LWSCC }\end{array}$ & 0.30 & 1.00 & 0.16 & 0.09 & 0.38 & 0.99 & 1.62 & 4.75 & 6.5 \\
\hline LWSCC & 0.30 & 1.00 & 0.15 & 0.09 & 0.37 & 1 & 1.61 & 4.75 & 0 \\
\hline
\end{tabular}

Table 3.4 specifies the properties of the cementitious materials such as cement, fly ash and silica fume used in concrete mixes.

Lightweight blast furnace slag aggregates were used to produce FRLWSCC and LWSCC mixtures as shown in Figure 3.5. Table 3.5 shows the coarse and fine lightweight aggregate physical properties and gradation according to ASTM C330 (2014). 
Table 3.4: Properties of cementitious materials

\begin{tabular}{|c|c|c|c|}
\hline Chemical composition & Cement & Fly Ash & Silica Fume \\
\hline $\mathrm{SiO}_{2}(\%)$ & 19.6 & 37.5 & 95.2 \\
\hline $\mathrm{Al}_{2} \mathrm{O}_{3}(\%)$ & 4.9 & 18.6 & 0.21 \\
\hline $\mathrm{Fe}_{2} \mathrm{O}_{3}(\%)$ & 3.1 & 5.8 & 0.13 \\
\hline $\mathrm{CaO}(\%)$ & 61.4 & 26.11 & 0.23 \\
\hline $\mathrm{MgO}(\%)$ & 3.0 & 5 & - \\
\hline $\mathrm{SO}_{3}(\%)$ & 3.6 & 2.38 & 0.33 \\
\hline Alkalis as $\mathrm{Na}_{2} \mathrm{O}(\%)$ & 0.9 & 2.8 & 0.85 \\
\hline
\end{tabular}

Table 3.5: Aggregates gradation and physical properties

\begin{tabular}{|c|c|c|c|c|}
\hline \multirow{3}{*}{ Sieve Size $(\mathrm{mm})$} & \multicolumn{4}{|c|}{ Passing (\%) } \\
\hline & \multicolumn{2}{|c|}{ ASTM- C330 Specifications } & \multicolumn{2}{|c|}{ Slag aggregate } \\
\hline & Fine & Coarse & Fine & Coarse \\
\hline 13.2 & 100 & 100 & 100 & 100 \\
\hline 9.5 & $80-100$ & $80-100$ & 99.3 & 91.9 \\
\hline 4.75 & $5-40$ & $5-40$ & 97.4 & 20.5 \\
\hline 2.36 & $0-20$ & $0-20$ & 81.2 & 15.2 \\
\hline 1.18 & $0-10$ & $0-10$ & 49 & - \\
\hline 0.3 & - & - & 6.5 & - \\
\hline 0.15 & - & - & 1.3 & - \\
\hline 0.075 & - & $0-10$ & 0 & - \\
\hline Bulk Specific gravity (dry) & - & - & 2.0 & 1.6 \\
\hline Bulk Specific gravity (SSD) & - & - & 2.19 & 1.82 \\
\hline Dry loose bulk density $\left(\mathrm{kg} / \mathrm{m}^{3}\right)$ & $1120(\max )$ & $880(\max )$ & 1356 & 950 \\
\hline Absorptions (\%) & - & - & 9.64 & 13.42 \\
\hline
\end{tabular}

Due to high porous nature of lightweight aggregates, both coarse and fine aggregates have been pre-soaked in water for minimum of 72 hours and then 24 hours out of water in room temperature to let the excess water drained out and used the aggregates in saturated surface dry (SSD) condition as shown in Figure 3.6. Loosing of fine particles during the procedure must be avoided. 


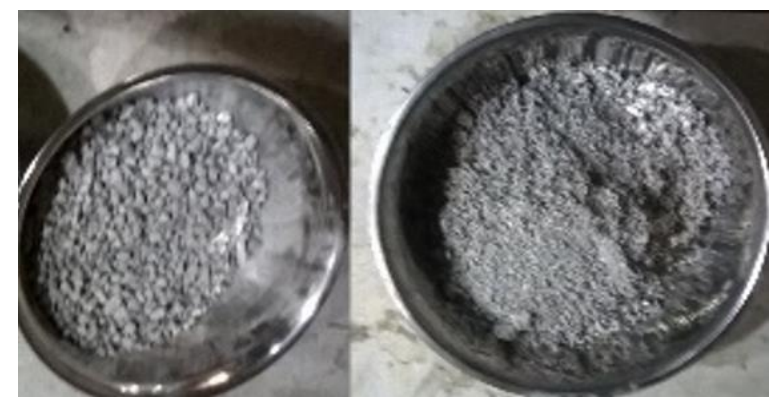

Figure 3.5: Blast furnace slag aggregate
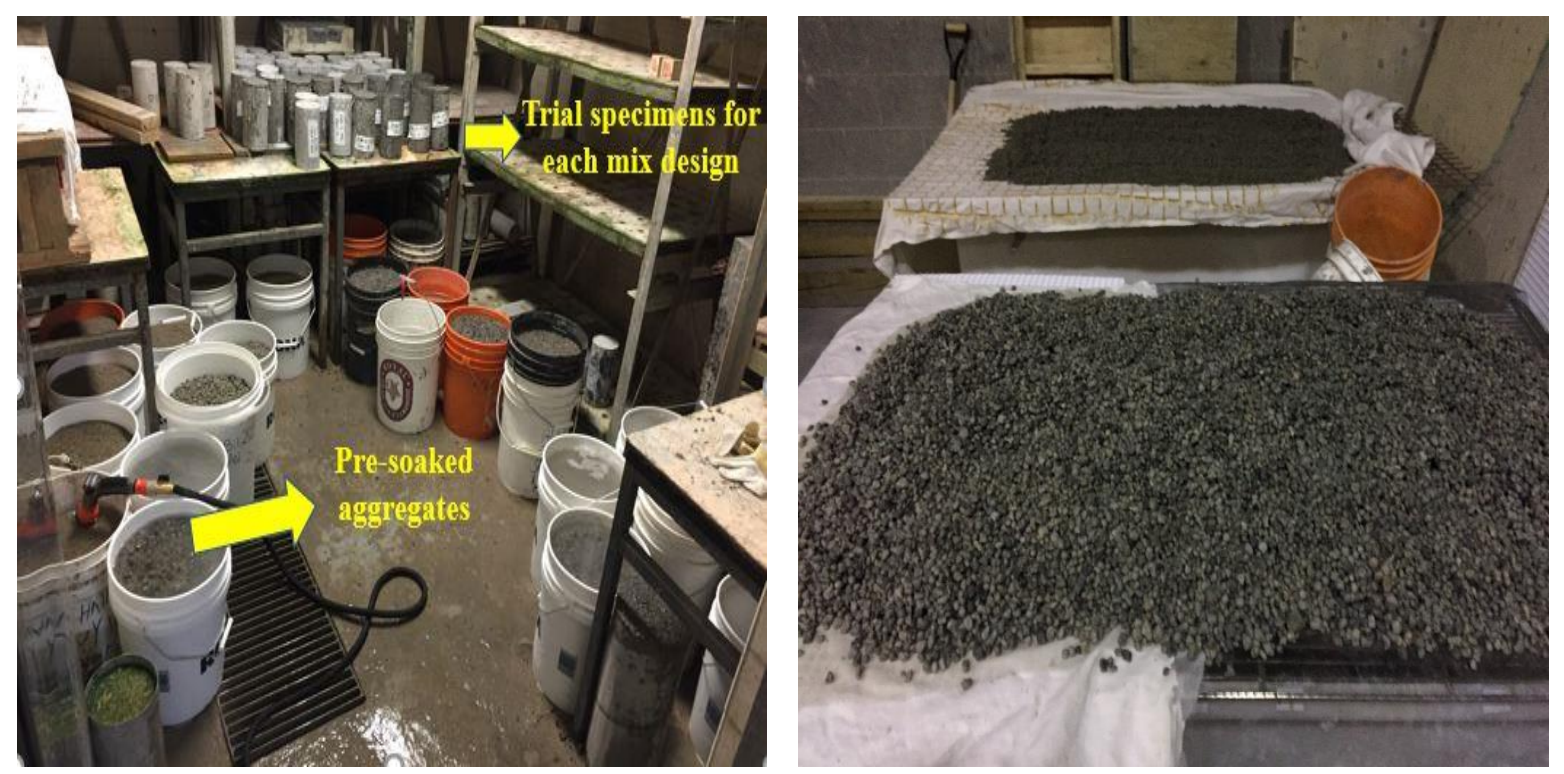

Figure 3.6: Aggregate pre-soaking and Aggregate in SSD condition

All three used fibers are shown in Figure 3.7 while the geometrical and mechanical properties of fibers are presented in Table 3.6
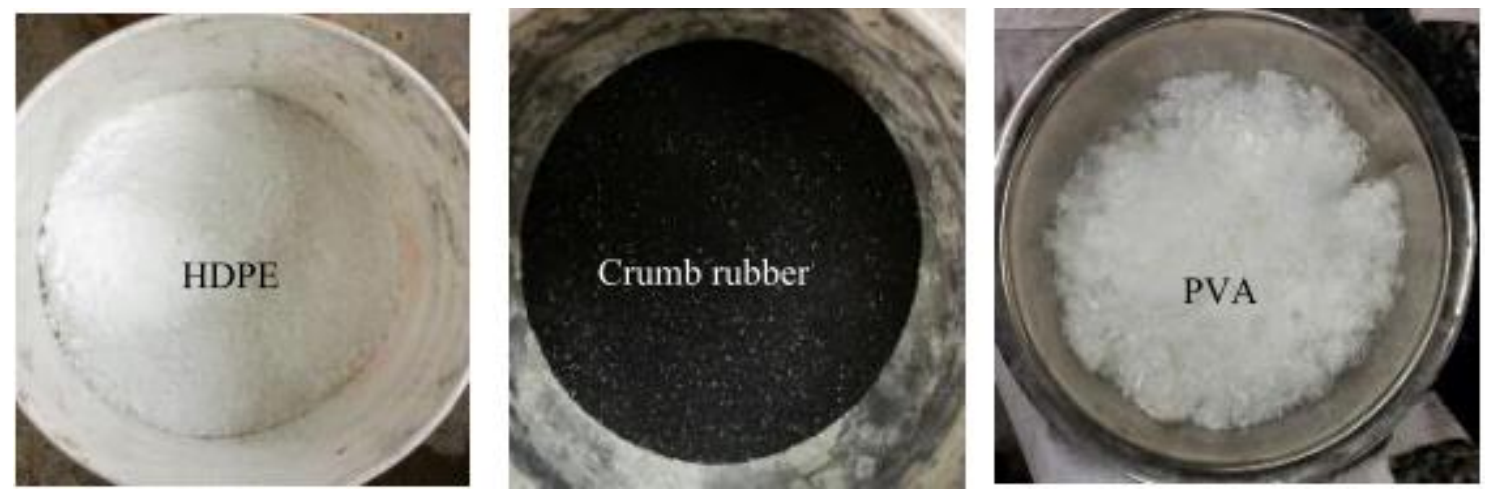

Figure 3.7: HDPE, PVA and Crumb rubber fibers 
Table 3.6: Geometrical and mechanical properties of fibers

\begin{tabular}{|c|c|c|c|c|}
\hline Fiber type & Length $(\mathrm{mm})$ & Specific Gravity $\left(\frac{\mathrm{Kg}}{\mathrm{m}^{3}}\right)$ & Melting point $\left({ }^{\circ} \mathrm{C}\right)$ & Diameter (Microns) \\
\hline PVA & 8 & 1.3 & 225 & 38 \\
\hline HDPE & 0.1 & 0.96 & 135 & 5 \\
\hline Crumb rubber & 0.4 & 0.9 & N/A & 2 \\
\hline
\end{tabular}

The 350-liter shear mixer was used for mixing all concrete mixes. For casting FRLWSCC, all required material were weighted and prepared beside the mixer. The slag coarse and fine aggregates were weighted in SSD condition and introduced first into the mixer and mixed $75 \%$ of the mixing water for 2 minutes at normal speed, then the rest of cementitious materials including fly ash, silica fume and cement were added and mixed for another 5 minutes. HRWRA slowly added to the mix with remained $25 \%$ water and mixed for another 5 minutes. Finally, fiber was added to the mixer and mix for 15 minutes. Same procedure has been applied for LWSCC mix as well.

\subsubsection{Steel reinforcement properties}

$10 \mathrm{~mm}$ rebars used as the longitudinal reinforcements and $6 \mathrm{~mm}$ rebars used as shear stirrups for all designed beams. The properties of the tested rebars provided in Figure 3.8 and Table 3.7.
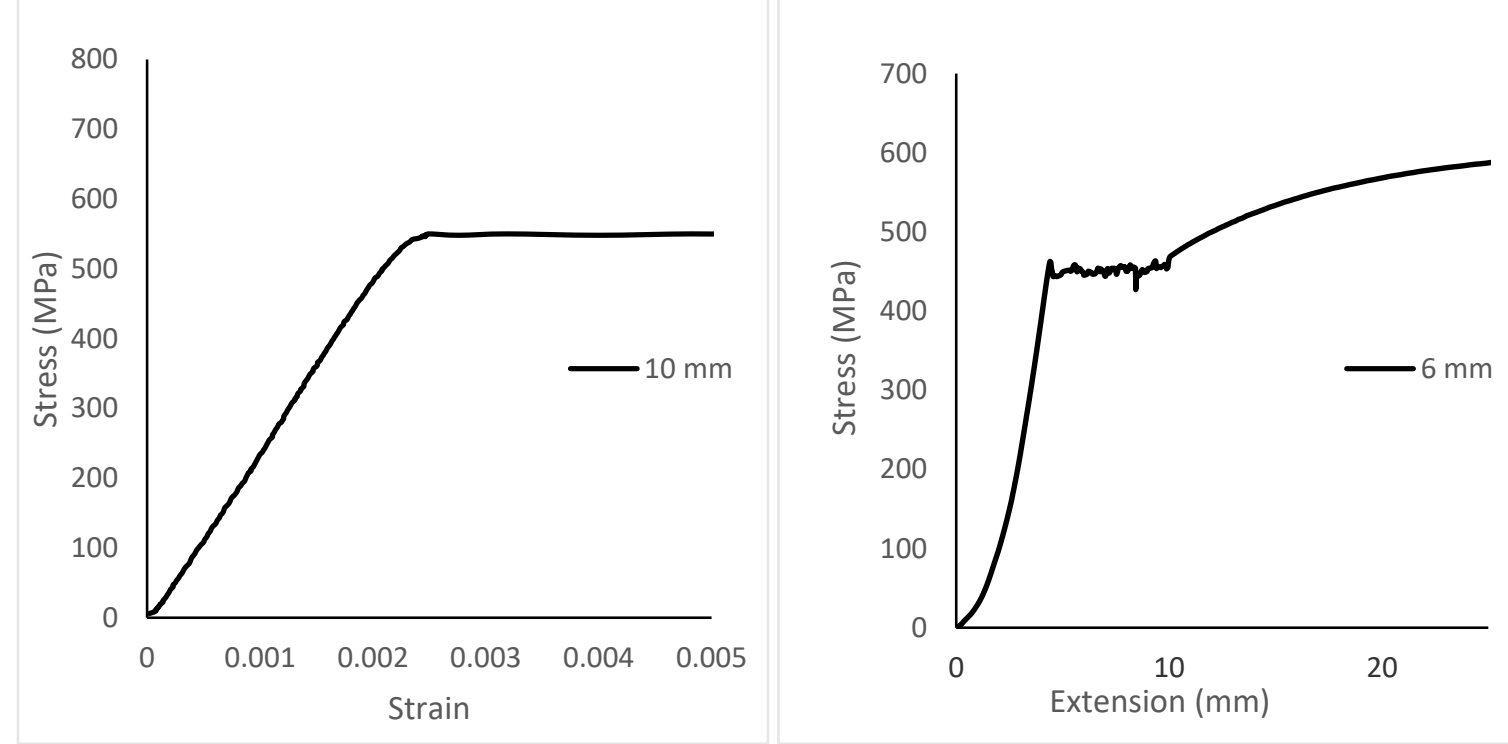

Figure 3.8: Rebar stress-strain/deformation responses of steel rebars 
Table 3.7: Properties of steel reinforcement

\begin{tabular}{|l|l|l|}
\hline Rebar & Yield strain (micro-strain) & Yield stress (MPa) \\
\hline $10 \mathrm{~mm}$ & 2015 & 504 \\
\hline $6 \mathrm{~mm}$ & $---*$ & 447 \\
\hline$*:$ mechanical machine limitation \\
\hline
\end{tabular}

\subsection{Beam fabrication, casting and curing}

For each concrete mixture three wooden form works were prepared to accommodate two shear beams and one flexure beam which were provided with designed reinforcement. Mid-span of bottom reinforcement for all beams were ground smooth to attach strain gauges to the bottom reinforcement and stirrup.

Total volume of 250 liter of concrete was needed to fulfill three beam specimens. Overall of three FRLWSCC batches and one batch of LWSCC were casted. Directly after mixing, flowable concrete were poured into formworks without any external vibration. Beam casting was fast and easy due to highly flowable mix. From each batch, ten cylinders for compressive strength with diameter and height of $100 \mathrm{~mm}$ and $200 \mathrm{~mm}$ respectively, and eight flexure beam specimens with length, height and width of 304.8, 76.0 and $50.0 \mathrm{~mm}$, respectively were poured. The compressive strength of concrete for all mixes were obtained and tested from control cylinders according to ASTM C39 (2003) at 28 days and flexural strength were determined based on ASTM C78 (2010) at 28 days under four-point bending test. Table 3.8 summarized the concrete compressive strength, flexural strength and dry air density of tested samples. Flexural strength test load-deflection response of all type of concretes shown Figure 3.9.

The formworks for all casted beams and specimens were removed after 72 hours of casting and moisture curing applied for another 4 days as it shown in Figure 3.10 and then air curing started at room temperature until 28 days of testing. The following Table 3.8 presented the mean compressive strength, mean flexural strength and the mean air dry density which obtained by testing of ten casted control cylinders and flexure speciemens. 
Table 3.8: Concrete compressive strength, flexural strength and density at 28 days

\begin{tabular}{|c|c|c|c|}
\hline Concrete & $\begin{array}{c}\text { Mean compressive } \\
\text { strength (MPa) }\end{array}$ & $\begin{array}{c}\text { Mean flexural strength } \\
(\mathrm{MPa})\end{array}$ & $\begin{array}{c}\text { Mean air dry density } \\
\left(\mathrm{kg} / \mathrm{m}^{3}\right)\end{array}$ \\
\hline HDPE-LWSSC-S & 38.7 & 2.8 & 1862 \\
\hline CR-LWSCC-S & 46.7 & 2.8 & 1890 \\
\hline PVA-LWSCC-S & 43.6 & 2.9 & 1810 \\
\hline LWSCC-S & 52.6 & 2.3 & 1826 \\
\hline
\end{tabular}
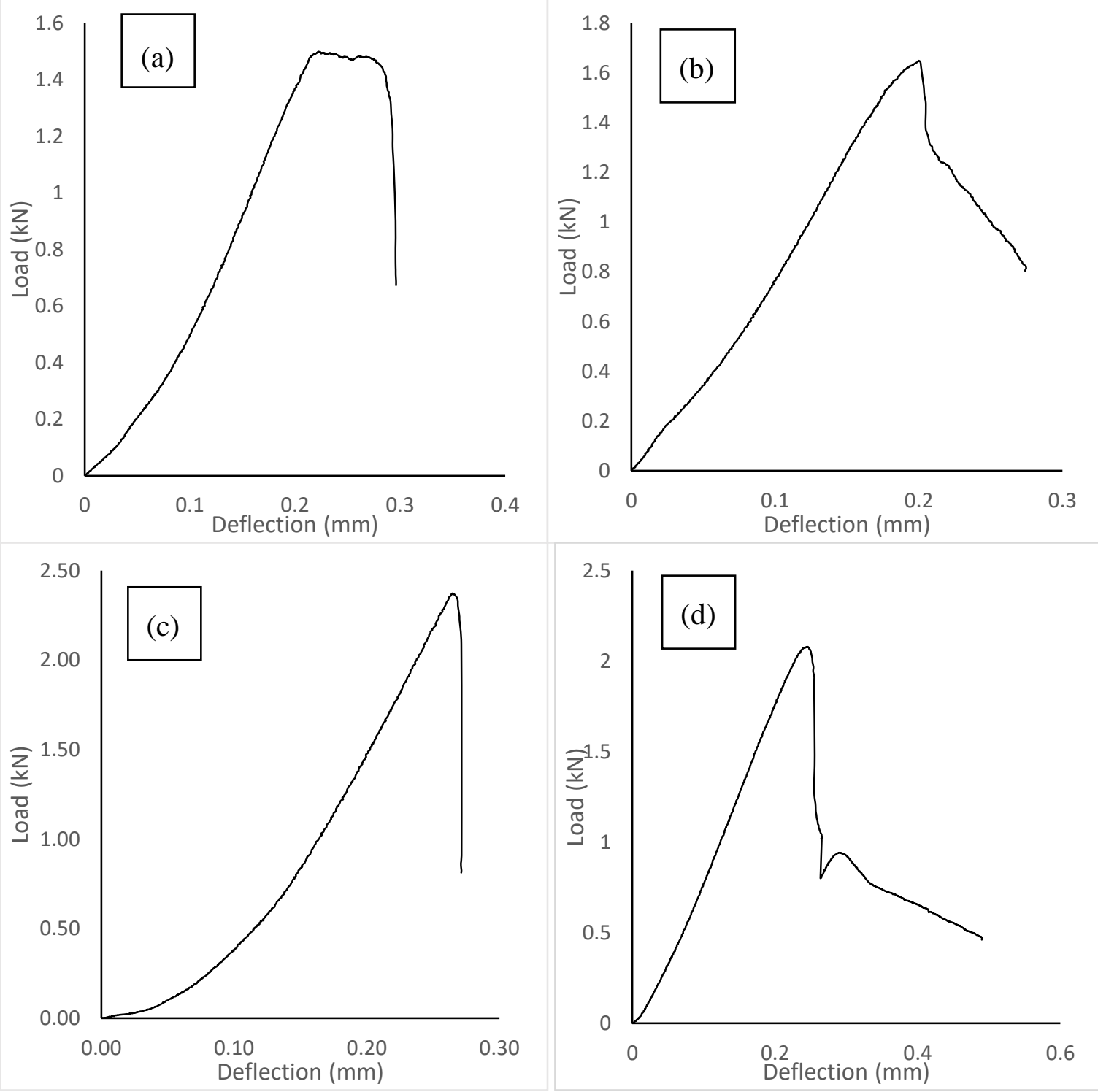

Figure 3.9: Flexural strength load-deflection curves (a) LWSCC (b) CR-LWSCC (c) HDPELWSCC (d) PVA-LWSCC 

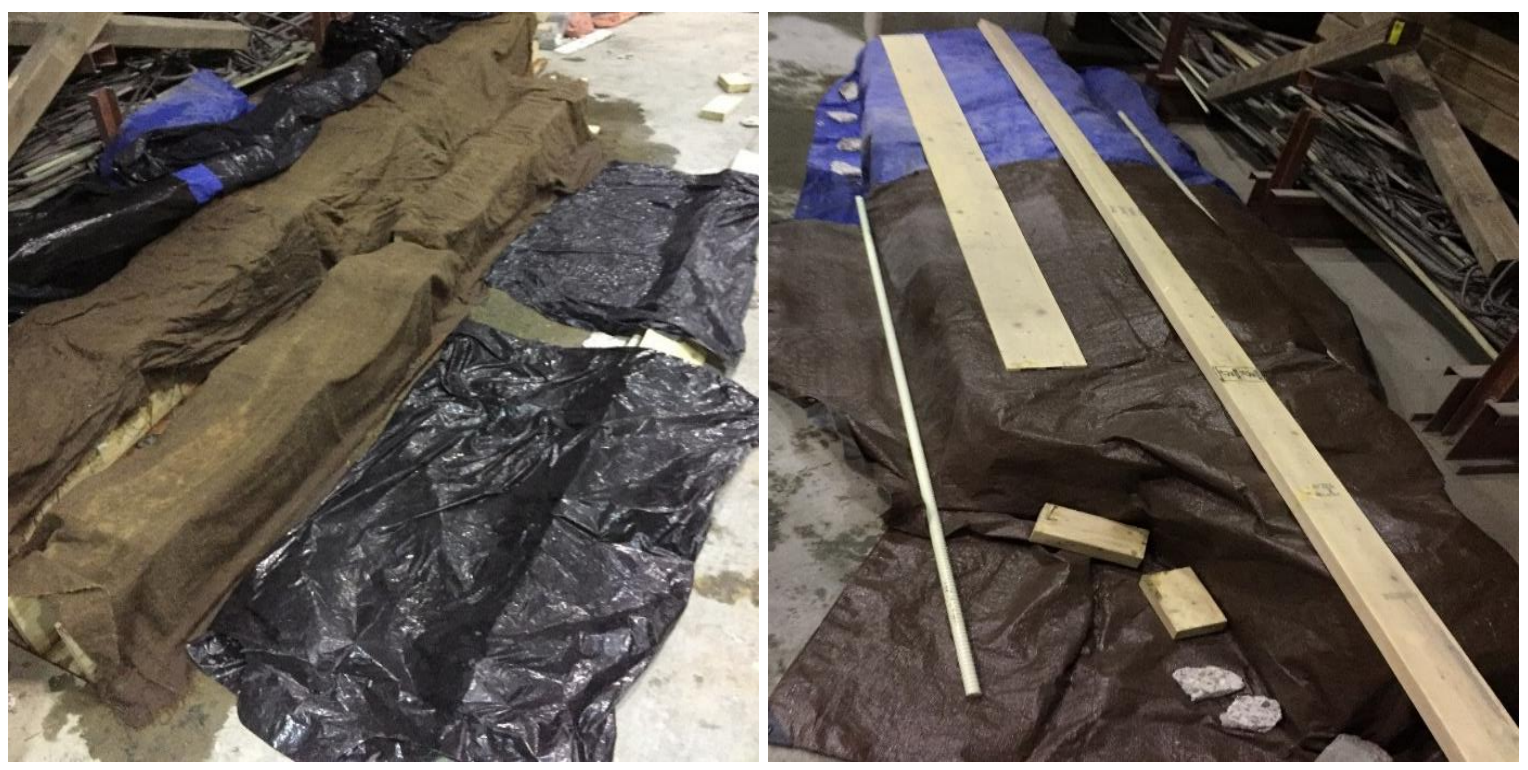

Figure 3.10: Curing condition of casted beams

\subsection{Experimental set up and instrumentation}

All casted beams were tested under four-point loading as per ASTM D7250 (2016). The experimental setup for shear beams with and without reinforcement shown in Figure 3.11. For all shear beams one LVDT (Linear variable displacement transducer) was installed at mid-span to record the corresponded deflection at every load during the testing process. In case of shear beams with shear reinforcement, same set up applied in addition to steel strain gauges that were attached to the shear and flexure reinforcement at the specified locations as it shown in to measure the strain development in reinforcements during the test.

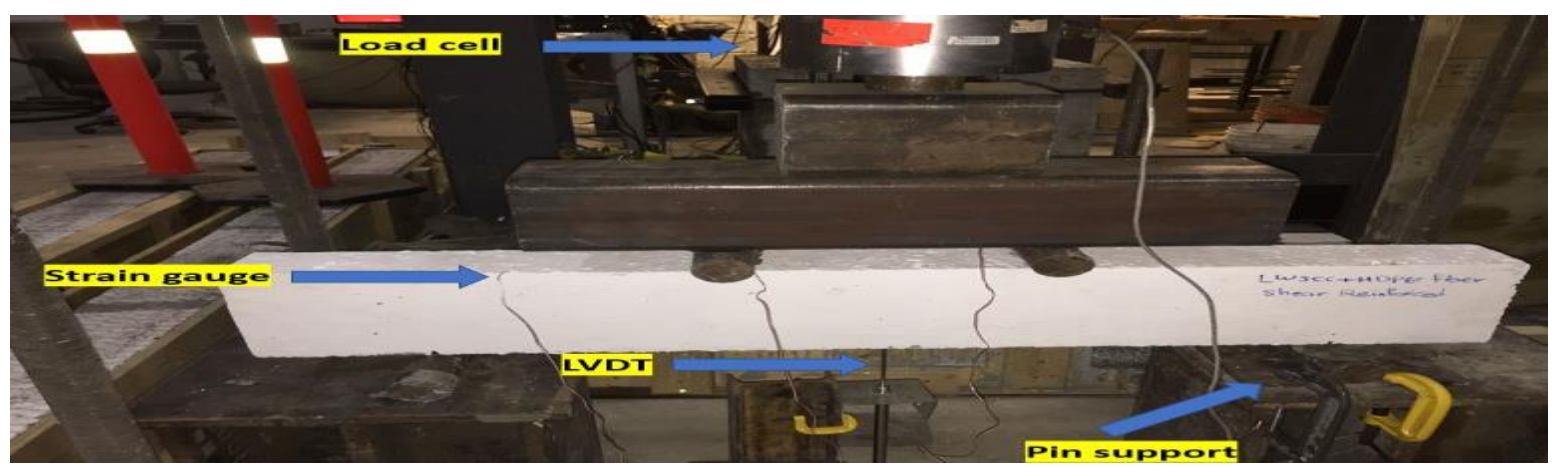

Figure 3.11: Test set-up for shear beams 

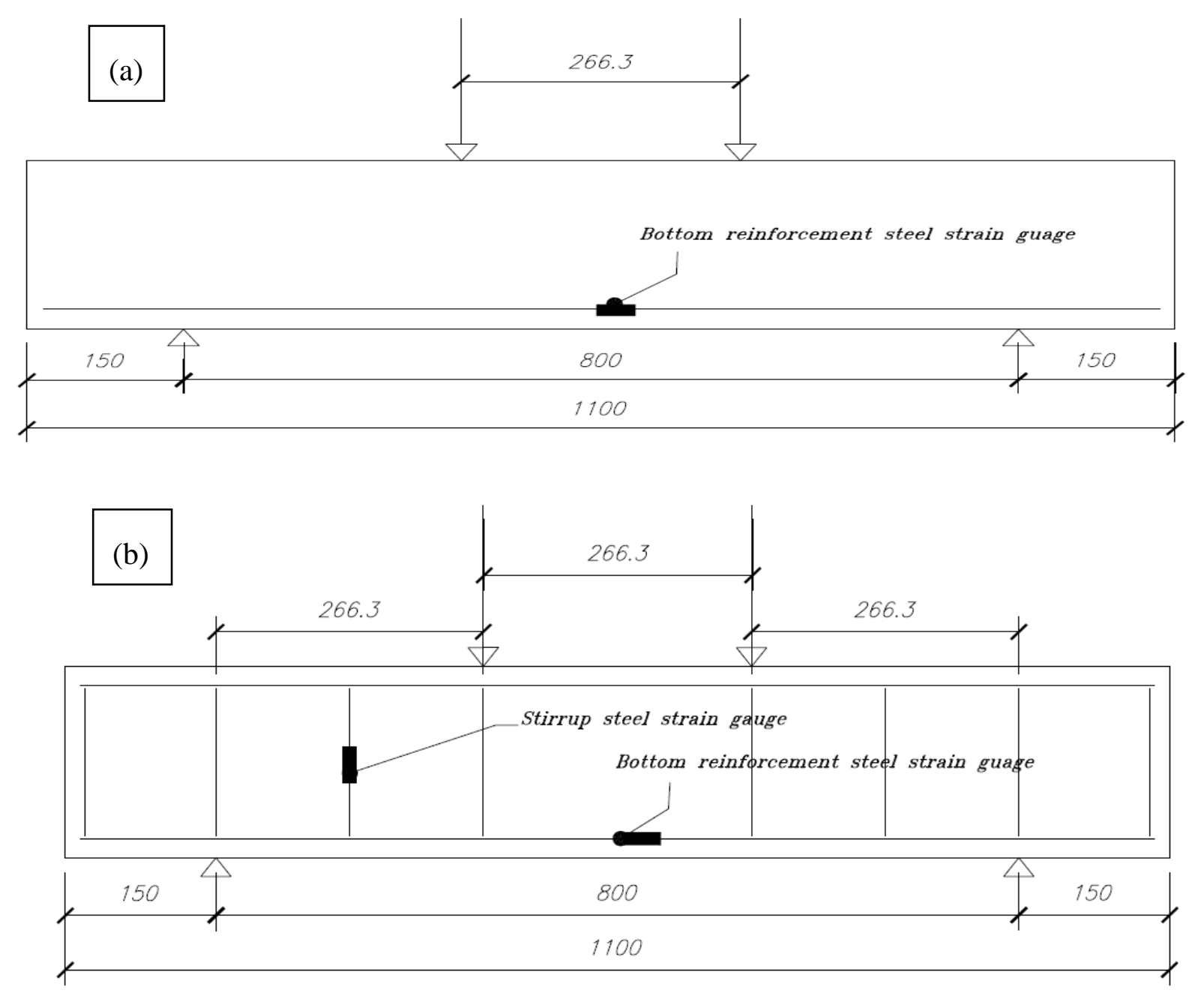

Figure 3.12: Location of strain gauges for shear beams with and without stirrups

All flexural beams were tested under four-point loading condition as it shown in Figure 3.13. Three LVDTs were fixed at $\mathrm{x}=750 \mathrm{~mm}, \mathrm{x}=1500 \mathrm{~mm}$ and $\mathrm{x}=2250 \mathrm{~mm}$ from the left support to record the deflection at corresponded locations. Two strain gauges were attached to the top and bottom reinforcement and one strain gauge installed at top surface of concrete mid span to measure the development of strain at different stages during the test shown in Figure 3.14. An inclinometer also was attached on cantilever side of the support to measure the rotation angle. A hydraulic jack was applying the load through the load cell at increment of $5 \mathrm{kN}$ while observing and marking the cracks at each increment. All the mentioned equipment was connected to the computer control data acquisition system. 


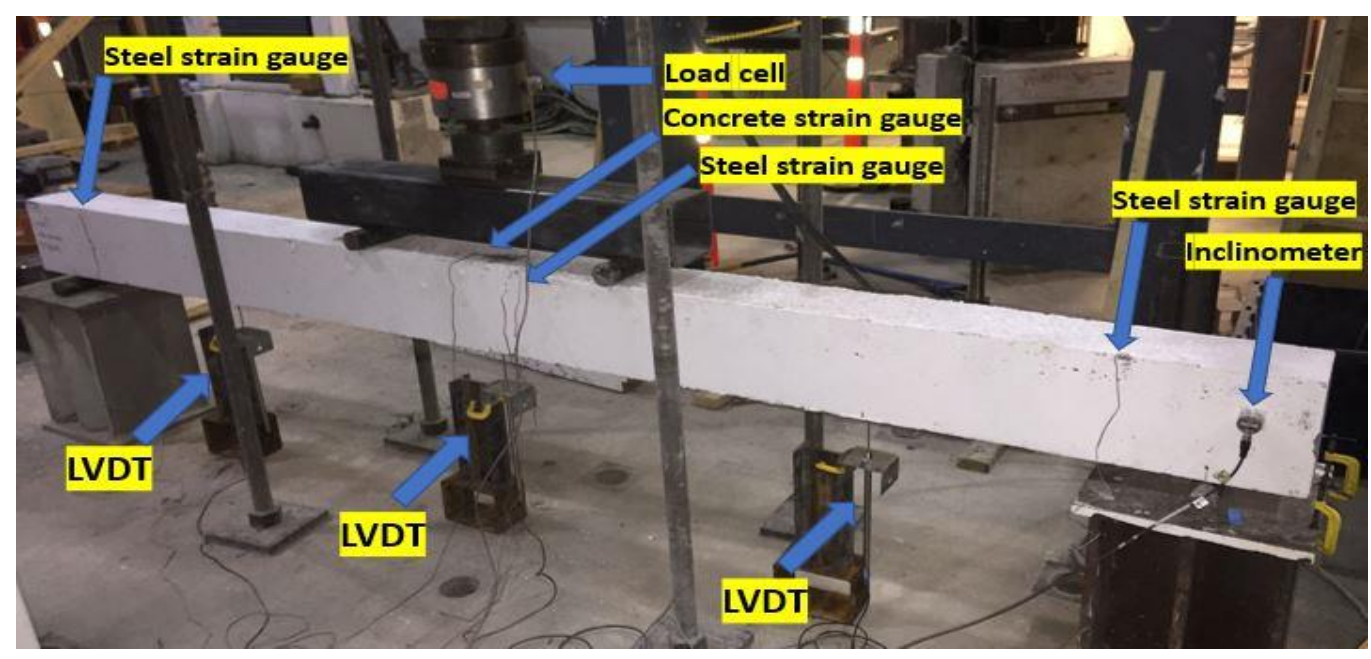

Figure 3.13: Test set-up for flexural beams

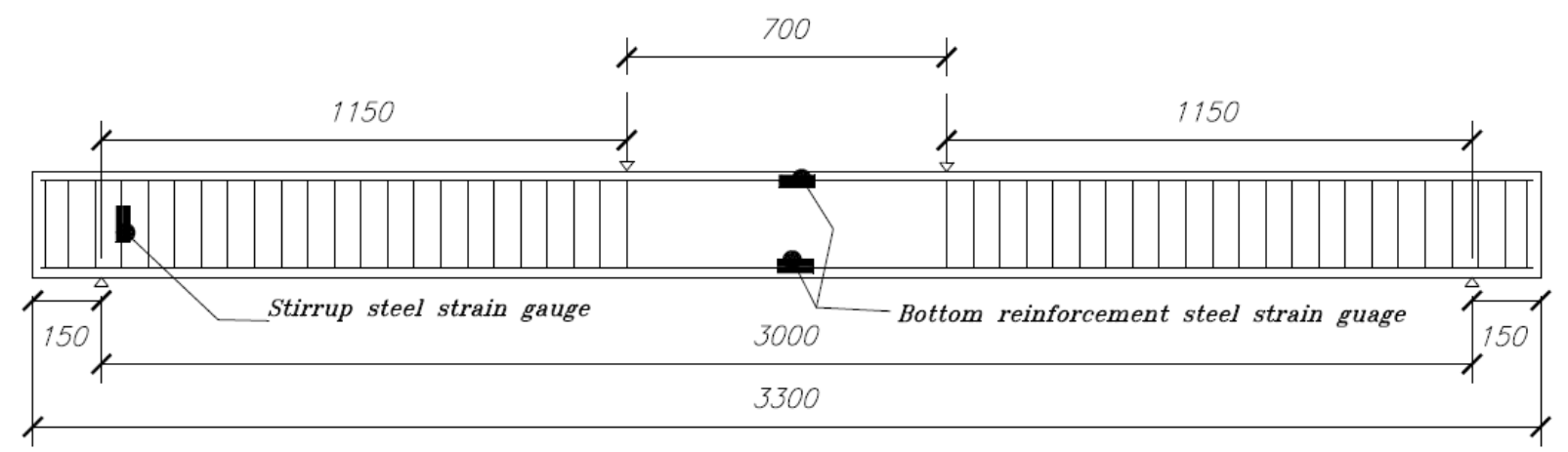

Figure 3.14: Location of strain gauges for flexural beams

\subsection{Summary}

The experimental research program is descried by demonstrating beam specimen preparation (fabrication and casting), material properties, specimen instrumentation and test procedure. Total of 8 shear beams and 4 flexural beams were tested to failure. The test results will be presented and described in Chapter Four. 


\section{CHAPTER FOUR}

\section{EXPERIMENTAL RESULTS AND DISCUSSION}

\subsection{Introduction}

This Chapter presents the results of the experimental investigation on shear and flexural behavior of fiber reinforced lightweight self-consolidating concrete (FRLWSCC) beams. The result of the tests evaluated and described based on load versus deflection response, moment-rotation response, first diagonal crack load, strain development in steel and concrete, energy absorption, ductility index, stiffness, crack formation and propagation and failure modes. The experimental load/shear and moment capacity of the beams are also compared with those obtained from Codes and other existing equations.

\subsection{FRLWSCC and LWSCC shear beams without shear reinforcement}

Shear behaviour of the FRLWSCC and LWSCC beams without shear reinforcement subjected to four-point loading is described and compared. Total of four shear beams without shear reinforcement consisting of three different type of fibers (HDPE, PVA and CR) and one LWSCC as control sample were casted. Shear span to effective depth ratios (a/d) was 1.53 for all beams with the height/total depth $(\mathrm{H})$ of $200 \mathrm{~mm}$. Shear beams were designed based on CSA A23.3 (2004) to have adequate longitudinal reinforcement with the reinforcement ratio of $1.15 \%$.

\subsubsection{Load deflection behavior}

Figure 4.1 and Figure 4.2 (a-d) shows the load-deflection responses of the tested FRLWSCC and LWSCC shear beams without shear reinforcement. Ultimate shear capacity of HDPE-LWSCC-S and CR-LWSCC-S beams were close to $48 \mathrm{kN}$ which was $53 \%$ and $31 \%$ higher than PVALWSCC-S and LWSCC-S beams, respectively. PVA-LWSCC-S beam specimen showed lowest shear capacity equal to $23 \mathrm{kN}$ which was $30 \%$ lower than the control beam (LWSCC-S). Experimental shear capacities of beams are summarized in Table 4.1.

HDPE-LWSCC-S beam had exhibited the highest mid-span deflection of $4.5 \mathrm{~mm}$ at the peak load. Mid-span deflection of beams at peak load are presented in the Table 4.1. 
The slope change in the load-deflection curve indicates the variation of stiffness of the beam. Formation or initiation of cracks in the beams leads to reduction in the stiffness of the beam. The initial straight-line segment of the curve shows that prior to flexural cracking, stiffness of the beam remained constant. Abrupt changes in the load-deflection curves indicate crack development and propagation during loading. Stiffness of all the FRLWSS-S-S suddenly decreased after formation of the diagonal cracks. Calculated shear capacity at the time of first diagonal crack and initial stiffness of all the specimens are summarized in Table 4.1.

For HDPE-LWSCC-S and CR-LWSCC-S beams when the load reached the ultimate shear capacity, a sudden brittle shear failure occurred. In case of PVA-LWSCC-S and LWSCC-S beams immediately after propagation of the shear crack from loading point to the support, a significant drop in the load carrying capacity was observed but the PVA-LWSCC-S beam withstood more deflection after reaching maximum shear capacity compared with the counterpart beams.

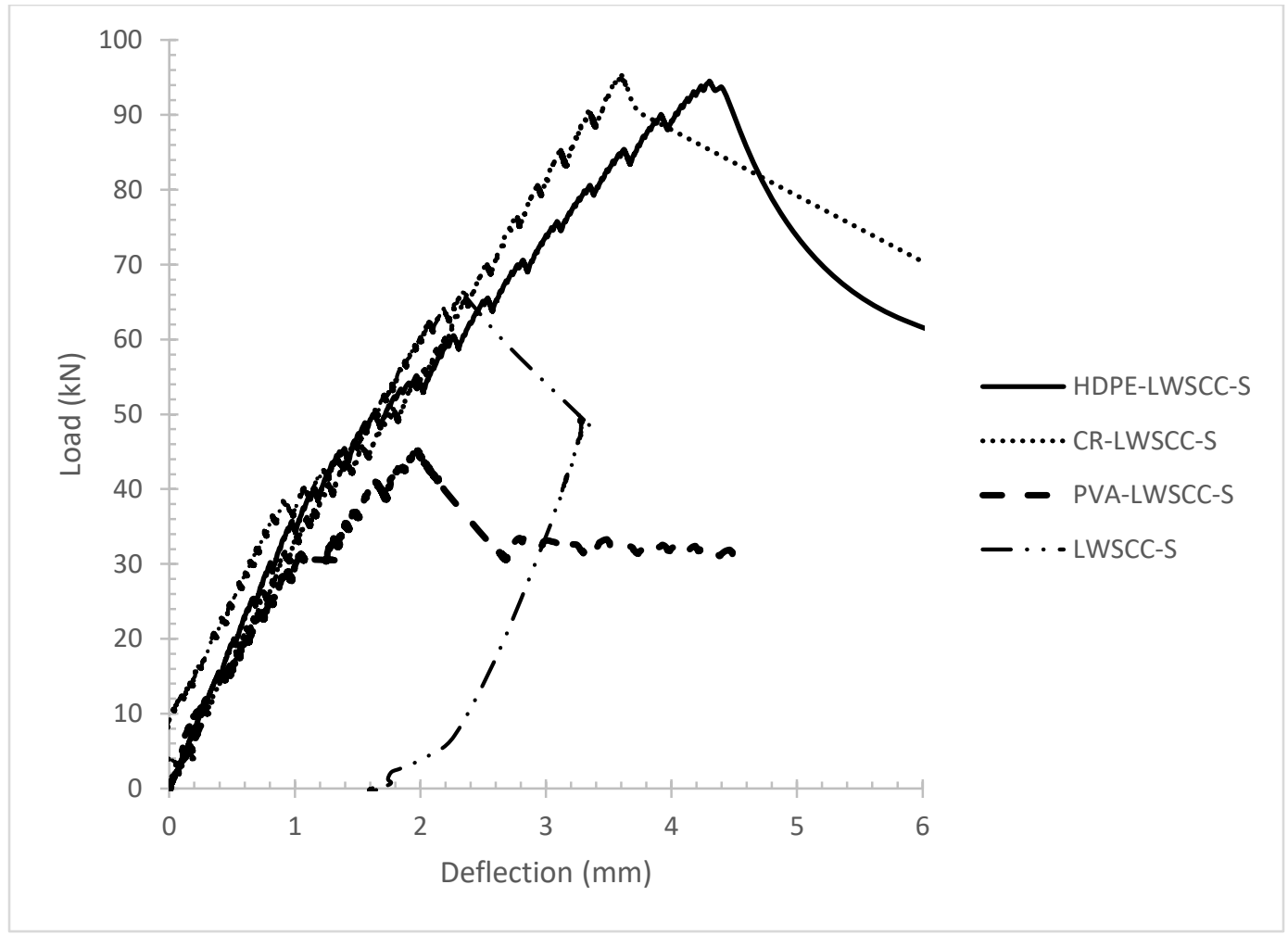

Figure 4.1: Comparative load-deflection curve for shear beams without shear reinforcement 

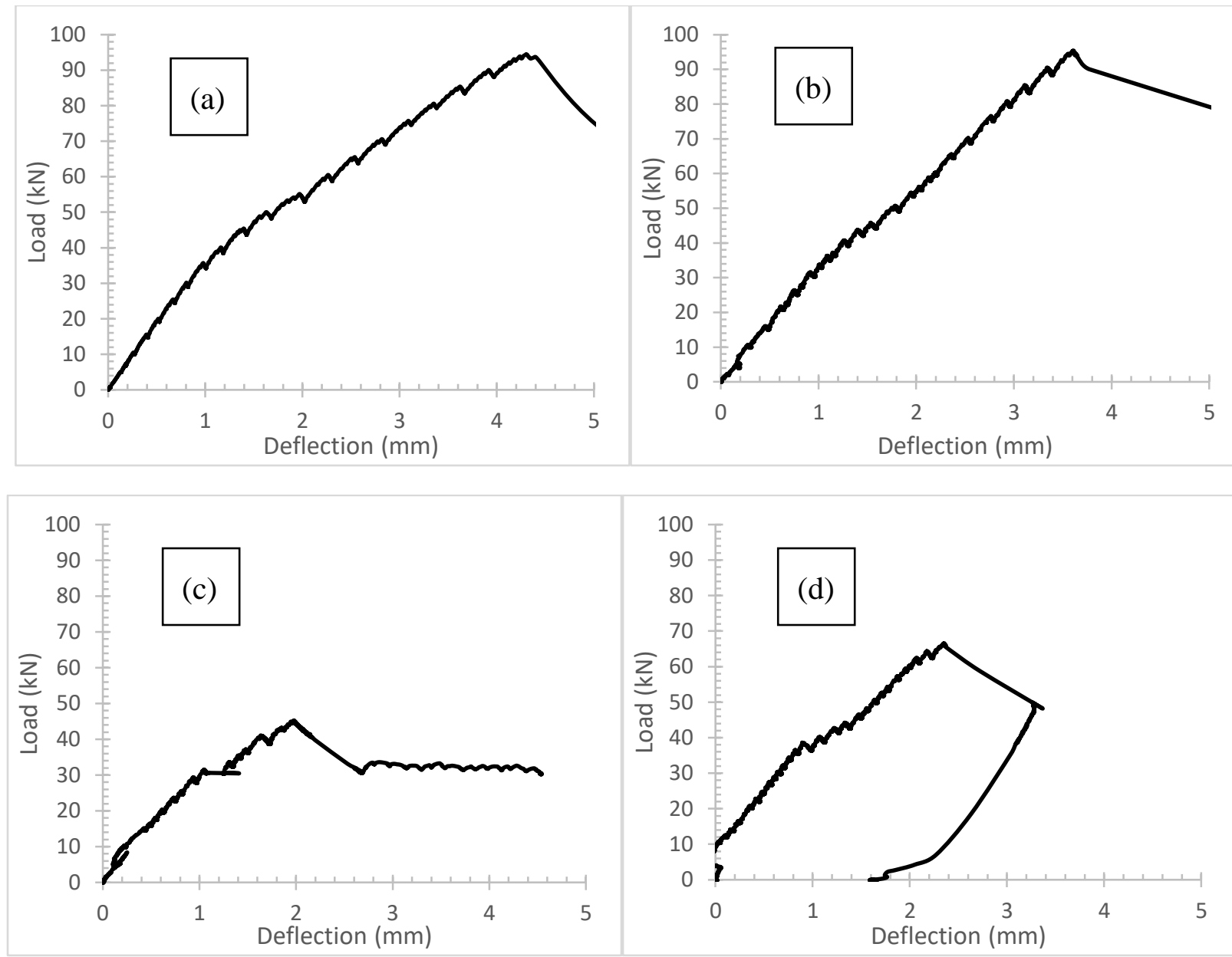

Figure 4.2: Load-deflection responses of beams (a) HDPE-LWSCC-S (b) CR-LWSCC-S (c) PVALWSCC-S (d) LWSCC-S

\subsubsection{Failure mode and crack patterns}

Failure modes of the beams with cracking are shown in Figure 4.3. During the loading history, formation of small vertical flexural cracks observed at lower loads in the mid span (zero shear span). The diagonal shear crack initially starts forming near the support propagated towards the loading point. With the increase of the load, number of flexural cracks within the zero-shear span also increased and diagonal shear cracks completely propagated towards the loading point. All shear beams suddenly failed in shear after complete formation of shear crack, except for CRLWSCC-S where the shear crack spread from load to the support at load $60 \mathrm{kN}$ and failed at load of $94 \mathrm{kN}$ as shown in Figure 4.3(c). The volume of sound at the time of failure was noticeably louder in HDPE-LWSCC-S and CR-LWSCC-S. Table 4.1 summarizes the experimental results 
for shear beams without shear reinforcement by indicating the concrete compressive strength, failure modes, shear loads at first flexure/diagonal crack, deflection at first diagonal crack, peak shear load, peak load deflection and angle of diagonal crack.

The first flexural crack occurred at lower load of $7.5 \mathrm{kN}$ and $8 \mathrm{kN}$ in HDPE-LWSCC-S and PVALWSCC-S, respectively compared to CR-LWSCC-S and LWSCC-S. For all beams the angle of diagonal shear crack was varied within the range of 45-55 degree. The formation of first inclined shear crack for HDPE-LWSCC-S and CR-LWSCC-S was at 37\% of their ultimate load of about $47.5 \mathrm{kN}$ at failure. However, in case of PVA-LWSCC-S and LWSCC-S the inclined shear crack formed at $65 \%$ and $50 \%$ of their ultimate loads which were $23 \mathrm{kN}$ and $33.3 \mathrm{kN}$, respectively. The highest number of cracks was exhibited by CR-LWSCC-S and LWSCC-S beams which was about 15 to 18 cracks at failure while PVA-LWSCC-S and HDPE-LWSCC-S beams exhibited around 11 to 13 cracks. The highest deflections of $4.3 \mathrm{~mm}$ and $3.6 \mathrm{~mm}$ at peak shear load were shown by HDPE-LWSCC-S and CR-LWSCC-S beams compared to $2 \mathrm{~mm}$ and $2.3 \mathrm{~mm}$, respectively of PVALWSCC-S and LWSCC-S beams.

Table 4.1: Experimental summary for shear beams without shear reinforcement

\begin{tabular}{|c|c|c|c|c|c|c|c|c|}
\hline Beam code & $\begin{array}{c}\text { Concrete } \\
\text { Strength }\end{array}$ & $\begin{array}{c}\text { Failure } \\
\text { pattern } \\
(\mathrm{MPa})\end{array}$ & $\begin{array}{c}\text { Shear at } \\
\text { first } \\
\text { flexure } \\
\text { crack } \mathrm{V}_{\mathrm{fl}} \\
\mathrm{(kN})\end{array}$ & $\begin{array}{c}\text { Shear at } \\
\text { first } \\
\text { diagonal } \\
\text { crack } \\
\mathrm{V}_{\mathrm{c}}(\mathrm{kN})\end{array}$ & $\begin{array}{c}\text { Deflection } \\
\text { at first } \\
\text { diagonal } \\
\text { crack } \\
\mathrm{D}_{\mathrm{c}}(\mathrm{mm})\end{array}$ & $\begin{array}{c}\text { Peak/ } \\
\text { failure } \\
\text { shear } \\
\mathrm{V}_{\mathrm{u}}(\mathrm{kN})\end{array}$ & $\begin{array}{c}\text { Deflection } \\
\text { at peak } \\
\text { shear load } \\
\mathrm{D}_{\mathrm{u}}(\mathrm{mm})\end{array}$ & $\begin{array}{c}\text { Diagonal } \\
\text { crack } \\
\text { angle } \\
\text { (Degree) }\end{array}$ \\
\hline $\begin{array}{c}\text { HDPE- } \\
\text { LWSC-S }\end{array}$ & 38.7 & Shear & 7.5 & 17.5 & 1 & 47.5 & 4.3 & 45 \\
\hline $\begin{array}{c}\text { CR- } \\
\text { LWSCC-S }\end{array}$ & 46.7 & Shear & 11 & 17.5 & 1.1 & 47.7 & 3.6 & 40 \\
\hline $\begin{array}{c}\text { PVA- } \\
\text { LWSCC-S }\end{array}$ & 43.6 & Shear & 8 & 15 & 0.9 & 23 & 2 & 55 \\
\hline $\begin{array}{c}\text { LWSCC-S } \\
\text { LWS }\end{array}$ & 52.6 & Shear & 11 & 17 & 0.8 & 33.3 & 2.3 & 50 \\
\hline
\end{tabular}

All the beams failed under shear but in case of CR-LWSCC-S and HDPE-LWSCC-S beams, diagonal shear crack width increased and two section of the beam completely separated from each other as shown in Figure 4.3 (a) and (c) - shear crack had an angle of 40 degree and 45 degree, respectively and sudden failure occurred. For PVA-LWSCC-S and LWSCC beams as shown in Figure 4.3 (b) and (d), the inclined crack width increased with increase of load, but the beam 
sections remained intact to each other even after ultimate load and failure. The diagonal crack angle for PVA-LWSCC-S and LWSCC beams was higher than their other beam counterparts which was 50 degrees and 55 degrees, respectively.
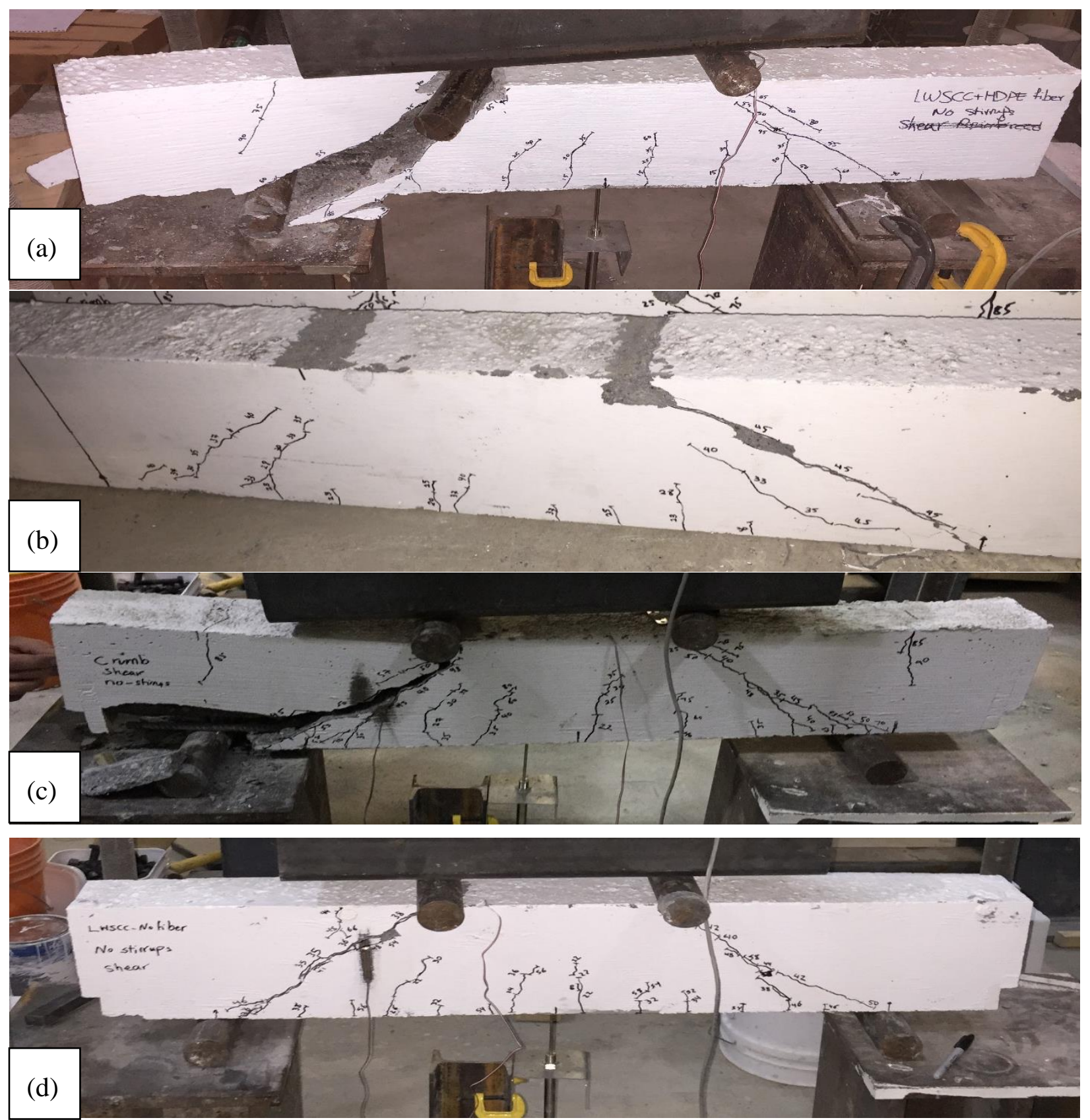

Figure 4.3: (a) Failure modes of tested shear beams without shear reinforcement, (a) HDPELWSCC-S (b) PVA-LWSCC-S (c) CR-LWSCC-S (d) LWSCC-S

Crack width, number of cracks, maximum crack width and type of failure crack for all tested beams without shear reinforcement are provided in Table 4.2. 
Table 4.2: Summery of crack width and number of shear beams without shear reinforcement

\begin{tabular}{|l|l|l|l|l|}
\hline Beam code & Number of cracks & $\begin{array}{l}\text { Average crack width } \\
(\mathrm{mm})\end{array}$ & $\begin{array}{l}\text { Maximum crack } \\
\text { width (mm) }\end{array}$ & $\begin{array}{l}\text { Failure crack } \\
\text { type }\end{array}$ \\
\hline HDPE-LWSC-S & 12 & 0.5 & 5 & $\begin{array}{l}\text { Concrete } \\
\text { crushing }\end{array}$ \\
\hline CR-LWSC-S & 19 & 0.8 & 8 & $\begin{array}{l}\text { Concrete } \\
\text { crushing }\end{array}$ \\
\hline PVA-LWSCC-S & 14 & 0.2 & 8 & Shear crack \\
\hline LWSCC-S & 17 & 0.7 & 6 & Shear crack \\
\hline
\end{tabular}

CR-LWSCC-S beam had most number of cracks (19 cracks) and highest average crack width of $0.8 \mathrm{~mm}$ compared to other tested beams. PVA-LWSCC-S beam had the smallest crack width due to fiber bridging of PVA fiber, average crack width of PVA-LWSCC-S beam obtained from test result was $0.2 \mathrm{~mm}$. HDPE-LWSC-S and CR-LWSC-S shear crack completely divided the beam in the two section with concrete crushing failure shown in Figure 4.4 (a) and (b) but in case of PVALWSCC-S and LWSCC-S beams, the shear cracks width increased with the increase of load but they remained intact. Detail of crack patterns and widths for each beam obtained from experiments are shown in Figure 4.4.
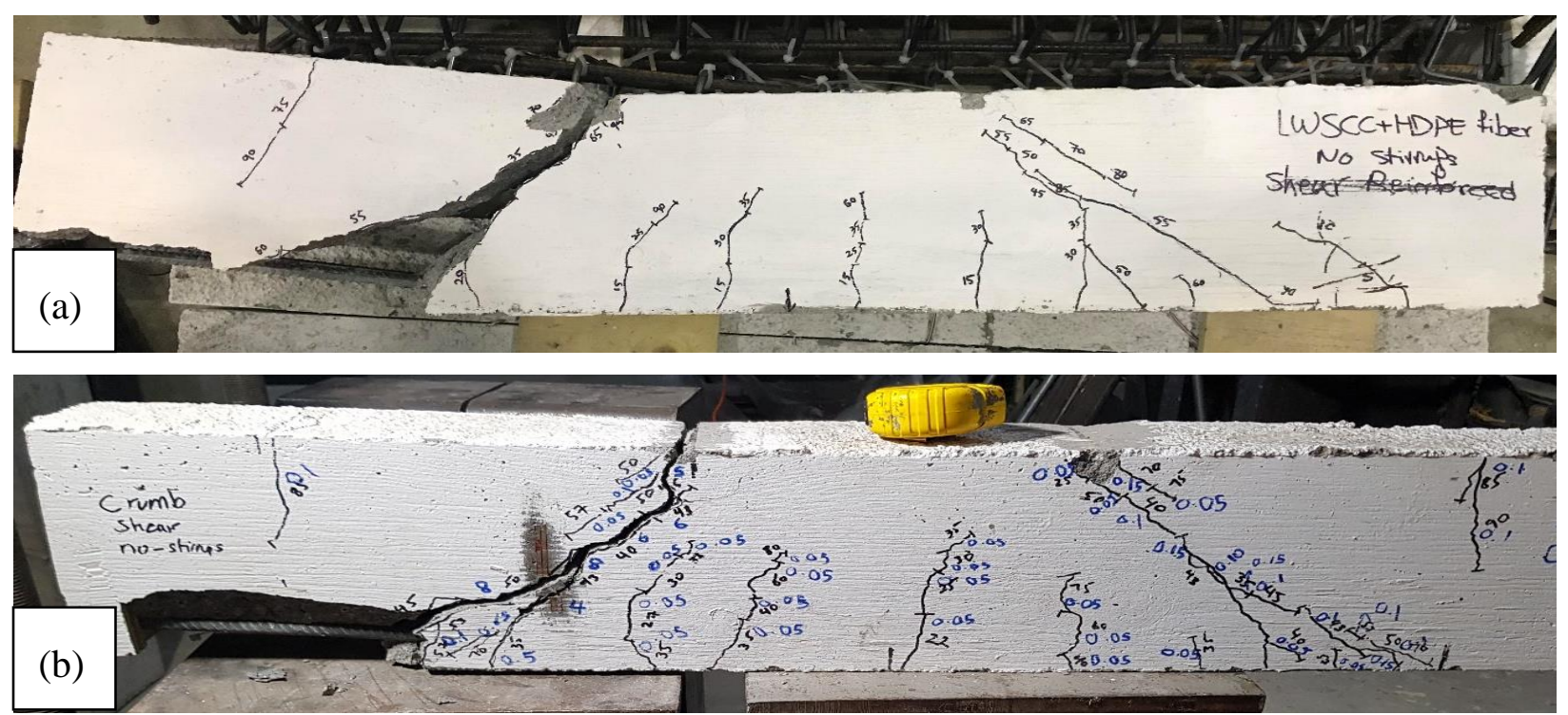

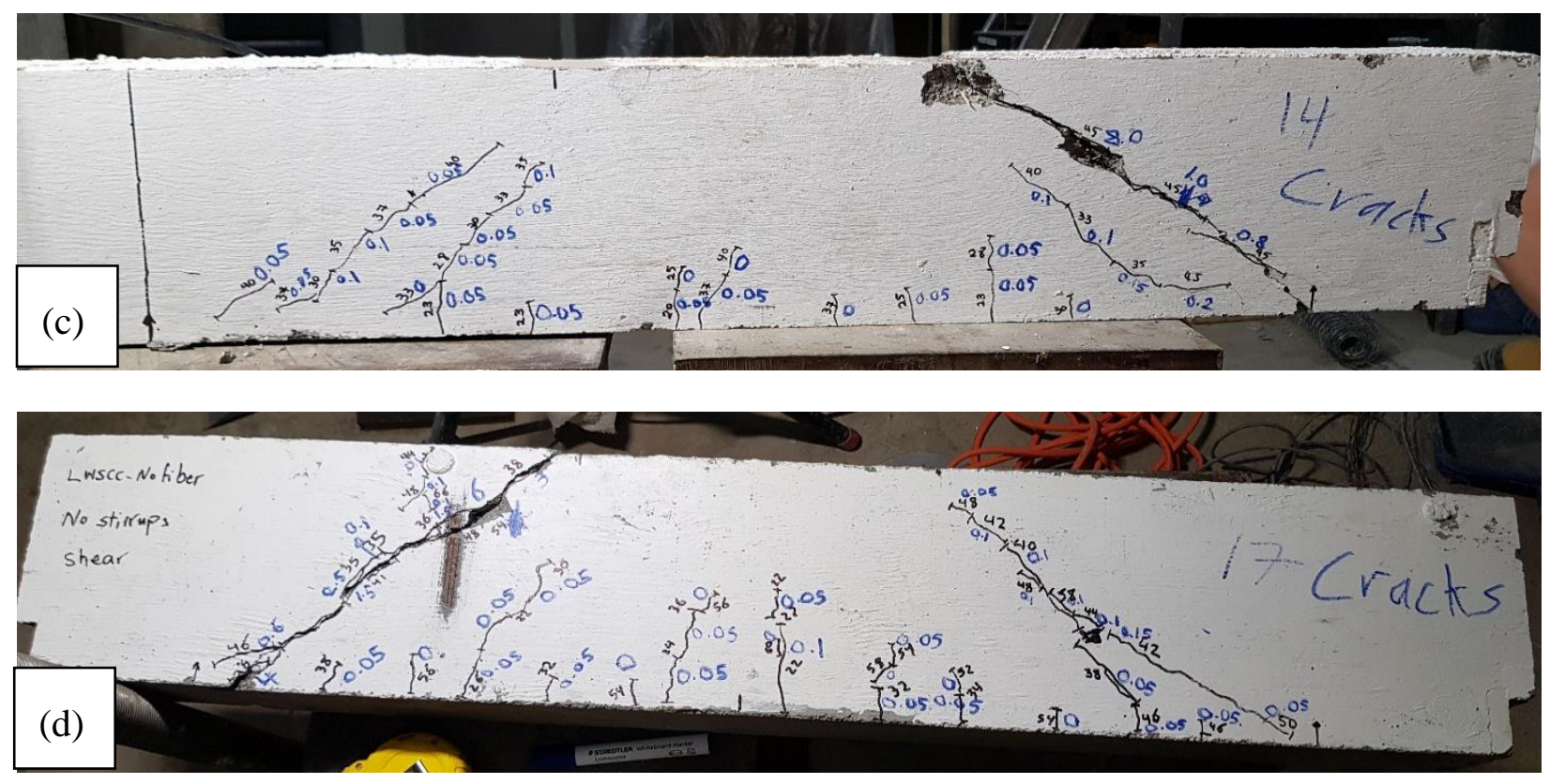

Figure 4.4: Crack width and pattern for shear beans without shear reinforcement, (a) HDPELWSCC-S (b) PVA-LWSCC-S (c) CR-LWSCC-S (d) LWSCC-S

\subsubsection{Post cracking shear resistance, ductility and energy absorption}

After formation of first diagonal shear crack which is defined as concrete shear resistance $V_{c}$, the dowel action and aggregate interlock mechanism played important role to improve the concrete shear capacity to reach its maximum ultimate shear failure load $\mathrm{V}_{\mathrm{u}}$. In experiment, both concrete shear resistance and the ultimate shear resistance were identified based on visual observation during the testing.

To describe the post cracking behaviour of FRLWSCC and LWSCC, comparable analysis was accomplished by introducing a shear resistance factor (SRF) by earlier researchers. SRF is illustrated as the ratio of the ultimate load to the load at the first inclined crack $\frac{\mathrm{v}_{\mathrm{u}}}{\mathrm{V}_{\mathrm{c}}}$ according to Lachimi et al. (2005) and Hassan et al. (2010). To consider the difference in concrete compressive strength in post cracking analysis shear loads need to be normalized. The normalized shear loads (based on concrete compressive strength $\mathrm{f}^{\prime}$ ) and SRF were obtained as per CSA A23.3-04 and ACI M318-08 standards from equations (4.1), (4.2) and (4.3):

Normalized ultimate shear load $\left(\mathrm{V}_{\mathrm{nu}}\right): \quad \mathrm{V}_{\mathrm{nu}}=\frac{\mathrm{V}_{\mathrm{u}}}{\sqrt{\mathrm{f}_{\mathrm{c}}}}$ 
Normalized inclined cracking shear load $\left(\mathrm{V}_{\mathrm{nc}}\right): \quad \mathrm{V}_{\mathrm{nc}}=\frac{\mathrm{V}_{\mathrm{c}}}{\sqrt{\mathrm{f}_{\mathrm{c}}}}$

$\mathrm{SRF}=\frac{\mathrm{V}_{\mathrm{u}}}{\mathrm{V}_{\mathrm{c}}}=\frac{\mathrm{V}_{\mathrm{nu}}}{\mathrm{V}_{\mathrm{nc}}}$

To investigate and compare the post cracking shear ductility behaviour of tested beams, ductility factor (DF) based on previous studied by Hassan et.al (2010) illustrated as the ratio of deflection at ultimate load to the deflection at first diagonal crack defined based on the following equation can be used:

$\mathrm{DF}=\mathrm{D}_{\mathrm{u}} / \mathrm{D}_{\mathrm{c}}$

where $D_{u}$ and $D_{c}$ are the deflections at first inclined crack and the ultimate load, respectively as described in Table 4.1

Shear resistance factor and ductility behavior of FRLWSCC and LWSCC beams are shown in Table 4.3.

At the formation of inclined/diagonal shear crack dowel action, aggregate interlock and fiber volume play significant roles in the increase of shear resistance from $\mathrm{V}_{\mathrm{c}}$ to ultimate shear resistance $\mathrm{V}_{\mathrm{u}}$. Higher SRF is an indication of better aggregate interlock mechanism in the shear beams which in case of HDPE-LWSCC-S and CR-LWSCC-S the SRF was 2.7 compared to 2.0 and 1.5, respectively of LWSCC-S and PVA-LWSCC-S.

Table 4.3: Shear resistance and ductility factor for the shear beams without shear reinforcement

\begin{tabular}{|c|c|c|c|c|c|c|c|}
\hline $\begin{array}{c}\text { Beam } \\
\text { code }\end{array}$ & $\begin{array}{c}\text { Concrete } \\
\text { compressive } \\
\text { strength } \\
\left(\mathrm{f}^{\prime} \mathrm{c}\right) \\
(\mathrm{MPa})\end{array}$ & $\begin{array}{c}\text { Normalized } \\
\text { inclined } \\
\text { cracking } \\
\text { shear load } \\
(\mathrm{Vnc}) \\
(\mathrm{kN} / \sqrt{\mathrm{MPa}})\end{array}$ & $\begin{array}{c}\text { Normalized } \\
\text { ultimate } \\
\text { shear load } \\
(\mathrm{Vnu}) \\
(k N / \sqrt{M P a})\end{array}$ & $\begin{array}{c}\text { Shear } \\
\text { resistance } \\
\text { factor } \\
(\mathrm{SRF})\end{array}$ & $\begin{array}{c}\text { Ductility } \\
\text { factor } \\
(\mathrm{DF})\end{array}$ & $\begin{array}{c}\text { Energy } \\
\text { absorption }\end{array}$ & Stiffness \\
\hline $\begin{array}{c}\text { HDPE- } \\
\text { LWSCC-S }\end{array}$ & 38.7 & 2.9 & 7.8 & 2.7 & 4.3 & 237.45 & 38.28 \\
\hline $\begin{array}{c}\text { CR- } \\
\text { LWSCC-S }\end{array}$ & 46.7 & 2.6 & 7.0 & 2.7 & 3.3 & 182.37 & 24.25 \\
\hline $\begin{array}{c}\text { PVA- } \\
\text { LWSCC-S }\end{array}$ & 43.6 & 2.4 & 3.7 & 1.5 & 2.2 & 119.92 & 29.14 \\
\hline LWSCC-S & 52.6 & 2.3 & 4.6 & 2.0 & 2.9 & 60.36 & 36.7 \\
\hline
\end{tabular}

HDPE-LWSCC-S beam reached highest ductility factor (DF) which was 4.3 and $48 \%$ higher than LWSCC-S. In case of CR-LWSCC-S beam, the DF value was 3.3 which was $30 \%$ lower than HDPE-LWSCC-S, however, the SRF value for both are the same. Contribution of HDPE fiber in 
LWSCC has shown better result (in beams) in terms of ductility factor and SRF compared to other mixes.

The energy absorption capacity of each beam has been calculated based on the area under the normalized shear load-deflection curves shown in Figure 4.5 up to the post peak shear of $85 \%$ of the ultimate load $\left(\mathrm{V}_{\mathrm{u}}\right)$ and presented in Table 4.3.

Beams with HDPE fiber showed highest energy absorption capacity $237.45 \mathrm{~J}$ which was $293 \%$ higher compared to control beam LWSCC. CR-LWSCC and PVA-LWSCC beams also had more energy absorption capacity $182.4 \mathrm{~J}$ and $119.9 \mathrm{~J}$ which were $202 \%$ and $98.7 \%$ higher, respectively compared to LWSCC control beam. From the result, it can be concluded that the energy absorption capacity increased with the use of fiber and the type of fiber also had huge influence in increasing the shear capacity.

Stiffness of each beam was calculated based on the slope of linear part of load-deflection curves shown in Figure 4.1. HDPE-LWSCC-S beam was stiffer compared to its counterpart beams (Table 4.3). PVA and CR-LWSCC-S beam had lower stiffness compared to the control LWSCC specimen $(36.7 \mathrm{~N} / \mathrm{mm})$ with stiffness values of $29.14 \mathrm{~N} / \mathrm{mm}$ and $24.25 \mathrm{~N} / \mathrm{mm}$, respectively.

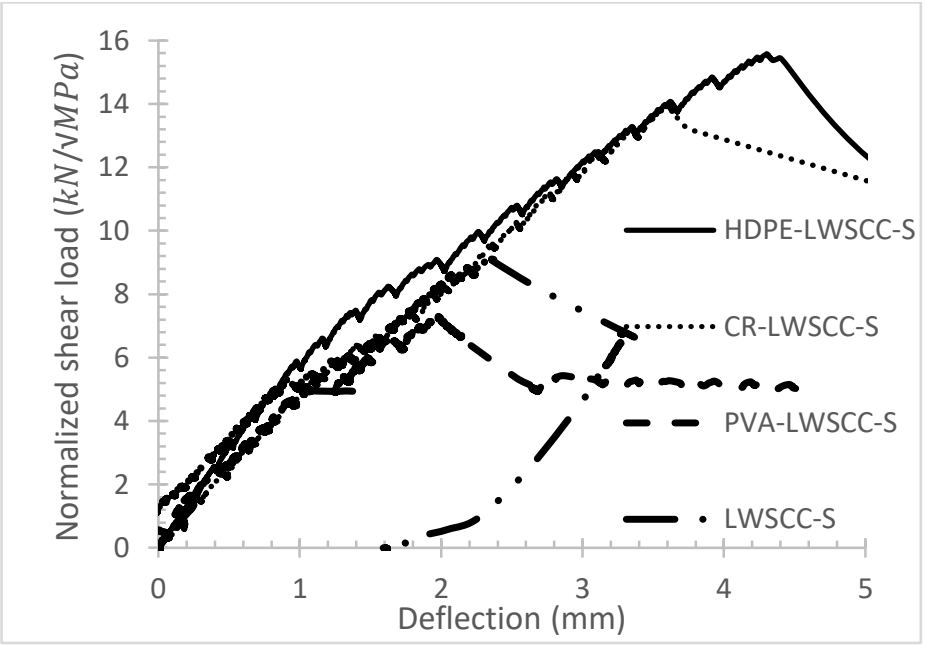

Figure 4.5: Normalized comparative shear load-deflection responses for all shear beams without shear reinforcement

\subsection{LWSCC shear beams with shear reinforcement}

Total of four shear beams with shear reinforcement were tested. LWSCC beam was considered as an control specimen and was used to compare performance of FRLWSCC beams with different 
fibers such as: HDPE, PVA and CR. Shear span to effective depth ratio $(\mathrm{a} / \mathrm{d})$ of beams was kept constant at 1.53 for all beams with the height/total depth (H) $200 \mathrm{~mm}$. Beams were designed based on CSAA23.3-04 (2004) to have adequate flexural reinforcement with the reinforcement ratio of $1.15 \%$ and without shear reinforcement so that all beam fail in shear. In these beams shear reinforcement was provided based on CSA A23.3-04 (2004) throughout the shear span using 6 $\mathrm{mm}$ reinforcing bars at $133 \mathrm{~mm}$ center to center.

\subsubsection{Load deflection behaviour}

Figure 4.6 and Figure 4.7 (a-d) showed the load-deflection responses of the tested shear beams with shear reinforcement. Compared to shear beams without shear reinforcement, after the formation of first diagonal crack less reduction and drop in stiffness and the slope of the loaddeflection curve of tested beams were observed. All shear reinforced beams had shown higher deflection compared to their without shear reinforced counterparts except the beam containing CR fiber which showed $3.7 \mathrm{~mm}$ deflection at failure (same in both shear beams with stirrups and without stirrups). The ultimate/peak shear capacity varied from $39 \mathrm{kN}$ to $57.5 \mathrm{kN}$ with peak deflection of $5.6 \mathrm{~mm}$ to $6 \mathrm{~mm}$ which were corresponded to PVA-LWCC-S-S and HDPE-LWSCCS-S beams, respectively.

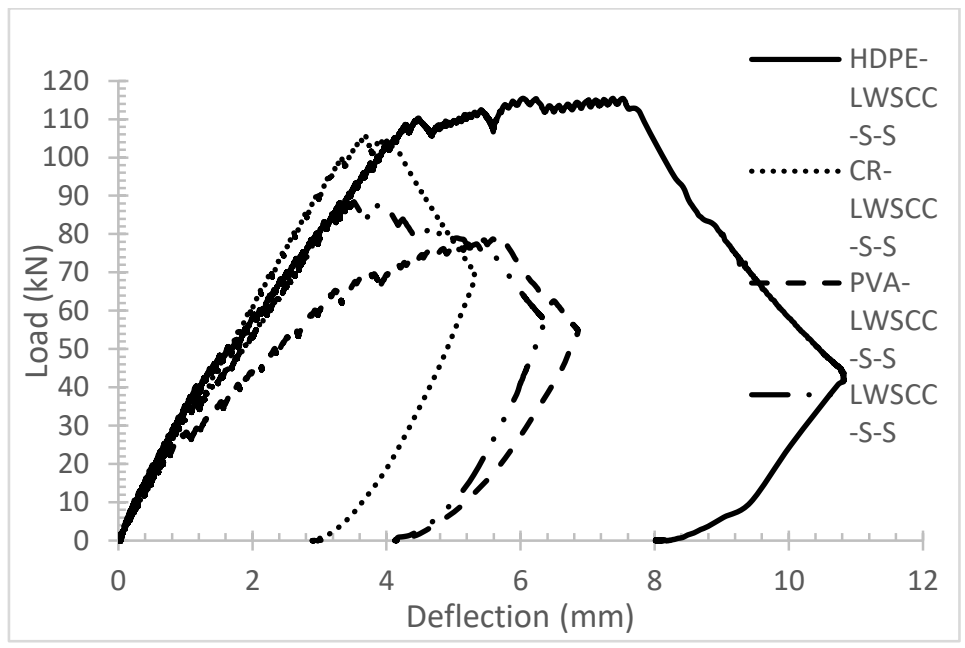

Figure 4.6: Comparative load-mid span deflection curve for beams with shear reinforcement 

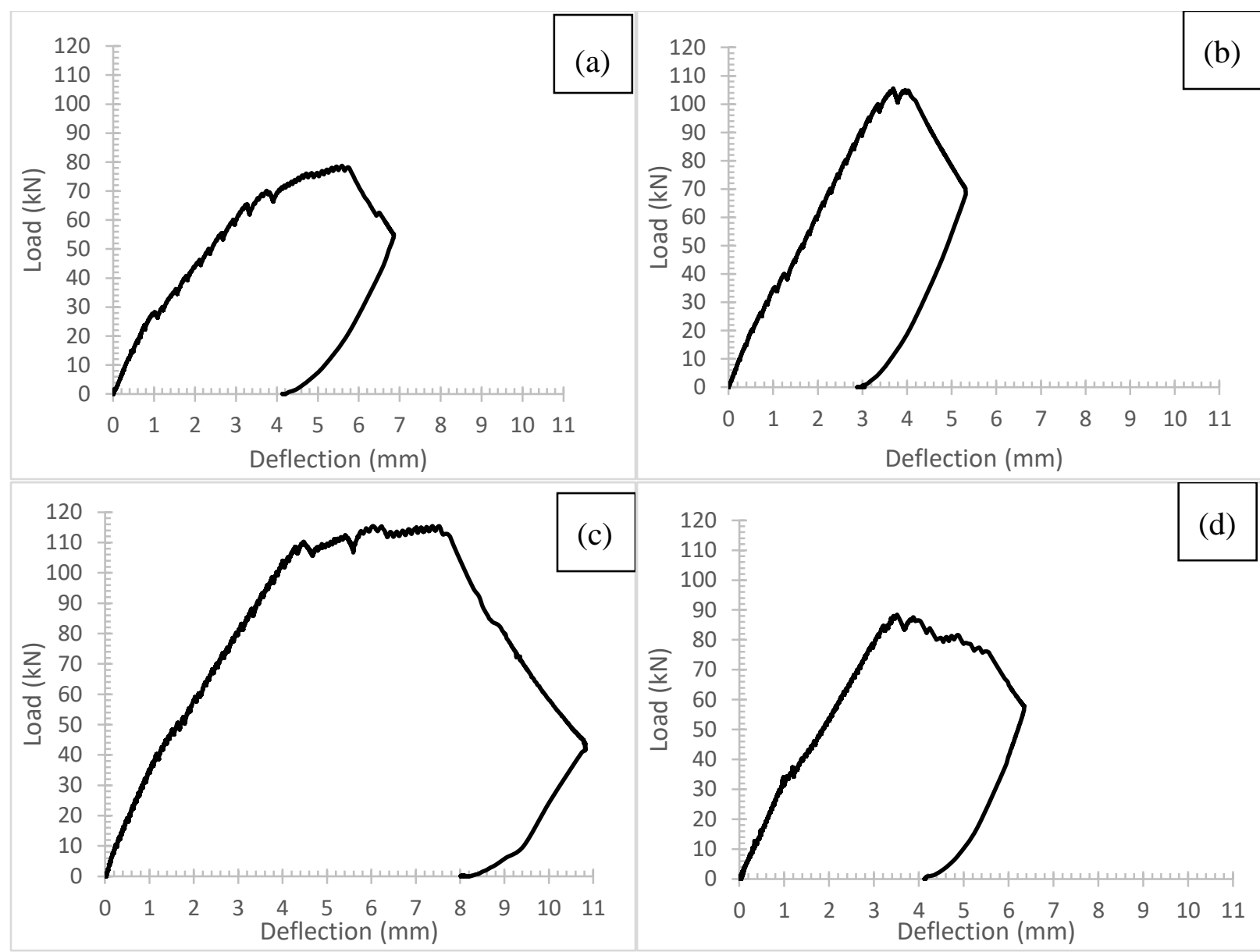

Figure 4.7: Load-deflection responses (a) HDPE-LWSCC-S-S (b) CR-LWSCC-S-S (c) PVALWSCC-S-S (d) LWSCC-S-S

The ultimate/peak shear failure load and the peak deflection improved as expected in all shear beams with shear reinforcement compared to beams without shear reinforcement. In both cases, beams with HDPE mixes obtained the best result in terms of failure load and peak load deflection.

Detail of failure pattern, shear at first flexural crack, shear at first diagonal crack, deflection at first diagonal crack, peak failure shear, deflection at peak shear load and diagonal crack angle obtained from experimental test on beams presented in Table 4.4.

\subsubsection{Failure mode and cracking behaviour}

Summary of experimentally tested FRLWSCC and LWSCC shear beams with shear reinforcement is shown in Table 4.4. In general, the formation of first diagonal crack in shear beams with shear reinforcement occurred at same load as shear beams without shear reinforcement with first diagonal cracking load ranging from $15 \mathrm{kN}$ to $20 \mathrm{kN}$ where HDPE-LWSCC-S-S beams showed 
the highest shear at first diagonal crack compared to counterpart beams. The first diagonal shear crack occurred at $33 \%$ to $38 \%$ of the ultimate/peak load which were very close to each other for all tested beams with shear reinforcement. However, for shear beams without shear reinforcement, the range was wide $33 \%$ to $65 \%$ of the peak shear load.

Table 4.4: Experimental results summary for tested shear beams with shear reinforcement

\begin{tabular}{|c|c|c|c|c|c|c|c|c|}
\hline $\begin{array}{l}\text { Beam } \\
\text { code }\end{array}$ & $\begin{array}{c}\text { Concrete } \\
\text { Strength } \\
(\mathrm{MPa})\end{array}$ & $\begin{array}{l}\text { Failure } \\
\text { pattern }\end{array}$ & $\begin{array}{l}\text { Shear at } \\
\text { first } \\
\text { flexure } \\
\mathrm{V}_{\mathrm{fl}}(\mathrm{kN})\end{array}$ & $\begin{array}{l}\text { Shear at } \\
\text { first } \\
\text { diagonal } \\
\text { crack } \\
\mathrm{V}_{\mathrm{c}}(\mathrm{kN})\end{array}$ & $\begin{array}{c}\text { Deflection at } \\
\text { first diagonal } \\
\text { crack } \\
\mathrm{D}_{\mathrm{c}}(\mathrm{mm})\end{array}$ & $\begin{array}{c}\text { Peak/ } \\
\text { failure } \\
\text { shear } \\
\mathrm{V}_{\mathrm{u}}(\mathrm{kN})\end{array}$ & $\begin{array}{l}\text { Deflection } \\
\text { at peak } \\
\text { shear load } \\
\mathrm{D}_{\mathrm{u}}(\mathrm{mm})\end{array}$ & $\begin{array}{c}\text { Diagonal } \\
\text { crack } \\
\text { angle } \\
\text { (Degree) }\end{array}$ \\
\hline $\begin{array}{c}\text { HDPE- } \\
\text { LWSC- } \\
\text { S-S }\end{array}$ & 38.7 & Shear & 5 & 20 & 1.2 & 57.5 & 6 & 43 \\
\hline $\begin{array}{c}\text { CR- } \\
\text { LWSCC } \\
-S-S \\
\end{array}$ & 46.7 & Shear & 7.5 & 17.5 & 1.1 & 52.5 & 3.7 & 57 \\
\hline $\begin{array}{c}\text { PVA- } \\
\text { LWSCC } \\
-S-S\end{array}$ & 43.6 & Shear & 7.5 & 15 & 1.3 & 39 & 5.6 & 48 \\
\hline $\begin{array}{c}\text { LWSCC } \\
-S-S\end{array}$ & 52.6 & Shear & 10 & 17 & 1.1 & 44 & 3.5 & 56 \\
\hline
\end{tabular}

After the formation of first diagonal shear crack, shear reinforcement took most of the loads and for FRLWSCC beams, also contribution of fiber prevented further opening of the shear crack compared to control LWSCC-S-S beam with no fiber. The shear crack width in all fiber reinforced shear beams were smaller compared to the control LWSCC-S-S beam which could be attributed to the contribution of fibers. Details of crack width and number of cracks in each zone are provided in Table 4.6.

All tested beams had shear failure as was expected. The highest shear capacity of FRLWSCC beams was exhibited by HDPE-LWSCC-S-S beam in which at ultimate failure stage a single vertical crack occurred from the bottom right support to top of the beam in addition to the propagation of the inclined shear crack from the support to the point of load Figure 4.8.The formation of diagonal crack started at a shear load of $20 \mathrm{kN}$ and completed towards the point of loading at shear load $57.5 \mathrm{KN}$ with corresponding deflection of $1.2 \mathrm{~mm}$ and $6 \mathrm{~mm}$, respectively. At failure stage, all FRLWSCC shear beams with stirrups had shown higher deflection values compared to control LWSCC beam. Details of shear load capacity and related deflections for all tested beams are presented in Table 4.4. 
During the testing of the LWSCC-S-S beam, the first diagonal crack was observed at a shear load of $17 \mathrm{kN}$ (at $1.1 \mathrm{~mm}$ deflection) near the support and started expanding to the loading point until the peak shear load of $44 \mathrm{kN}$ with corresponding deflection of $3.5 \mathrm{~mm}$. The level of sound at failure stage of the LWSCC-S-S beam was noticeably higher compared to all other FRLWSCC shear beams and concrete was separated along the shear crack near the tension zone and the stirrups in the beam were visible as shown in Figure 4.8. The control LWSCC-S-S shear beam at failure stage had shown large concrete spalling at tension zone along the diagonal shear crack.

Based on the obtained results, the first flexural crack occurred in fiber reinforced concrete beams at earlier load compared to control LWSCC-S-S beam, but all FRLWSCC shear beams had higher deflections at the onset of the formation of first flexural crack and at ultimate/peak load compared to the control beam.

Figure 4.8 shows the crack patterns and failure modes of FRLWSCC and LWSCC beams with shear reinforcement. Comparing crack pattern and failure of HDPE-LWSCC-S and CR-LWSCC$\mathrm{S}$ beams with no shear stirrups (as shown in Figure 4.9 a \& c) with HDPE-LWSCC-S-S and CRLWSCC-S-S with stirrups (shown in Figure 4.8 a \& b), it can be observed that more cracks occurred in both beams with shear reinforcement without showing separation of concrete at failure stage.

HDPE-LWSCC-S-S beam had the highest ductility factor compared to other tested beams and was $56 \%$ more ductile compared to control LWSCC-S-S beam. Details of ductility for each beam with shear reinforcement are provided in Table 4.5. Summery of ductility factor, energy absorption and stiffness of shear beams with shear reinforcement are also are also provided in Table 4.5.

All FRLWCC-S-S beams had exhibited higher energy absorption capacity ranging from 306.17 J to $785.05 \mathrm{~J}$ showing $94 \%$ to $397 \%$ increase due to the contribution of fiber. All FRLWCC-S-S beams had shown higher stiffness compared to the control LWSCC-S-S beam ranging from 31.4 to $36.9 \mathrm{~N} / \mathrm{mm}$. 
Table 4.5: Summery of ductility factor, energy absorption and stiffness of shear beam with shear reinforcement

\begin{tabular}{|c|c|c|c|c|c|}
\hline Beam code & $\begin{array}{c}\text { Concrete } \\
\text { compressive } \\
\text { strength (f'c) } \\
(\mathrm{MPa})\end{array}$ & $\begin{array}{c}\text { Peak/failure } \\
\text { shear Vu }\end{array}$ & $\begin{array}{c}\text { Ductility } \\
\text { factor (DF) }\end{array}$ & $\begin{array}{c}\text { Energy } \\
\text { absorption }\end{array}$ & Stiffness \\
$(\mathrm{kN})$ & 57.5 & 5.0 & 785.05 & 35.4 \\
\hline HDPE-LWSCC-S-S & 38.7 & 52.5 & 3.4 & 306.17 & 36.9 \\
\hline CR-LWSCC-S-S & 46.7 & 39 & 4.3 & 401.93 & 31.4 \\
\hline PVA-LWSCC-S-S & 43.6 & 44 & 3.2 & 157.79 & 25.8 \\
\hline LWSCC-S-S & 52.6 & $\mathrm{~J} / \mathrm{mm})$ \\
\hline
\end{tabular}

Crack width, number of cracks, maximum crack width and type of failure crack for all tested beam with shear reinforcement are provided in Table 4.6.

Table 4.6: Summery of crack width and number of shear beams without shear reinforcement

\begin{tabular}{|l|l|l|l|l|}
\hline Beam code & Number of cracks & $\begin{array}{l}\text { Average crack width } \\
(\mathrm{mm})\end{array}$ & $\begin{array}{l}\text { Maximum crack } \\
\text { width }(\mathrm{mm})\end{array}$ & $\begin{array}{l}\text { Failure crack } \\
\text { type }\end{array}$ \\
\hline HDPE-LWSC-S-S & 16 & 0.40 & 3 & Shear crack \\
\hline CR-LWSC-S-S & 19 & 0.15 & 1.5 & Shear crack \\
\hline PVA-LWSCC-S-S & 14 & 0.10 & 2 & Shear crack \\
\hline LWSCC-S-S & 8 & 0.15 & 3 & Shear crack \\
\hline
\end{tabular}

CR-LWSCC-S-S beam (with shear reinforcement) similar to CR-LWSCC-S (without shear reinforcement) had the most number of cracks (19 cracks) with the average crack width of 0.15 mm. PVA-LWSCC-S-S beam had the smallest crack width due to fiber bridging of PVA fiber similar to PVA shear beam without shear reinforcement. Average crack width of PVA-LWSCC$\mathrm{S}-\mathrm{S}$ beam obtained from test result was $0.1 \mathrm{~mm}$. Details of crack widths and patterns are provided in Table 4.6 and Figure 4.9 (a-d). 

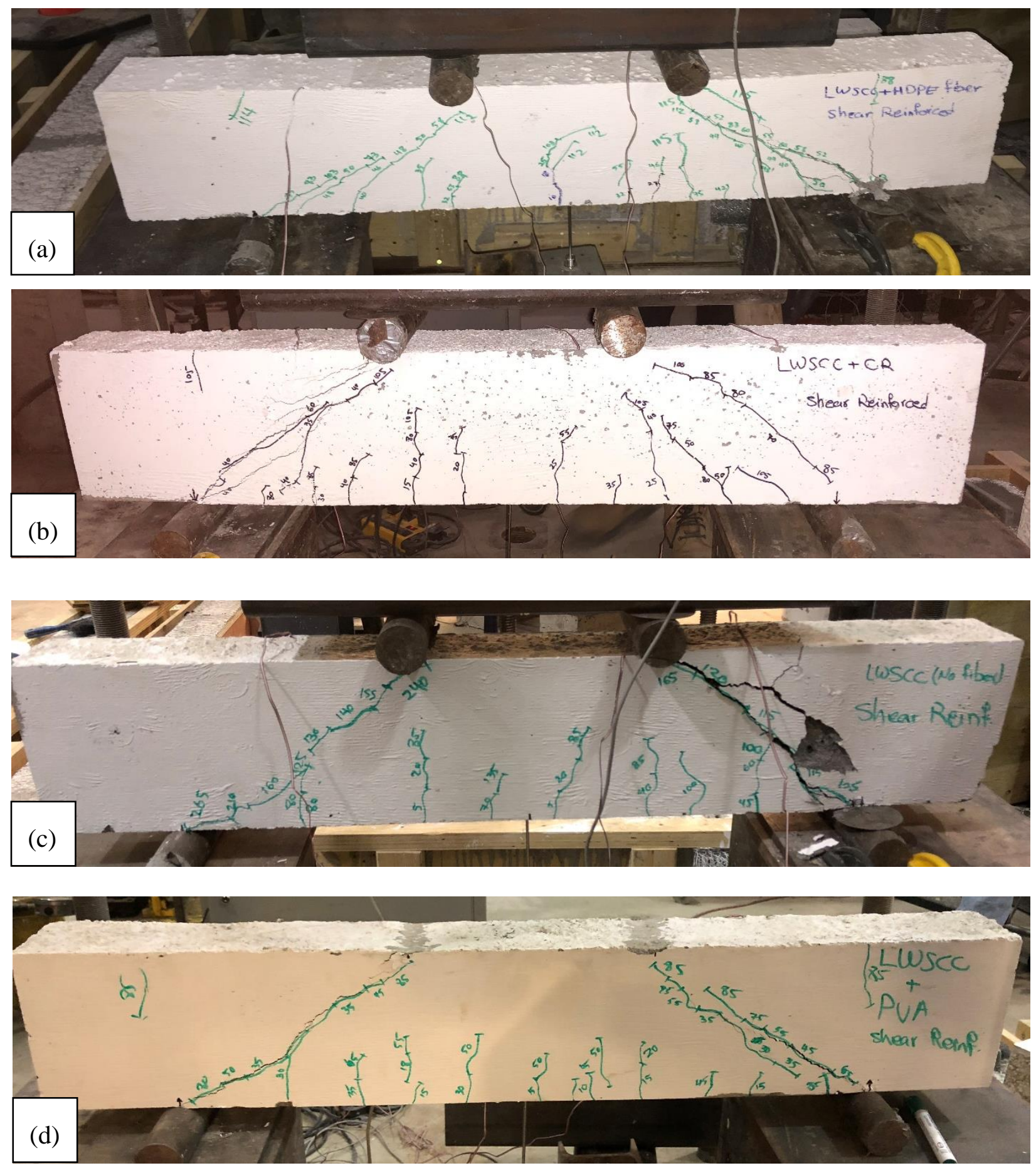

Figure 4.8: Failure modes of tested shear beams with shear reinforcement (a) HDPE-LWSCC-S-S (b) CR-LWSCC-S-S (c) PVA-LWSCC-S-S (d) LWSCC-S-S 

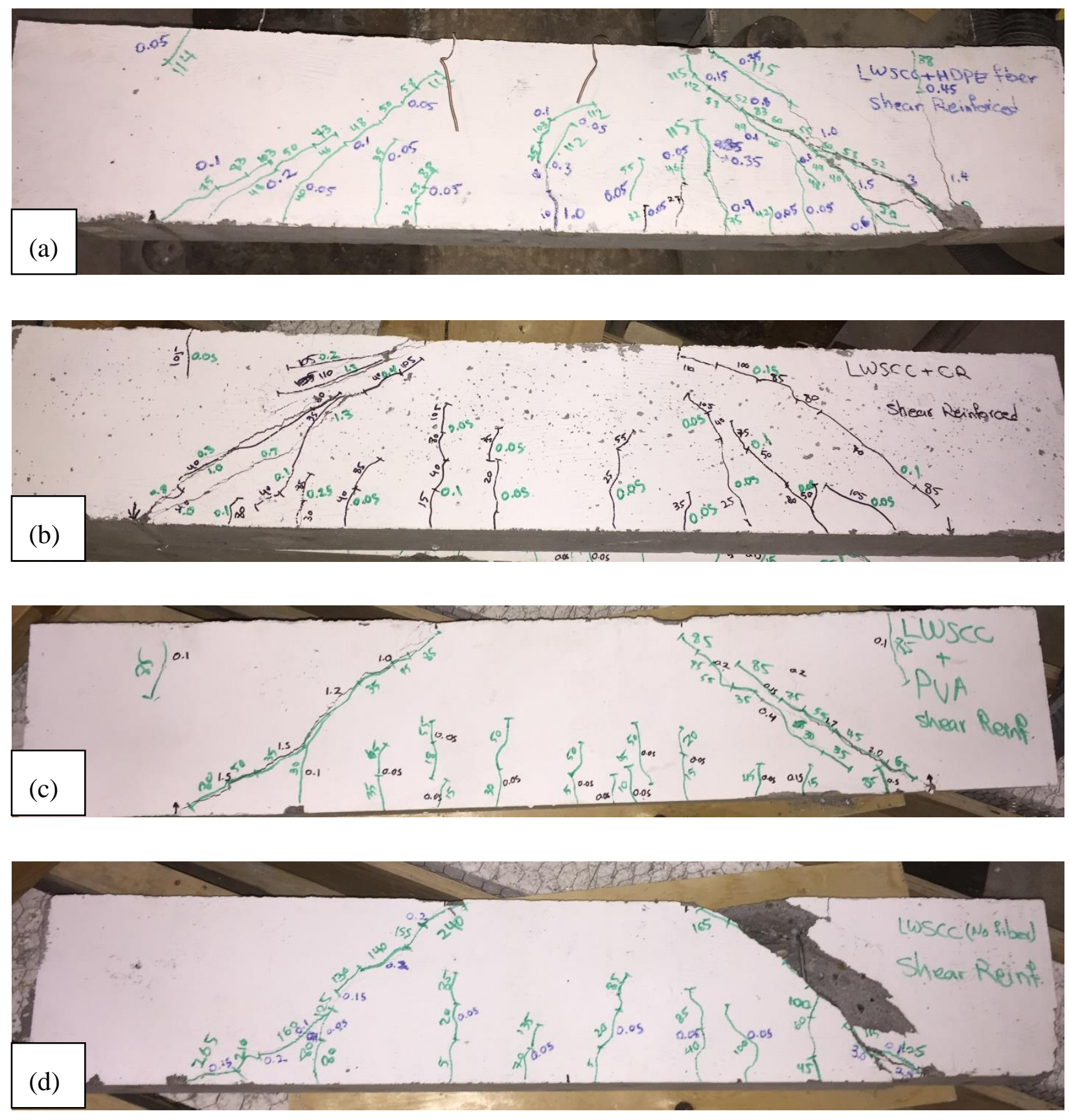

Figure 4.9: Crack width and pattern for shear beans without shear reinforcement (a) HDPELWSCC-S-S (b) CR-LWSCC-S-S (c) PVA-LWSCC-S-S (d) LWSCC-S-S 


\subsubsection{Strain development in the flexural and shear reinforcement}

Figure 4.10 (a-d) presents the strain development in flexural and shear reinforcements for the tested beams. Table 4.7 presents the summary of load-strain behaviour of shear and longitudinal reinforcement at the formation of the first diagonal crack and at the ultimate shear failure stage. Due to the formation of the diagonal shear crack, the strain in shear reinforcement increased in all tested beams with the increase of the applied load.

HDPE-LWSCC-S-S and CR-LWSCC-S-S ultimate load capacity were $57.5 \mathrm{kN} 52.5 \mathrm{kN}$ respectively which were higher than PVA-LWSCC-S-S $39 \mathrm{kN}$ and LWSCC-S-S $44 \mathrm{kN}$ respectively.

Shear and bottom longitudinal reinforcement in both HDPE-LWSCC-S-S and CR-LWSCC-S-S beams yielded at the same ultimate/peak shear load of the beam. In case of PVA-LWSCC-S-S and LWSCC-S-S beams, bottom flexural reinforcement yielded at the ultimate/peak shear load prior to the yielding of shear reinforcement.

Table 4.7: Summery of load strain performance of tested shear reinforced beams

\begin{tabular}{|c|c|c|c|c|c|c|c|}
\hline \multirow[t]{3}{*}{ Beam code } & \multirow{3}{*}{$\begin{array}{c}\text { Failure } \\
\text { mode }\end{array}$} & \multicolumn{4}{|c|}{ Steel strain } & \multirow{2}{*}{\multicolumn{2}{|c|}{ Shear load $(\mathrm{KN})$}} \\
\hline & & \multicolumn{2}{|c|}{ Stirrup (micro-strain) } & \multicolumn{2}{|c|}{$\begin{array}{l}\text { Bottom flexural re- } \\
\text { bar (micro-strain) }\end{array}$} & & \\
\hline & & $\begin{array}{l}\text { At first } \\
\text { diagonal } \\
\text { cracking } \\
\text { stage }\end{array}$ & $\begin{array}{l}\text { At ultimate } \\
\text { stage }\end{array}$ & $\begin{array}{l}\text { At first } \\
\text { diagonal } \\
\text { cracking } \\
\text { stage }\end{array}$ & $\begin{array}{c}\text { At } \\
\text { ultimate } \\
\text { stage }\end{array}$ & $\begin{array}{c}\text { At } \\
\text { stirrup } \\
\text { yielding }\end{array}$ & $\begin{array}{l}\text { At bottom } \\
\text { flexural } \\
\text { rebar } \\
\text { yielding }\end{array}$ \\
\hline $\begin{array}{c}\text { HDPE- } \\
\text { LWSCC-S-S }\end{array}$ & Shear & 154 & yielded & 1693 & yielded & 56 & 56 \\
\hline $\begin{array}{c}\text { CR- } \\
\text { LWSCC-S-S }\end{array}$ & Shear & 290 & yielded & 867 & yielded & 52 & 52 \\
\hline $\begin{array}{c}\text { PVA- } \\
\text { LWSCC-S-S }\end{array}$ & Shear & 107 & 517 & 427 & 1836 & $\begin{array}{c}\text { Not } \\
\text { yielded }\end{array}$ & 39 \\
\hline LWSCC-S-S & Shear & 96 & 1091 & 721 & 1893 & $\begin{array}{c}\text { Not } \\
\text { yielded }\end{array}$ & 44 \\
\hline
\end{tabular}



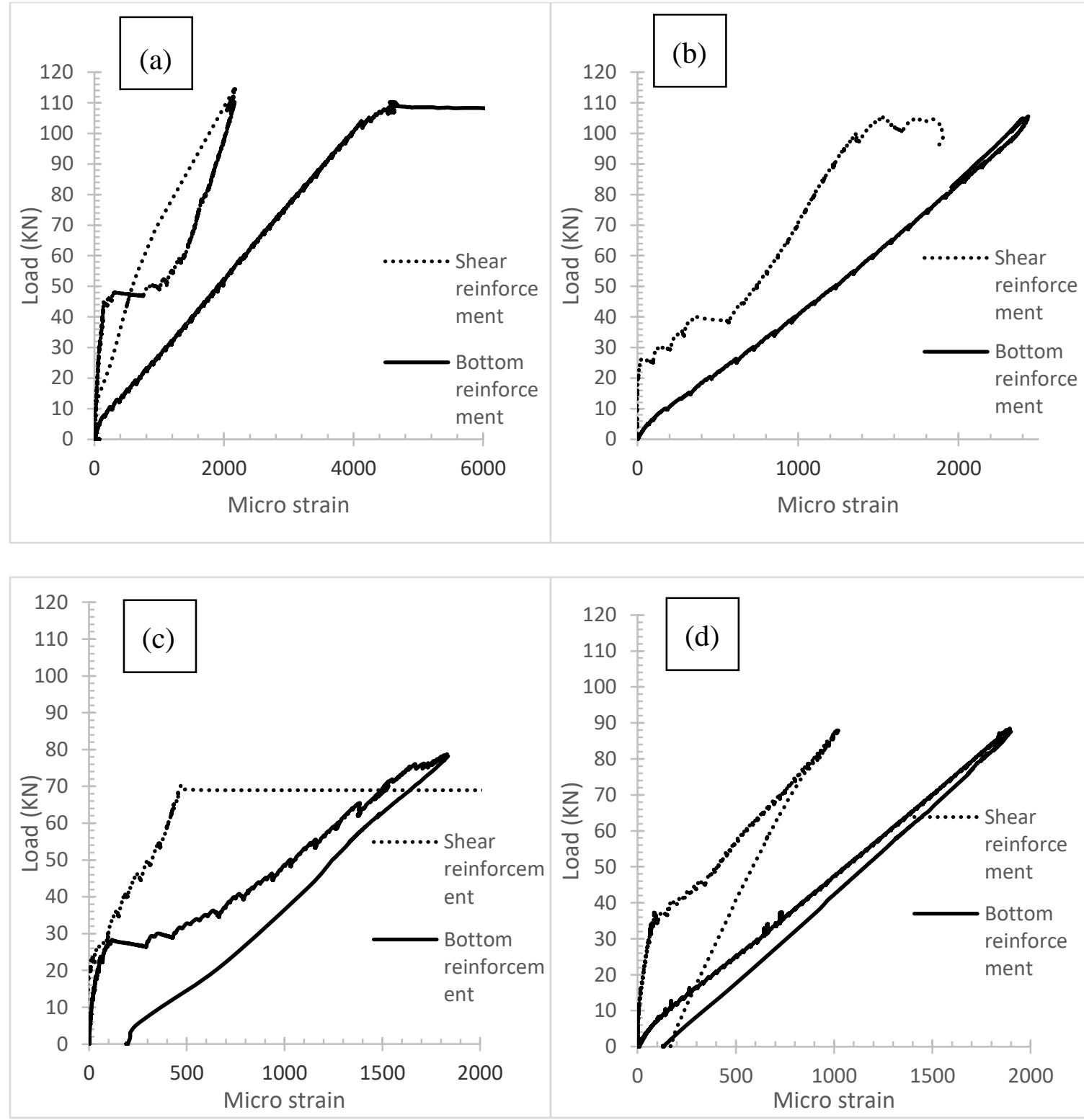

Figure 4.10(a): Load-strain curves for shear beams with shear reinforcement (a) HDPE-LWSCCS-S (b) CR-LWSCC-S-S (c) PVA-LWSCC-S-S (d) LWSCC-S-S 


\subsection{Flexural LWSCC beams}

\subsubsection{General}

Three singly reinforced FRLWSCC beams and one singly reinforced LWSCC as control were tested under four-point loading to failure. The flexural reinforcement ratio and shear span to effective depth ratio $(\mathrm{a} / \mathrm{d})$ were kept constant at $1 \%$ and 5.75 , respectively for all tested flexural beams. Beams were designed based on CSA.A23.3 (2004) and sufficient shear reinforcement based on code was provided within the shear span with no stirrups at the zero-shear region (700 $\mathrm{mm}$ between the two-point loads).

\subsubsection{Load deflection behavior}

Figure 4.11 (a-d) presents load deflection behaviour of all tested FRLWSCC and LWSCC flexural beams. Three LVDTs had been installed along the $3000 \mathrm{~mm}$ span of the beams as shown in Figure 4.13 as previously explained in test setup in Chapter 3, to record the corresponding deflections at distances of $750 \mathrm{~mm}, 1500 \mathrm{~mm}$ and $2250 \mathrm{~mm}$ from the left support. For all tested flexural beams except CR-LWSCC-F beam, the maximum deflection values at mid-span $(\mathrm{x}=1500 \mathrm{~mm})$ were in the range of $42 \%$ to $66 \%$ higher than those recorded close to the support $(x=750 \mathrm{~mm}$ and $\mathrm{x}=2250$ $\mathrm{mm}$, respectively) at failure stage. In case of CR-LWSCC-F beam, the maximum mid-span deflection was $31.4 \mathrm{~mm}$ which was $88 \%$ more than the obtained deflection value near each support which was $16.9 \mathrm{~mm}$ and $16.8 \mathrm{~mm}$ at $\mathrm{x}=750 \mathrm{~mm}$ and $\mathrm{x}=2250$ respectively at failure stage. Details of deflections at each location for all flexural beams are provided in Table 4.8.

The ultimate/peak moment capacity at failure stage of tested beams HDPE-LWSCC-F, CRLWSCC-F, PVA-LWSCC-F and control LWSCC-F were $24.3 \mathrm{kNm}, 24.9 \mathrm{kNm}, 26.2 \mathrm{kNm}$ and $24.2 \mathrm{kNm}$, respectively. The highest ultimate moment capacity of $26.2 \mathrm{kNm}$ was obtained by PVALWSCC-F beam and the lowest ultimate moment value of $24.2 \mathrm{kNm}$ was obtained by the LWSCCF beam with corresponding mid-span deflections of $33.5 \mathrm{~mm}$ and $17.7 \mathrm{~mm}$, respectively. 

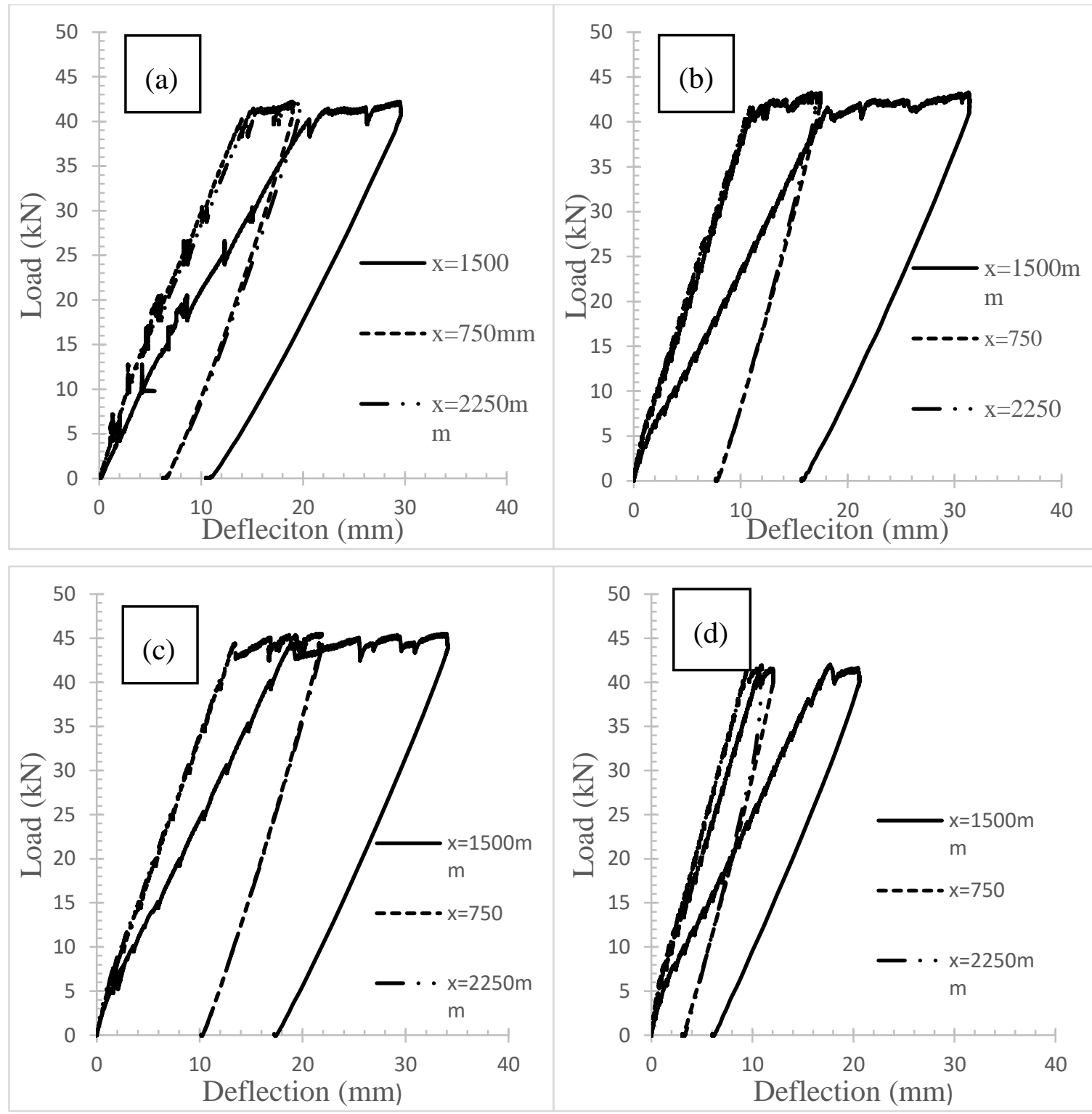

Figure 4.11: Load-deflection curve for tested flexural beams: (a) HDPE-LWSCC-F, (b) CRLWSCC-F, (c) PVA-LWSCC-F and (d) LWSCC-F

\subsubsection{Failure mode, crack pattern and ultimate load capacity}

Summary of ultimate load, ultimate moment, deflection at ultimate load, first flexural crack load, deflection at first flexural crack and failure mode of tested flexural beams are provided in Table 4.8. All tested beams failed in flexure as was expected.

The first flexural cracks were formed within the zero-shear region at mid-span of all beams at about $11.8 \%$ to $32 \%$ of the applied ultimate load. PVA-LWSCC-F had the highest first flexural 
crack load of $15 \mathrm{kN}$ which was approximately twice that of the control beam with mid-span deflection of $6 \mathrm{~mm}$ which was considerably higher than the $1.5 \mathrm{~mm}$ deflection of the control beam. HDPE-LWSCC-F beam had lower first flexural crack load $5 \mathrm{kN}$ which was $40 \%$ lower than control LWSCC-F beam. With increasing applied load, new vertical flexural cracks were formed along the beam and the shear span. Due to higher deflection of PVA-LWSCC-F, formation of cracks were distributed along the beam even close to the supports whereas for the LWSCC-F beams, most of the cracks were formed within the mid-span and propagated from the bottom of the beam towards the top with no flexural cracks identified close to the supports compared to all other FRLWSCC flexural beams. Details of crack pattern are shown in Figure 4.9 (a-d).

Table 4.8: Summary of loads, moment and failure modes of flexural beams

\begin{tabular}{|c|c|c|c|c|c|c|c|}
\hline Beam code & $\begin{array}{c}\text { Concrete } \\
\text { compressive } \\
\text { strength } \\
(\mathrm{MPa})\end{array}$ & $\begin{array}{c}\text { Failure } \\
\text { mode }\end{array}$ & $\begin{array}{c}\text { First } \\
\text { flexural } \\
\mathrm{crack} \\
\mathrm{load} \\
(\mathrm{kN})\end{array}$ & $\begin{array}{c}\text { Ultimate } \\
\text { load } \\
(\mathrm{kN})\end{array}$ & $\begin{array}{c}\text { Ultimate } \\
\text { Moment } \\
(\mathrm{kNm})\end{array}$ & $\begin{array}{c}\text { Deflection } \\
\text { at ultimate } \\
\text { load } \\
\text { Du }(\mathrm{mm})\end{array}$ & $\begin{array}{c}\text { Deflection } \\
\text { at first } \\
\text { flexural } \\
\text { crack } \\
(\mathrm{mm})\end{array}$ \\
\hline $\begin{array}{c}\text { HDPE- } \\
\text { LWSCC-F }\end{array}$ & 38.7 & Flexural & 5 & 42.2 & 24.3 & 29.3 & 1.6 \\
\hline $\begin{array}{c}\text { CR- } \\
\text { LWSCC-F }\end{array}$ & 46.7 & Flexural & 10 & 43.3 & 24.9 & 31.3 & 4 \\
\hline $\begin{array}{c}\text { PVA- } \\
\text { LWSCC-F }\end{array}$ & 43.6 & Flexural & 15 & 45.5 & 26.2 & 34.1 & 6 \\
\hline LWSCC-F & 52.6 & Flexural & 8 & 42.0 & 24.2 & 17.7 & 1.5 \\
\hline
\end{tabular}

Crack width, number of cracks, maximum crack width and type of failure cracks for all tested beam with shear reinforcement are provided in Table 4.9. PVA-LWSCC-F beam had most number of cracks ( 46 cracks) with average crack width of $0.07 \mathrm{~mm}$ compared to other tested beams. HDPELWSCC-F beam had the smallest maximum crack width of $0.5 \mathrm{~mm}$ compared to those of other beam counterparts. Approximately all the tested beams had the same average crack width with only flexural crack type. Details of cracks pattern and crack width for each beam obtained from experiments are shown in Figure 4.12 and Figure 4.13. 
Table 4.9: Summery of crack width and number of flexural beams

\begin{tabular}{|l|l|l|l|l|}
\hline Beam code & Number of cracks & $\begin{array}{l}\text { Average crack width } \\
(\mathrm{mm})\end{array}$ & $\begin{array}{l}\text { Maximum crack } \\
\text { width (mm) }\end{array}$ & $\begin{array}{l}\text { Failure crack } \\
\text { type }\end{array}$ \\
\hline HDPE-LWSCC-F & 42 & 0.05 & 0.5 & $\begin{array}{l}\text { Flexural } \\
\text { crack }\end{array}$ \\
\hline CR-LWSCC-F & 39 & 0.05 & 1 & $\begin{array}{l}\text { Flexural } \\
\text { crack }\end{array}$ \\
\hline PVA-LWSCC-F & 46 & 0.07 & 1 & $\begin{array}{l}\text { Flexural } \\
\text { crack }\end{array}$ \\
\hline LWSCC-F & 36 & 0.05 & 0.8 & $\begin{array}{l}\text { Flexural } \\
\text { crack }\end{array}$ \\
\hline
\end{tabular}
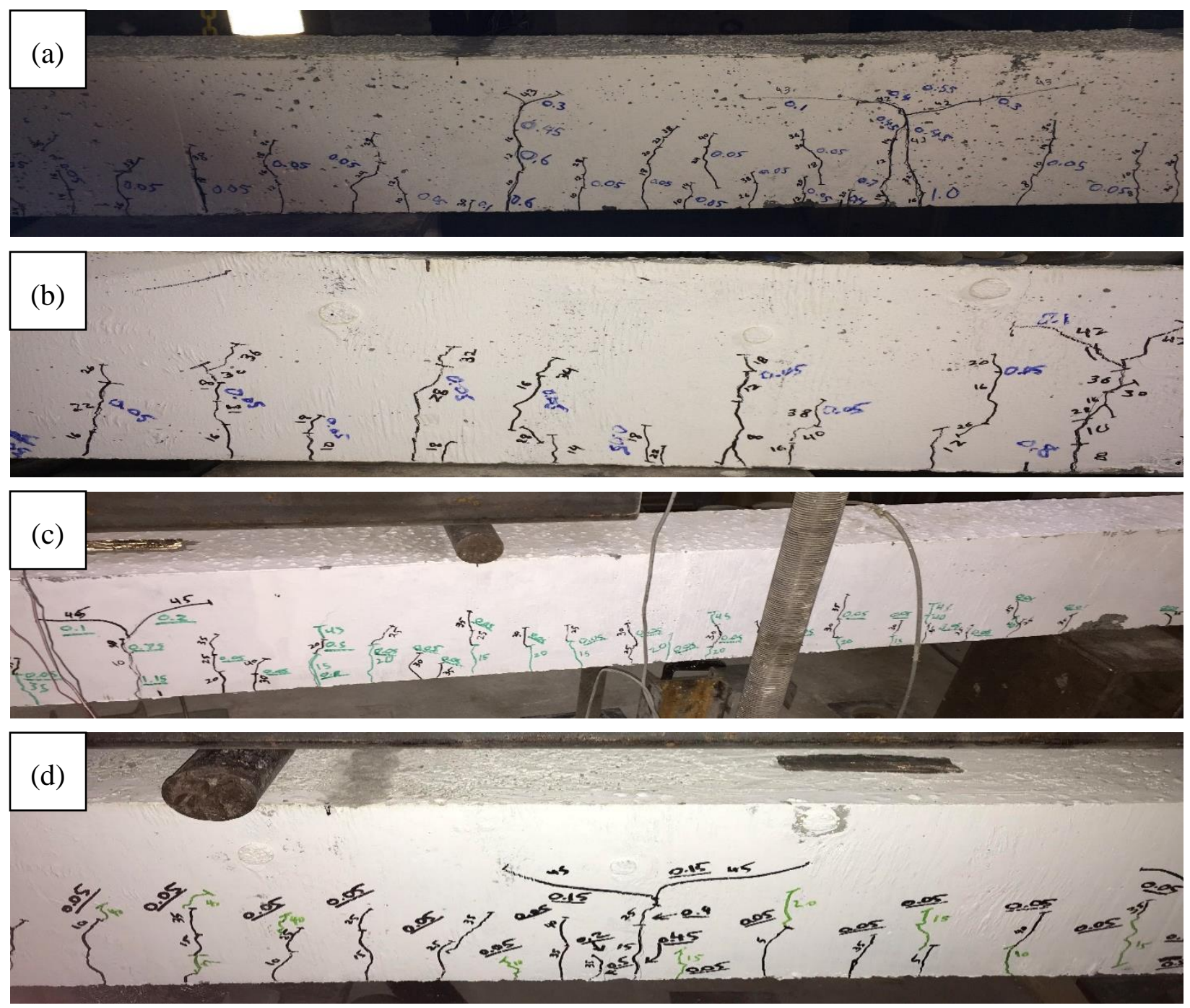

Figure 4.12: Crack patterns at the centre of flexural beams (a) CR-LWSCC-F, (b) LWSCC-F, (c) PVA-LWSCC-F and (d) HDPE-LWSCC-F 

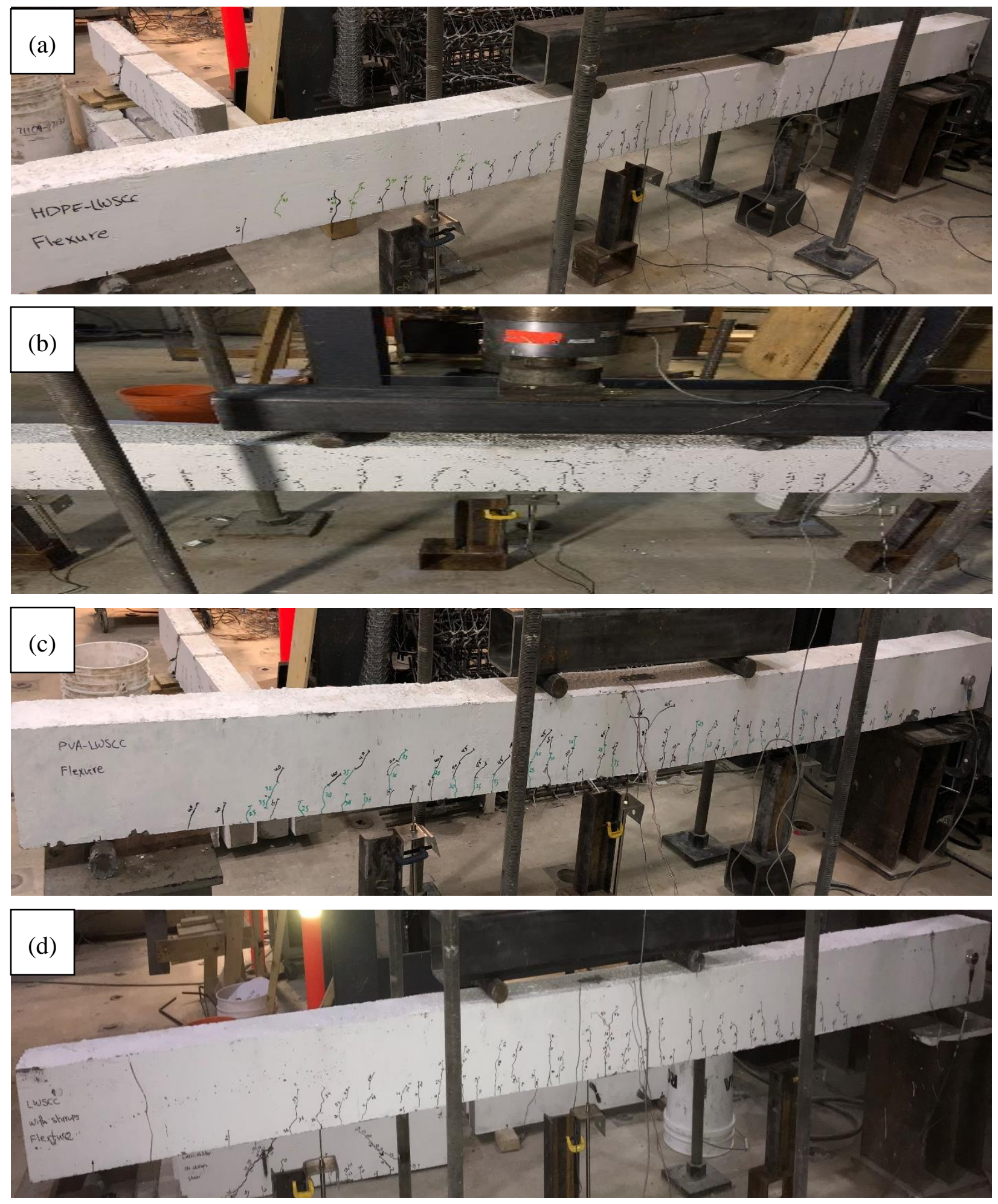

Figure 4.13: Crack pattern and failure modes of flexural beams (a) HDPE-LWSCC-F, (b) CRLWSCC-F, (c) PVA-LWSCC-F and (d) LWSCC-F 


\subsubsection{Strain development in concrete and flexural/shear reinforcements}

Figure 4.14 (a), (b), (c) and (d) shown the strain development of concrete at compression zone, flexural and shear reinforcements during the loading history for FRLWSCC and LWSCC flexural beams.
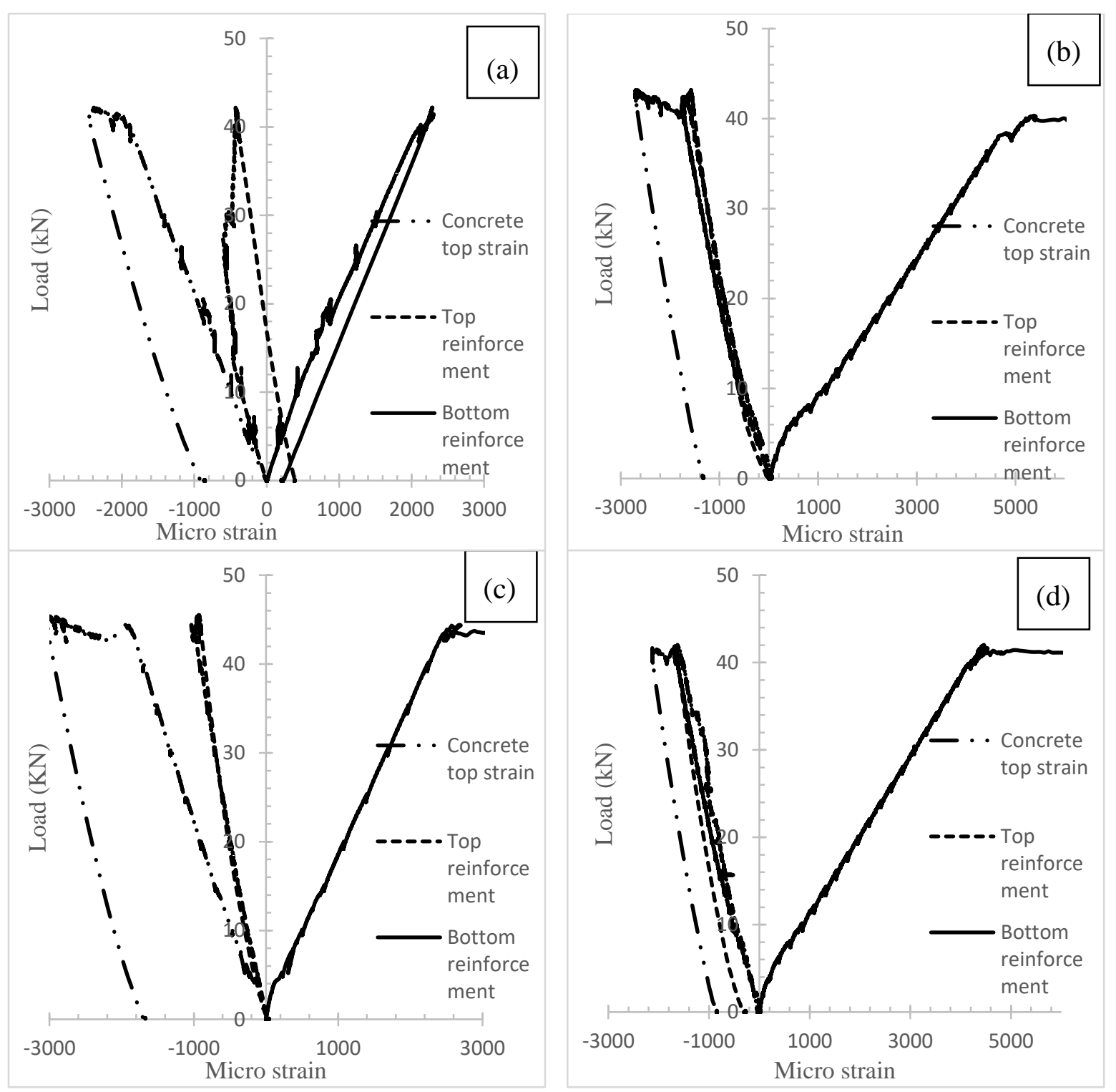

Figure 4.14: Load-strain curves for tested: (a) HDPE-LWSCC-F, (b) CR-LWSCC-F, (c) PVALWSCC-F and (d) LWSCC-F

The tensile strain developed gradually in bottom reinforcement with increase in the applied load and ended by yielding of the flexural reinforcement at ultimate stage. The load-strain response of 
CR-LWSCC-F and LWSCC-F beams shown that the obtained value of the developed strain in the top reinforcement and the concrete at compression were close as it presented in Figure 4.14(b) and (d) which could be due to their similar distance from the natural axis.

Table 4.10 summarized load at first steel yield, strain at yielding and ultimate stages and the ultimate failure load values for the tested FRLWSCC and LWSCC flexure beams.

After the bottom reinforcement of HDPE-LWSCC-F and CR-LWSCC-F beams yielded, beams failed by increase of applied load therefore the value of the load at first steel yielding were $6 \%$ and $14 \%$ lower than the ultimate load capacity, while the value of the concrete strain at compression zone were 2475 micro strain and 2667 micro strain, respectively.

In case of PVA-LWSCC-F and LWSCC-F, immediately after yielding of the flexural reinforcement the beam failed where the concrete strain value at compression were 3003 micro strain and 2129 micro strain which have found as the maximum and minimum obtained concrete strain among the tested beams, correspondingly. As per CSA A23.3-04. (2004) standards, the maximum concrete compressive strain is equal to 3500 micro strain at ultimate stage which the obtained results were within the specified limit.

Table 4.10: Summary of yield load, ultimate load/moment and strain for tested flexural beams

\begin{tabular}{|c|c|c|c|c|c|c|c|c|}
\hline \multirow[t]{2}{*}{ Beam } & \multirow{2}{*}{$\begin{array}{l}\text { Load at first } \\
\text { steel } \\
\text { yielding } \\
(\mathrm{kN})\end{array}$} & \multicolumn{3}{|c|}{$\begin{array}{l}\text { Yielding stage (beginning of large } \\
\text { strain development) (micro strain) }\end{array}$} & \multicolumn{3}{|c|}{$\begin{array}{l}\text { Ultimate/failure stage strain } \\
\text { (micro strain) }\end{array}$} & \multirow{2}{*}{$\begin{array}{l}\text { Ultimate } \\
\text { Load, } \\
(\mathrm{kN})\end{array}$} \\
\hline & & $\begin{array}{l}\text { Bottom } \\
\text { rebars }\end{array}$ & $\begin{array}{l}\text { Top } \\
\text { rebars }\end{array}$ & $\begin{array}{l}\text { Concrete } \\
\text { strain at } \\
\text { compression }\end{array}$ & $\begin{array}{l}\text { Bottom } \\
\text { rebars }\end{array}$ & $\begin{array}{l}\text { Top } \\
\text { rebars }\end{array}$ & $\begin{array}{l}\text { Concrete } \\
\text { strain at } \\
\text { compression }\end{array}$ & \\
\hline HDPE-LWSCC-F & 39.7 & 2281 & 381 & 1984 & 2285 & 444 & 2475 & 42.2 \\
\hline CR-LWSCC-F & 37.2 & 5537 & 1516 & 1723 & 22295 & 1758 & 2667 & 43.3 \\
\hline PVA-LWSCC-F & 45.5 & 2592 & 894 & 1889 & 15758 & 977 & 3003 & 45.5 \\
\hline LWSCC-F & 42.0 & 4587 & 1677 & 2002 & 27499 & 1648 & 2129 & 42.0 \\
\hline
\end{tabular}

\subsubsection{Bending moment and beam end rotation development}

The moment-rotation curves of FRLWSCC and LWSCC flexural beams are shown in Figure 4.15.The curves show linear behavior similar to load-deflection response until yielding of steel reinforcement for HDPE-LWSCC-F AND CR-LWSCC-F beams. After steel yielding of bottom reinforcement beam rotation suddenly increased while insignificant amount of increase in the moment was observed rotation approximately changed from 0.7 degree to 1.7 degree and 0.4 
degree to 0.9 degree respectively. PVA-LWSCC-F and HDPE-LWSCC-F had approximately same and highest rotation angle with end angle of 1.7 degree comparing to CR-LWSCC-F and LWSCCF with end angle of rotation of 0.9 degree and 1.3 degree.

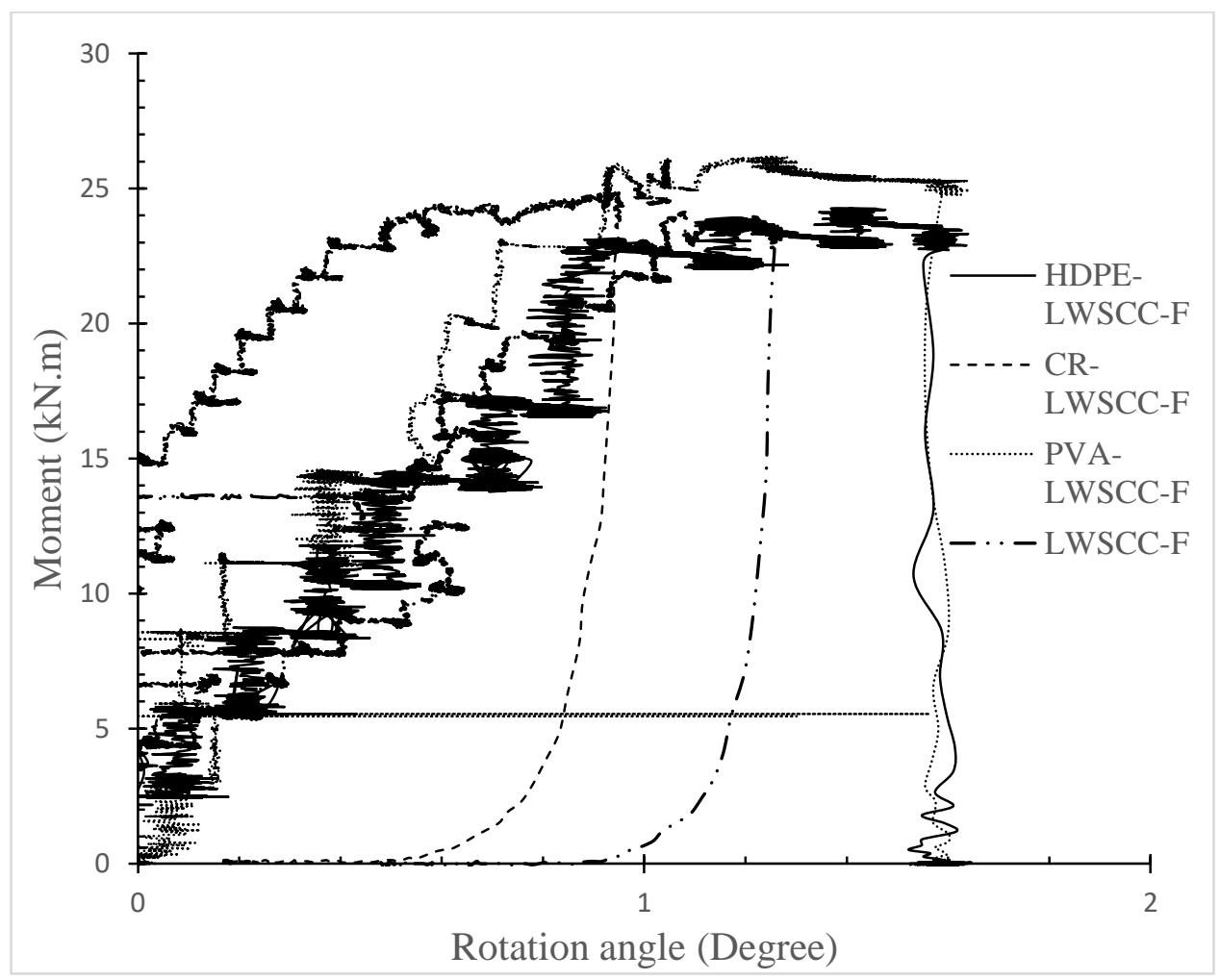

Figure 4.15: Moment-rotation curves for tested flexural beams

\subsubsection{Ductility behavior, energy absorption capacity and stiffness of FRLWSCC-F beams}

Ductility of a member is defined based on the ability of a member to deform without a significant loss of its strength. The ductility index (DI) here is defined as the ratio of deflection at failure/ultimate stage $\left(D_{u}\right)$ to that at first yielding of steel $\left(D_{y}\right)$. The ability of a member to absorb energy calculated from the area under the load-deflection responses is shown in Figure 4.11. PVALWSCC-F and CR-LWSCC-F beams had the highest energy absorption capacity which was 113\% and $100 \%$ higher than control beam, respectively.

The control beam LWSCC-F was stiffer (stiffness of $4.26 \mathrm{~N} / \mathrm{mm}$ ) than other FRLWSCC beams as expected (Table 4.11). Existence of fiber in the concrete decreased the stiffness of flexural beams. Table 4.11 provides the DI values for FRLWSCC flexural beams based on $\mathrm{D}_{\mathrm{y}}$ and $\mathrm{D}_{\mathrm{u}}$ obtained from load-deflection responses shown in Figure 4.11. Generally, the ductility index is strongly 
affected by the crushing strain of concrete. PVA-LWSCC-F CR-LWSCC-F beams showed better ductility with DI approximately equal to 2.0 compared to HDPE-LWSCC-F and LWSCC-F beams. The ability of a member to absorb energy calculated from the area under the load-deflection responses is shown in Figure 4.11. PVA-LWSCC-F and CR-LWSCC-F beams had the highest energy absorption capacity which was $113 \%$ and 100\% higher than control beam, respectively.

The control beam LWSCC-F was stiffer (stiffness of $4.26 \mathrm{~N} / \mathrm{mm}$ ) than other FRLWSCC beams as expected (Table 4.11). Existence of fiber in the concrete decreased the stiffness of flexural beams.

Table 4.11: Summery of ductility factor, energy absorption and stiffness of flexural beams

\begin{tabular}{|c|c|c|c|c|c|}
\hline Beam code & $\begin{array}{c}\text { Concrete } \\
\text { compressive } \\
\text { strength (f'c) }\end{array}$ & $\begin{array}{c}\text { Peak/failure } \\
\text { load (kN) }\end{array}$ & $\begin{array}{c}\text { Ductility } \\
\text { factor (DI) }\end{array}$ & $\begin{array}{c}\text { Energy } \\
\text { absorption (J) }\end{array}$ & $\begin{array}{c}\text { Stiffness } \\
(\mathrm{N} / \mathrm{mm})\end{array}$ \\
\hline HDPE-LWSCC-F & 38.7 & 42.2 & 1.5 & 794.9 & 2.12 \\
\hline CR-LWSCC-F & 46.7 & 43.3 & 1.9 & 1025.3 & 3.14 \\
\hline PVA-LWSCC-F & 43.6 & 45.5 & 2.0 & 1084.6 & 2.82 \\
\hline LWSCC-F & 52.6 & 42.0 & 1 & 508.2 & 4.26 \\
\hline
\end{tabular}

\subsection{Summary}

The shear and flexure performance of FRLWSCC beams are described based on experimental results. Formation of first flexural crack was observed at lower loads in FRLWSCC beams with and without shear reinforcement compared to their LWSCC counterparts. Diagonal shear crack load was approximately the same for all FRLWSCC with respect to their respective control LWSCC beam with and without shear reinforcement. FRLWSCC beams with and without shear reinforcements had higher deflection, ranging from $15 \%$ to $86 \%$ for beams without shear reinforcement and $6 \%$ to $71 \%$ for beams with shear reinforcements, compared control LWSCC shear beams with and without shear reinforcement, respectively.

FRLWSCC beams with and without shear reinforcements had higher number of cracks at failure and lower crack widths compared to those observed for LWSCC beams.

All FRLWSCC-S beams had higher ductility, higher energy absorption capacity (increasing from $98 \%$ to $293 \%$ ) and lower stiffness (decreased from 5\% to 35\%) compared to control LWSCC-S beams. In case of FRLWSCC-S-S beams, higher ductility was achieved with the presence of fiber 
with higher energy absorption capacity (94\% to $400 \%$ increase) and stiffness (22\% to $43 \%$ increase) compared to control LWSCC-S-S.

All FRLWSCC flexural beams showed typical structural behavior in flexure. Since the beams were under-reinforced, yielding of the tensile reinforcement happened before crushing of the compression concrete in the pure bending region. All FRLWSCC flexural beams had higher number of cracks and smaller crack widths compared with their control LWSCC-F counterpart. FRLWSCC-F beams had higher ultimate load capacity, better ductility and higher deflection at ultimate load compared with LWSCC-F control beam. FRLWSCC flexural beams showed higher ability to absorb energy - energy absorption capacity was increased by $100 \%$ and had approximately $100 \%$ lower stiffness compared to control LWSCC-F beam. 


\section{CHAPTER FIVE}

\section{THEORITICAL ANALYSIS OF SHEAR AND FLEXURAL CAPACITIES OF EXPERIMENTAL BEAMS}

\subsection{Introduction}

This Chapter compares the experimental shear capacities of fiber reinforced lightweight selfconsolidating concrete (FRLWSCC) and lightweight self-consolidating concrete (LWSCC) beams with and without shear reinforcement with those obtained from Code based equations/procedures namely ACI 318M-08 (2008), CSA A23.3-04 (2004), BS8110-97 (1997) and existing equations from previous researchers. The experimental cracking and ultimate moment capacities of FRLWSCC flexural beams are compared with those obtained from different codes and equations.

\subsection{Codes and the prediction of shear capacity of beams}

An accepted rational physical method does not yet exist (specifically for LWSCC and FRLWSCC) due to the complex nature of the shear failure mechanism in reinforced concrete beams. Most design codes introduce some factors/modifications to be applicable to lightweight selfconsolidating concrete (LWSCC) or lightweight concrete (LWC). Codes normally do not consider contribution of fibers especially for shear strength and codes use reduction factor to take into account weaker LWSCC with lower tensile strength. Therefore, it is important to study the performance of such Code based equations/procedures in predicting shear strength of SCC especially LWSCC/FRLWSCC beams with lower volume of aggregate. For reinforced concrete beam with shear reinforcement, the total shear resistance $\left(V_{n}\right)$ can be calculated by adding concrete shear resistance $\left(\mathrm{V}_{\mathrm{c}}\right)$ to the transverse shear reinforcement contribution $\left(\mathrm{V}_{\mathrm{s}}\right)$.

$\mathrm{V}_{\mathrm{n}}=\mathrm{V}_{\mathrm{c}}+\mathrm{V}_{\mathrm{s}}$

In this study, the performance of Canadian CSA A23.3-04 (2004), American ACI 318M-08 (2008) and British (BS8110 1997) Codes and equations proposed by previous researchers in predicting the shear strength and flexure resistance of FRLWSCC/LWSCC beams is studied based on experimental results of current and previous research studies. These Codes and equations are already introduced in Chapter Two, however, they are reintroduced again in this section. 
According to Canadian standard CSA A23.3-04 (2004) based on modified compression field theory $\mathrm{V}_{\mathrm{c}}$ and $\mathrm{V}_{\mathrm{s}}$ can be obtained from following equations:

$\mathrm{V}_{\mathrm{c}}=\lambda \beta \sqrt{\mathrm{f}_{\mathrm{c}}^{\prime}} \mathrm{b}_{\mathrm{w}} \mathrm{d}$ when $\sqrt{\mathrm{f}_{\mathrm{c}}^{\prime}} \leq 8 \mathrm{Mpa}$

where $\lambda$ is the redution factor is equal to 0.75 for all low density concrete

Stirrups contribution can be calculated from equations 5.3 and 5.4.

Using Simplified method:

$$
V_{s}=1.43 \frac{A_{v}}{S} f_{y} d_{v}
$$

Using General method:

$V_{s}=\frac{A_{v}}{S} f_{y} d_{v} \cot \theta$

According to ACI381M-08 (2008), following equations can be used to calculate the concrete and shear reinforcement contribution in SI units:

Shear capacity of concrete $V_{c}$ can be obtained from equation 5.5:

$V_{c}=\left(0.16 \lambda \sqrt{f_{c}^{\prime}}+17 \rho_{w} \frac{V_{u} d}{M_{u}}\right)\left(b_{w} d\right)$

Where; $\sqrt{f_{c}^{\prime}} \leq 8.3 M p a, V_{c} \leq 0.29 \lambda \sqrt{f_{c}^{\prime}} b_{w}$ d and $\frac{V_{u} d}{M_{u}} \leq 1.0$

$\lambda$ is the redution factor equal to 0.75 for low density concrete with an air density is less than $1850 \mathrm{~kg} / \mathrm{m}^{3}$.

Contribution of shear reinforcement $\left(\mathrm{V}_{\mathrm{s}}\right)$ can be obtained from equation 5.6:

$V_{s}=\frac{A_{v} f_{y} d_{v}}{s}$

According to British standard design code BS8110-part1 (1997), shear capacity of concrete can be obtained from following equations.

$\mathrm{V}_{\mathrm{c}}=0.79 *\left(\left(\frac{100 * \mathrm{~A}_{\mathrm{s}}}{\mathrm{b}_{\mathrm{w}} \mathrm{d}}\right)^{1 / 3} *\left(\frac{400}{\mathrm{~d}}\right)^{1 / 4} *\left(\mathrm{~b}_{\mathrm{w}} \mathrm{d}\right) *\left(\frac{\mathrm{f}_{\mathrm{cu}}}{25}\right)^{1 / 3}\right.$

Shear resistance provided by stirrups, $\mathrm{V}_{\mathrm{S}}$ can be calculated from equation 5.8:

$\mathrm{V}_{\mathrm{S}}=\frac{\mathrm{A}_{\mathrm{sv}}}{\mathrm{S}_{\mathrm{v}}} 0.95 \mathrm{f}_{\mathrm{yv}} \mathrm{d}$ 
Campione (2013) proposed equation 5.9 to obtain the shear resistance $\left(\mathrm{V}_{\mathrm{u}}\right)$ of $\mathrm{LWC}$ as follows:

$V_{u}=0.125\left(1+\frac{c}{D} \cdot F\right) \cdot \sqrt{f^{\prime}{ }_{c}}+21 \cdot \rho \cdot \frac{d}{a}+0.15 \cdot F \cdot \frac{d}{a} \cdot \sqrt{f^{\prime}{ }_{c}}$

where $\mathrm{c}=$ cover of the longitudinal bars, $\mathrm{D}=$ diameter of the ith bar belonging to the main reinforcements, fiber factor $F=\left(L_{f} / D_{f}\right) V_{f} d_{f}, d_{f}=$ bond factor $(0.5$ for round, 0.75 for crimped, and 1.0 for independent fiber), $\mathrm{L}_{\mathrm{f}}=$ fiber length $(\mathrm{mm}), \mathrm{D}_{\mathrm{f}}=$ fiber diameter $(\mathrm{mm}), \mathrm{V}_{\mathrm{f}}=$ volume fraction of steel fiber, $\rho=$ flexural reinforcement ratio, $a=$ shear span length, $d=$ effective depth, $\mathrm{f}^{\prime}{ }^{\prime}=$ cylinders compressive strength, $\tau=$ average fiber-matrix interfacial bond stress (assumed to be 4.15 MPa), e = arch action factor $(1.0$ for $\mathrm{a} / \mathrm{d}>2.5$ and $2.5 \mathrm{~d} / \mathrm{a}$ for $\mathrm{a} / \mathrm{d} \leq 2.5)$.

In a research by Al-Taan et al. (1990), the following equation 5.10 proposed for fiber reinforced concrete beams.

$\mathrm{V}_{\mathrm{u}}=\mathrm{e}\left[0.17 \sqrt{\mathrm{f}_{\mathrm{c}}^{\prime}}+10.6 \rho\left(\frac{\mathrm{d}}{\mathrm{a}}\right)\right]+1.128 \mathrm{~F}$

Research done by Narayanan and Darwish (1988) proposed equation 5.11 by taking into consideration the contribution of concrete and fiber, and the contribution of stirrups for calculating the shear strength $\left(\mathrm{V}_{\mathrm{u}}\right)$ (in MPa) of Steel fiber-reinforced concrete SFRC beams.

$$
\mathrm{V}_{\mathrm{u}}=\mathrm{e}\left[0.24 \mathrm{f}_{\text {spfc }}+80 \rho\left(\frac{\mathrm{d}}{\mathrm{a}}\right)\right]+0.41 \tau \mathrm{F}
$$

where $\rho=$ flexural reinforcement ratio, $e=$ arch action factor $(1.0$ for $\mathrm{a} / \mathrm{d}>2.8$ and $2.8 \mathrm{~d} / \mathrm{a}$ for $\mathrm{a} / \mathrm{d}$ $\leq 2.8), \mathrm{f}_{\text {spfc }}=$ split cylinder strength $(\mathrm{MPa}), \mathrm{f}_{\text {spfc }}=\mathrm{f}_{\text {cuf }} /((20-\sqrt{\mathrm{F}}))+0.7+\sqrt{\mathrm{F}}, \mathrm{f}_{\text {cuf }}=$ cube strength of fibre concrete $(\mathrm{MPa})$, fiber factor $\mathrm{F}=\left(\mathrm{l}_{\mathrm{f}} / \mathrm{d}_{\mathrm{f}}\right) \mathrm{V}_{\mathrm{f}} \mathrm{d}_{\mathrm{f}}, \mathrm{D}_{\mathrm{f}}=$ bond factor $(0.5$ for round, 0.75 for crimped, and 1.0 for independent fiber), $\mathrm{l}_{\mathrm{f}}=$ fibre length $(\mathrm{mm}), \mathrm{d}_{\mathrm{f}}=$ fibre diameter $(\mathrm{mm}), \mathrm{V}_{\mathrm{f}}=$ volume fraction of steel fibre, and $\tau=$ average fibre-matrix interfacial bond stress (assumed to be 4.15 $\mathrm{MPa})$.

Ashour et al. (1992) proposed equation 5.12 for the shear strength by modifying ACI equation to include effect of shear span to depth ratio, the cylinder compressive strength of concrete $\left(f_{c}^{\prime}\right)$, fiber factor $(F)$ and flexural reinforcement ratio $(\rho)$.

$$
\mathrm{V}_{\mathrm{u}}=\left(0.7 \sqrt{\mathrm{f}_{\mathrm{c}}^{\prime}}+7 \mathrm{~F}\right) \frac{\mathrm{d}}{\mathrm{a}}+17.20 \rho \frac{\mathrm{d}}{\mathrm{a}}
$$


Sharma (1986) proposed following equation for predicting the shear strength of SFRC beam.

$\mathrm{V}_{\mathrm{u}}=\mathrm{kf}_{\mathrm{t}}^{\prime}\left(\frac{\mathrm{d}}{\mathrm{a}}\right)^{0.25}$

where $\mathrm{k}=1$ if $\mathrm{f}_{\mathrm{t}}{ }^{\prime}$ is obtained by direct tension test; $\mathrm{k}=2 / 3$ if $\mathrm{f}_{\mathrm{t}}{ }_{\mathrm{t}}$ is obtained by indirect tension test; $\mathrm{k}=4 / 9$ if $\mathrm{f}_{\mathrm{t}}$ is obtained using modulus of rupture. $\mathrm{f}_{\mathrm{t}}$ is the tensile strength of steel fiber reinforced concrete to be calculated as $9.5 \mathrm{f}^{\prime}{ }_{\mathrm{c}}^{0.5}$. Even though Sharma (1986) used $\mathrm{f}_{\mathrm{t}}^{\prime}$ in the equation, it is indirectly based on the cylinder compressive strength of concrete $\left(\mathrm{f}^{\prime}{ }_{\mathrm{c}}\right)$.

In a research done by Khuntia, et al. (1992) following equation proposed for predicting the shear strength of the fiber reinforced concrete beam where $\alpha=1$ for $\mathrm{a} / \mathrm{d} \geq 2.5$, and $\alpha=2.5 \mathrm{~d} / \mathrm{a}$ for $\mathrm{a} / \mathrm{d}<2.5$.

$\left.\mathrm{V}_{\mathrm{u}}=(0.167 \propto+0.25 \mathrm{~F}) \sqrt{\mathrm{f}_{\mathrm{c}}^{\prime}}\right)$

Shin et al. (1996) proposed equation 5.15 and 5.16 for the shear strength of the fiber reinforced concrete beam.

$\mathrm{V}_{\mathrm{u}}=0.22 \mathrm{f}_{\mathrm{spfc}}+217 \rho \frac{\mathrm{d}}{\mathrm{a}}+0.834 \mathrm{~F}$, if $\frac{\mathrm{a}}{\mathrm{d}}<3$

$\mathrm{V}_{\mathrm{u}}=0.19 \mathrm{f}_{\mathrm{spfc}}+93 \rho \frac{\mathrm{d}}{\mathrm{a}}+0.834 \mathrm{~F}$, if $\frac{\mathrm{a}}{\mathrm{d}} \geq 3$

\subsection{Shear strength prediction of FRLWSCC beams without shear reinforcement}

Shear resistances of FRLWSCC beams without shear reinforcement obtained from current experiments and different codes/standards are compared in Table 5.1. Detailed calculations are provided in the appendix A.

It can be observed that all design codes were conservative in predicting the ultimate shear strength of FRLWSCC beams. CSA A23.3 and BS8110 provided the highest safety margin (ratio ranged between 1.59 and 3.6 for all tested FRLWSCC beams compared to ACI318 (ratio ranged between 1.26 and 2.60). Existing standards does not consider contribution of fiber in shear capacity of the beams. 
Table 5.1: Shear resistance of beams without shear reinforcement from experiment and codebased predictions

\begin{tabular}{|l|l|l|l|l|l|l|l|}
\hline \multirow{2}{*}{ Beams } & \multicolumn{3}{|l|}{ Total shear resistance, Vn $=\mathrm{Vc}(\mathrm{kN})$} & \multicolumn{2}{l}{ Ratio of experimental to code predicted } \\
shear
\end{tabular}

\subsection{Shear strength prediction of FRLWSCC-S-S beams based on design codes}

Table 5.2 compares shear resistance of beams with shear reinforcement from experiments and code based predictions. Detailed calculations are provided in the appendix A. CR-LWSCC-S, PVALWSCC-S and LWSCC-S beams failed in shear but shear reinforcements did not yield. This might be associated with the contribution of fiber in resisting shear suggesting the use of lower shear reinforcement than those provided. The ratio of experimental to Code-predicted shear reinforcement capacities for those beams ranged between 1.10 and 1.40 with a mean value of 1.2 - therefore, codes are found safe. 
Table 5.2: Shear resistance of beams shear reinforcement from experiment and code based predictions

\begin{tabular}{|c|c|c|c|c|c|c|c|}
\hline \multirow[t]{3}{*}{ Beams } & \multicolumn{4}{|c|}{ Concrete shear resistance $\mathrm{V}_{\mathrm{c}}(\mathrm{kN})$} & \multicolumn{3}{|c|}{ Ratio of experimental to Code predicted shear } \\
\hline & \multirow[t]{2}{*}{ Experiment(Exp) } & \multicolumn{3}{|c|}{ Code-based predictions } & & & \\
\hline & & CSA & $\mathrm{ACI}$ & BS & Exp/CSA & Exp/ACI & Exp/BS \\
\hline HDPE-LWSCC-S-S & 20 & 13.1 & 18.3 & 13.9 & 1.53 & 1.09 & 1.44 \\
\hline CR-LWSCC-S-S & 17.5 & 14.5 & 19.8 & 14.8 & 1.21 & 0.88 & 1.18 \\
\hline PVA-LWSCC-S-S & 15 & 13.9 & 19.2 & 14.5 & 1.08 & 0.78 & 1.03 \\
\hline LWSCC-S-S & 17 & 15.3 & 20.8 & 15.4 & 1.11 & 0.82 & 1.1 \\
\hline \multirow[t]{3}{*}{ Beam } & \multicolumn{4}{|c|}{ Stirrups shear resistance $\mathrm{V}_{\mathrm{s}}(\mathrm{kN})$} & \multirow{2}{*}{\multicolumn{3}{|c|}{ Ratio of experimental to Code predicted shear }} \\
\hline & \multirow[t]{2}{*}{ Experiment(Exp) } & \multicolumn{3}{|c|}{ Code-based predictions } & & & \\
\hline & & CSA & $\mathrm{ACI}$ & $\mathrm{BS}$ & Exp/CSA & Exp/ACI & Exp/BS \\
\hline HDPE-LWSCC-S-S & 37.5 & 40.4 & 36.8 & 35.1 & 0.93 & 1.02 & 1.07 \\
\hline CR-LWSCC-S-S & 35 & 31.9 & 29.1 & 27.7 & 1.1 & 1.2 & 1.26 \\
\hline PVA-LWSCC-S-S & 24 & 20.4 & 18.6 & 17.7 & 1.18 & 1.29 & 1.36 \\
\hline LWSCC-S-S & 27 & 24.5 & 22.3 & 21.5 & 1.1 & 1.21 & 1.26 \\
\hline \multirow[t]{3}{*}{ Beam } & \multicolumn{4}{|c|}{ Beam shear resistance $V_{r}=V_{c}+V_{s}(k N)$} & \multirow{2}{*}{\multicolumn{3}{|c|}{ Ratio of experimental to Code predicted shear }} \\
\hline & \multirow[t]{2}{*}{ Experiment(Exp) } & \multicolumn{3}{|c|}{ Code-based predictions } & & & \\
\hline & & CSA & $\mathrm{ACI}$ & $\mathrm{BS}$ & Exp/CSA & Exp/ACI & Exp/BS \\
\hline HDPE-LWSCC-S-S & 57.5 & 53.5 & 55.1 & 49 & 1.07 & 1.04 & 1.17 \\
\hline CR-LWSCC-S-S & 52.5 & 46.4 & 48.9 & 42.5 & 1.13 & 1.07 & 1.24 \\
\hline PVA-LWSCC-S-S & 39 & 34.3 & 37.8 & 32.2 & 1.14 & 1.03 & 1.21 \\
\hline LWSCC-S-S & 44 & 39.8 & 43.1 & 36.9 & 1.11 & 1.02 & 1.19 \\
\hline
\end{tabular}

HDPE-LWSCC-F beam failed by yielding of shear reinforcement prior to shear failure, therefore this beam's experimental shear capacity can be a true measure of the performance of the Codes. Total shear resistance capacities (Vr) predicted by all CSA-A23.3, ACI 18 and BS8110 were very close as summarized in Table 5.2.(Experimental to code predicted ratio ranges between 1.04 and 1.17).

Overall, current reduction factors suggested by the Codes in chapter two can be increased for the prediction of shear resistance of FRLWSCC beams. This is reasonable considering the lower volume of weak lightweight aggregate (hence higher volume of strong paste) in LWSCC compared 
to lightweight concrete (LWC) and contribution of fiber in increasing shear capacity of FRLWSCC.

\subsection{Shear strength prediction of FRLWSCC-S and FRLWSCC-S-S beams with existing equations}

Shear capacity values obtained from experiments and those calculated from existing equations for all FRLWSCC shear beams with and without shear reinforcement are compared in Table 5.3. Detailed calculations are provided in the appendix A.

Table 5.3: Experimental and theoretical shear capacity comparison

\begin{tabular}{|c|c|c|c|c|c|c|c|c|c|c|c|c|c|c|c|}
\hline \multirow[t]{2}{*}{ Beam } & \multicolumn{8}{|c|}{ Shear Capacity $\left(\mathrm{V}_{\mathrm{u}}\right)$} & \multicolumn{7}{|c|}{ Ratio: experimental to existing equation } \\
\hline & (E) & [1] & [2] & [3] & [4] & [5] & [6] & [7] & $\frac{(E)}{[1]}$ & $\frac{(\mathrm{E})}{[2]}$ & $\frac{(E)}{[3]}$ & $\frac{(E)}{[4]}$ & $\frac{(E)}{[5]}$ & $\frac{(E)}{[6]}$ & $\frac{(\mathrm{E})}{[7]}$ \\
\hline $\begin{array}{c}\text { HDPE- } \\
\text { LWSCC-S }\end{array}$ & 47.5 & 19.8 & 52.8 & 23.9 & 29.7 & 39.2 & 17.3 & 32.7 & 2.4 & 0.9 & 2 & 1.6 & 1.2 & 2.7 & 1.6 \\
\hline $\begin{array}{c}\text { CR- } \\
\text { LWSCC-S }\end{array}$ & 47.7 & 26.3 & 45.9 & 33.7 & 38.3 & 47.5 & 21.9 & 34.2 & 1.8 & 1.0 & 1.4 & 1.3 & 1.0 & 2.2 & 1.4 \\
\hline $\begin{array}{c}\text { PVA- } \\
\text { LWSCC-S }\end{array}$ & 23.0 & 29.2 & 48.9 & 32.3 & 39.4 & 48.9 & 23.2 & 31.8 & 0.8 & 0.5 & 0.7 & 0.6 & 0.5 & 0.9 & 0.7 \\
\hline LWSCC-S & 33.3 & 27.6 & 47.0 & 34.3 & 40.4 & 48.2 & 23.0 & 30.8 & 1.2 & 0.7 & 1.0 & 0.8 & 0.7 & 1.4 & 1.1 \\
\hline $\begin{array}{c}\text { HDPE- } \\
\text { LWSCC-S-S }\end{array}$ & 57.5 & 19.8 & 52.8 & 23.9 & 29.7 & 39.2 & 17.3 & 32.7 & 2.5 & 1.4 & 1.9 & 1.7 & 1.3 & 2.7 & 1.6 \\
\hline $\begin{array}{c}\text { CR- } \\
\text { LWSCC-S-S }\end{array}$ & 52.5 & 26.3 & 45.9 & 33.7 & 38.3 & 47.5 & 21.9 & 34.2 & 2.0 & 1.2 & 1.6 & 1.4 & 1.1 & 2.2 & 1.4 \\
\hline $\begin{array}{c}\text { PVA- } \\
\text { LWSCC-S-S }\end{array}$ & 39.0 & 29.2 & 48.9 & 32.3 & 39.4 & 48.9 & 23.2 & 31.8 & 1.3 & 0.8 & 1.2 & 1.0 & 0.8 & 0.9 & 0.7 \\
\hline LWSCC-S-S & 44.0 & 27.6 & 47.0 & 34.3 & 40.4 & 48.2 & 23.0 & 30.8 & 1.6 & 0.9 & 1.3 & 1.1 & 0.9 & 1.4 & 1.1 \\
\hline
\end{tabular}

For HDPE-LWSCC-S prediction was obtained by Narayanan and Darwish (1988) (Eq. 5.11) with a ratio of 2.4 and closest prediction (with a ratio of 0.9) was obtained from Ashour et al., (1992) (Eq.5.12). CR-LWSCC-S beams yielded similar ratio values to HDPE-LWSCC-S, the ratio ranged from 1.0 to 2.2 with a mean value of 1.4 - which also suggested conservativeness of the equations. In case of PVA-LWSCC-S all equations underestimated the shear capacity and the closest values were obtained by Campione (2013). For LWSCC-S the highest ratio of 1.4 was obtained by Campione (2013) and except Narayanan and Darwish (1988) and Al-Taan et al., (1990), all other 
equations underestimated the shear capacity of LWSCC-S beams. In general, all equations over predicted the shear capacity of FRLWSCC-S beams and the use of such equations are in predictions is not recommended without any modifications and more investigations are necessary. In beams with shear reinforcement comparison between HDPE-LWSCC-S-S experimental results and values obtained from theoretical calculations showed the conservativeness of the equations. Campione (2013) (Eq. 5.9) was the most conservative with experimental to equation ratio of 2.7 and mean value of 1.73. CR-LWSCC-S-S beam also yielded higher experimental shear capacity compared to the values predicted from the equations with a mean ratio of 1.6 similar to CRLWSCC-S beam. Narayanan and Darwish equation (1988) and Sharma (1986) were conservative with ratios of 1.3 and 1.2, respectively for PVA-LWSCC-S-S beam. Khuntia et al., (1992) predicted the shear capacity of PVA-LWSCC-S-S beam more closely compared to other equations with experimental to equation ratio of 1.01. For LWSCC-S-S beams, experiment to equation ratio ranged between 0.94 and 1.6 with a mean ratio of 1.3 . Overall, these equations need to be modified for their application in FRLWSCC beams.

\subsection{Code based prediction of flexural capacity of FRLWSCC beams}

\subsubsection{Theoretical cracking moment of the FRLWSCC flexural beams}

When the concrete tensile stress reaches modulus of rapture $f_{r}$, the beam section will crack. The theoretical moment of cracking $\mathrm{M}_{\mathrm{cr}}$ at the first flexural crack of the beam can be obtain from ACI 318-08 using equation (5.15).

$\mathrm{M}_{\mathrm{cr}}=\frac{\mathrm{f}_{\mathrm{r}} \mathrm{I}_{\mathrm{g}}}{y_{t}}$

where $I_{g}$ gross moment area of cross-section and $y_{t}$ is the distance from the neutral axis.

Theoretical and experimental first flexural cracking moments for different FRLWSCC beams are compared in Table 5.4. The ratio of experimental to theoretical cracking moment for FRLWSCC beams ranges from 0.75 to 1.41 as shown in Table 5.4 Predicted cracking moments for LWSCC beam were reasonably close to those obtained from experiment. The ratio of experimental to theoretical cracking moment for LWSCC is 1.03. However, for FRLWSCC beams theoretical cracking moment was underestimated (experimental to predict ratios ranged between 1.36 and 1.41) compared to experiments except for HDPE LWSCC. 
Table 5.4 Experimental and theoretical cracking moment comparison

\begin{tabular}{|l|l|l|l|}
\hline Beam & $\begin{array}{l}\text { Experimental cracking } \\
\text { moment Mcr (kN.m) }\end{array}$ & $\begin{array}{l}\text { Theoretical cracking } \\
\text { moment Mcr (kN.m) }\end{array}$ & $\begin{array}{l}\text { Ratio of experimental to } \\
\text { theoretical cracking moment }\end{array}$ \\
\hline HDPE-LWSCC-F & 5 & 6.71 & 0.75 \\
\hline CR-LWSCC-F & 10 & 7.33 & 1.36 \\
\hline PVA-LWSCC-F & 10 & 7.1 & 1.41 \\
\hline LWSCC-F & 8 & 7.76 & 1.03 \\
\hline
\end{tabular}

\subsection{Theoretical ultimate moment of the LWSCC flexural beams}

According to engineering practice, it is required to evaluate the ultimate flexural capacity of a beam. At ultimate stage, maximum concrete compressive strain reaches to 0.0035 according to CSA A23.3 (2004) Code. At ultimate state, the tensile steel reinforcement could be either in elastic or plastic state. If the section is under-reinforced, it will be steel controlled failure by yielding of the tensile reinforcement and the nature of such failure is ductile. If the section is over reinforced, concrete-controlled failure by crushing of concrete can happen and the nature of this type of failure is brittle and, therefore steel-controlled failure are desirable and favored by designers.

As per CSA A23.3 (2004), the ultimate moment capacity $\left(\mathrm{M}_{\mathrm{u}}\right)$ can be obtained by using equations (5.16) and (5.17).

$\mathrm{M}_{\mathrm{u}}=\mathrm{f}_{\mathrm{y}} \mathrm{A}_{\mathrm{s}}\left(\mathrm{d}-\frac{\mathrm{a}}{2}\right)$

$a=\frac{f_{y} A_{s}}{\alpha_{1} f_{c}^{\prime} b}$

where As is the tensile steel area, fy is the yield strength of steel, b is the width of the beam and, $\propto_{1}$ is the stress factor.

Theoretical and experimental ultimate moments of FRLWSCC beams calculated as per CSA23.3 standard are presented in Table 5.5. Predicted ultimate moment for all different FRLWSCC beams based on CSA A23.3 were very close to those obtained from experiment - the ratio of experimental to theoretical ultimate moment ranged from 1.06 to 1.16. CSA A23.3 showed accurate prediction capabilities. 
Table 5.5 Comparison of experimental and theoretical ultimate moments of LWSCC beans

\begin{tabular}{|l|l|l|l|}
\hline Beam & $\begin{array}{l}\text { Experimental ultimate } \\
\text { moment } \mathrm{Mu}(\mathrm{kN} . \mathrm{m})\end{array}$ & $\begin{array}{l}\text { Theoretical ultimate } \\
\text { moment Mu (kN.m) }\end{array}$ & $\begin{array}{l}\text { Ratio of experimental to } \\
\text { theoretical ultimate moment }\end{array}$ \\
\hline HDPE-LWSCC-F & 24.3 & 22.43 & 1.08 \\
\hline CR-LWSCC-F & 24.9 & 22.68 & 1.10 \\
\hline PVA-LWSCC-F & 26.2 & 22.59 & 1.16 \\
\hline LWSCC-F & 24.2 & 22.81 & 1.06 \\
\hline
\end{tabular}

\subsection{Summery}

ACI 318, CSA A23.3 and BS8110 design codes were very conservative with the high margin of safety in predicting the ultimate shear strength of FRLWSCC beams without shear reinforcement. Lower margin of safety was also identified in predicting the concrete shear resistance of FRLWSCC beams with shear reinforcement compared to those without shear reinforcement, however, standards were also conservative in predicting shear capacity of beams with shear reinforcement. Narayanan and Darwish (1988) equation (5.11) was found most conservative in predicting shear capacity of beams with no shear reinforcement and with shear reinforcement.

CSA A23.3 code also found to predict closely the cracking moment and the ultimate moment capacities of FRLWSCC beams. 


\section{CHAPTER SIX}

\section{CONCLUSIONS}

\subsection{Introduction}

This research studied the shear and flexural strength of fiber reinforced lightweight selfconsolidating concrete (FRLWSCC) beams compared to their LWSCC counterparts. The variables of this experimental and theoretical (Code based and other existing equations) research are types of fiber (high density polyethylene 'HDPE', polyvinyl alcohol 'PVA' and crumb rubber 'CR') and the presence or absence of shear reinforcement.

\subsection{Shear resistance of FRLWSCC beams}

The test results of shear beams with and without shear reinforcement were described. Within the scope of the investigation, the following conclusions were drawn:

- The shear resistance capacity of FRLWSCC beams with and without shear reinforcement was higher than corresponding LWSCC beams.

- Higher deflection at peak load was observed for FRLWSCC beams with shear reinforcement compared to FRLWSCC beams without shear stiffness.

- FRLWSCC beams without shear reinforcement had higher post-cracking shear resistance (defined by shear resistance factor 'SRF) than their LWSCC counterparts except PVALWSCC beam which had lower SRF.

- Formation of first flexural crack was observed at lower loads among all FRLWSCC beams with and without shear reinforcements compared to their LWSCC counterparts.

- FRLWSCC beams without shear reinforcement had higher number of cracks and lower final crack width at failure stage compared to LWSCC beams.

- FRLWSCC beams with shear reinforcement behaved similar manner to FRLWSCC beams without shear reinforcement until formation of diagonal crack (showed the same diagonal cracking strength) and hence, shear reinforcement did not affect the concrete shear resistance capacity until the formation of diagonal crack. 
- FRLWSCC beams with shear reinforcement had higher stiffness, higher ultimate load carrying capacity and higher ductility compared to FRLWSCC beams without shear reinforcement.

- All FRLWSCC beams with and without shear reinforcement had higher ductility, higher energy absorption capacity compared to LWSCC beams.

- All design codes (CSA23.3, ACI M318 and BS8110) found to be conservatively predicted the shear capacity of the FRLWSCC beams with and without reinforcement. For all design codes, experimental to predicted shear strength ratios were high and these ratios ranged from 1.2 to 3.6 for FRLWSCC beams without shear reinforcement and 1.02 to 1.24 for FRLWSCC beams with shear reinforcement.

- It should be noted that overestimation by Codes was higher for FRLWSCC beams for both with and without shear reinforcements compared to LWSCC beams even after the use of reduction factors specified in the Codes. This could be attributed to contribution of fiber in increasing shear strength of FRLWSCC beams.

- Overall, current reduction factors suggested by the Codes for lightweight concrete can be increasedfor the prediction of shear resistance of FRLWSCC beams. This is reasonable considering the lower volume of weak lightweight aggregate (hence higher volume of strong paste) and presence of fiber in FRLWSCC compared to lightweight concrete.

- From the analysis of existing equations for shear strength, Shin (1996) equation predicted more accurately the shear capacity of FRLWSCC beams without shear reinforcement, except for PVA-LWSCC-S beams (over predicted by all equations).

- All existing equations (Narayanan and Darwish 1988, Ashour et al. 1992, Sharma 1986, Khuntia, et al. 1992, Campione 2013 and Al-Taan et al.1990) were very conservative in predicting shear strength of FRLWSCC beams with shear reinforcements except Shin et al. (1996) equation which overestimated the shear capacity of PVA-LWSCC beam with shear reinforcement.

\subsection{Flexural LWSCC beams}

The results of tested FRLWSCC and LWSCC flexural beams were discussed along with Canadian Code based (CSA.A23.3-04 2004) prediction of cracking and ultimate moment resistances. The following conclusions were drawn: 
- All FRLWSCC flexural beams showed typical structural behavior in flexure, since the beams were under-reinforced, yielding of the tensile reinforcement happened before crushing of the compression concrete in the pure bending region.

- The ultimate loads of the FRLWSCC beams were higher than LWSCC beam.

- All FRLWSCC beams had more cracks and lower crack width due to presence of fiber compared to LWSCC beam.

- FRLWSCC beams showed good ductility behavior since all the beams had shown significant amount of deformation before failure.

- FRLWSCC beams had higher energy absorption capacity with lower stiffness compared to LWSCC beam.

- CSA A23.3 code accurately predicted the cracking moment and ultimate moment capacities of FRLWSCC beams.

\subsection{Recommendations for future research studies}

The following recommendations are made for future research studies:

- Perform durability studies of FRLWSCC beams with different types of fibers under aggressive environments quantifying reinforcement corrosion and strength degradation.

- Investigate experimentally and theoretically (using various code based analyses) shear and flexure capacities of FRLWSCC beams with different type and volume of fibers.

- Perform strength and durability studies of FRLWSCC structural elements (such as columns, shear panels, beam-column joints, slabs etc.) made with different type of fibers.

- Perform investigation on the influence of geometry, shear span to depth ratio and reinforcement ratio on the shear strength.

- Develop or modify Code based procedures/specifications for structural design and durability requirements for various FRLWSCC structural elements. 


\section{Appendix A}

Based on the design procedure that explained in section 2.8, the calculated shear and moment resistance capacity of only FRLWSCC beams which contain HDPE fiber has been presented in appendix A as sample calculation.

\section{A.1 Shear and moment resisting capacity for HDPE-LWSCC beam}

\section{A.1.1 Beam shear resisting capacity}

Using equations 2.13 and 2.19, the shear resistance capacity of HDPE-LWCC-S-S can be calculated based on CSA A23.3-04 (2004).

$\mathrm{V}_{\mathrm{r}}=\mathrm{V}_{\mathrm{c}}+\mathrm{V}_{\mathrm{s}}$

Concrete shear capacity based on simplified method:

$\mathrm{V}_{\mathrm{c}}=\lambda \beta \sqrt{\mathrm{f}_{\mathrm{c}}^{\prime}} \mathrm{b}_{\mathrm{w}} \mathrm{d}$ when $\sqrt{\mathrm{f}_{\mathrm{c}}^{\prime}} \leq 8 \mathrm{Mpa}$

$\mathrm{V}_{\mathrm{c}}=0.75 \times 0.18 \times \sqrt{38.7} \times 100 \times 156.6=13151.6 \mathrm{~N}=13.15 \mathrm{kN}$

Stirrups contribution based on equation 2.17:

$\mathrm{V}_{\mathrm{s}}=1.43 \frac{\mathrm{A}_{\mathrm{v}}}{\mathrm{s}} \mathrm{f}_{\mathrm{y}} \mathrm{d}_{\mathrm{v}}$

$\mathrm{V}_{\mathrm{s}}=1.43 \frac{60}{133} 400 \times 156.6=40409.8 \mathrm{~N}=40.4 \mathrm{kN}$

$\mathrm{V}_{\mathrm{r}}=40.4+13.15=53.5 \mathrm{kN}$

Using equations 2.10 and 2.12 the ultimate shear capacity of tested beams can be calculated according to ACI 318M-08 (2008).

$\mathrm{V}_{\mathrm{r}}=\mathrm{V}_{\mathrm{c}}+\mathrm{V}_{\mathrm{s}}$

Concrete shear capacity:

$\mathrm{V}_{\mathrm{c}}=\left(0.16 \lambda \sqrt{\mathrm{f}_{\mathrm{c}}^{\prime}}+17 \rho_{\mathrm{w}} \frac{\mathrm{V}_{\mathrm{u}} \mathrm{d}}{\mathrm{M}_{\mathrm{u}}}\right)\left(\mathrm{b}_{\mathrm{w}} \mathrm{d}\right)$

$\mathrm{d}=200-20-\frac{10}{2}=175 \mathrm{~mm}$

$V_{c}=\left(0.16 \times 0.75 \times \sqrt{38.7}+17 \times 0.0115 \times \frac{47.5 \times 175}{12649}\right)(100 \times 175)=18284 \mathrm{~N}=18.28 \mathrm{kN}$ 
when: $\sqrt{\mathrm{f}_{\mathrm{c}}^{\prime}} \leq 8.3 \mathrm{Mpa}, \mathrm{V}_{\mathrm{c}} \leq 0.29 \lambda \sqrt{\mathrm{f}_{\mathrm{c}}^{\prime}} \mathrm{b}_{\mathrm{w}} \mathrm{d}$ and $\frac{\mathrm{V}_{\mathrm{u}} \mathrm{d}}{\mathrm{M}_{\mathrm{u}}} \leq 1.0$

$18.28 \leq 0.29 \times 0.75 \times \sqrt{38.7} \times 100 \times 175=23.67 \mathrm{kN}$ and $\frac{47.5 \times 175}{12649}=0.65 \leq 1.0$

Shear reinforcement capacity:

$V_{S}=\frac{A_{v} f_{y} d_{v}}{s}$

$d_{v} \geq\left\{\begin{array}{c}0.9 \times d \\ 0.72 \times h\end{array}\right.$

$\mathrm{d}_{\mathrm{v}}=0.9 \times 175=156.6 \mathrm{~mm}$

$\mathrm{V}_{\mathrm{S}}=\frac{60 \times 400 \times 204}{133}=36812 \mathrm{~N}=36.81 \mathrm{kN}$

$\mathrm{V}_{\mathrm{r}}=36.81+18.28=55.1 \mathrm{kN}$

Shear resistance capacity based on equations 2.20 and 2.21 according to BS8110-part1 (1997):

$\mathrm{V}_{\mathrm{c}}=0.79 *\left(\left(\frac{100 * \mathrm{~A}_{\mathrm{s}}}{\mathrm{b}_{\mathrm{w}} \mathrm{d}}\right)^{1 / 3} *\left(\frac{400}{\mathrm{~d}}\right)^{1 / 4} *\left(\mathrm{~b}_{\mathrm{w}} \mathrm{d}\right) *\left(\frac{\mathrm{f}_{\mathrm{cu}}}{25}\right)^{1 / 3}\right.$

$\mathrm{V}_{\mathrm{c}}=0.79 *\left(\left(\frac{100 \times 100}{100 \times 175}\right)^{\frac{1}{3}} \times\left(\frac{400}{175}\right)^{\frac{1}{4}} \times(100 \times 175) *\left(\frac{38.7}{25}\right)^{\frac{1}{3}}=13915 \mathrm{~N}=13.9 \mathrm{kN}\right.$

Shear resistance provided by stirrups:

$\mathrm{V}_{\mathrm{S}}=\frac{\mathrm{A}_{\mathrm{sv}}}{\mathrm{S}_{\mathrm{v}}} 0.95 \mathrm{f}_{\mathrm{yv}} \mathrm{d}$

$\mathrm{V}_{\mathrm{S}}=\frac{60}{133} \times 0.95 \times 400 \times 175=34971 \mathrm{~N}=35.1 \mathrm{kN}$

$\mathrm{V}_{\mathrm{r}}=35.1+13.9=49.0 \mathrm{kN}$ 
Proposed shear strength equation 2.1 by Campione (2013).

$V_{\mathrm{u}}=0.125\left(1+\frac{\mathrm{c}}{\mathrm{D}} \cdot \mathrm{F}\right) \cdot \sqrt{\mathrm{f}^{\prime}}+21 \cdot \rho \cdot \frac{\mathrm{d}}{\mathrm{a}}+0.15 \cdot \mathrm{F} \cdot \frac{\mathrm{d}}{\mathrm{a}} \cdot \sqrt{\mathrm{f}^{\prime}{ }_{\mathrm{c}}}$

$\mathrm{F}=\frac{0.1}{0.05} \times 0.5 \times 0.01=0.01$

$V_{\mathrm{u}}=0.125\left(1+\frac{20}{10} \times 0.01\right) \times \sqrt{38.7}+21 \times 0.0115 \times \frac{175}{266.3}+0.15 \times 0.01 \times \frac{175}{266.3} \times \sqrt{38.7}=$

$0.99 \mathrm{kN} / \mathrm{mm}^{2}$

$V_{\mathrm{c}}=0.99 \times 100 \times 175=17.32 \mathrm{kN}$

Proposed shear strength equation 2.2 by Al-Taan et al. (1990)

$v_{\mathrm{u}}=\mathrm{e}\left[0.17 \sqrt{{f^{\prime}}_{c}}+10.6 \rho\left(\frac{\mathrm{d}}{\mathrm{a}}\right)\right]+1.128 \mathrm{~F}$

where $\frac{\mathrm{a}}{\mathrm{d}} \leq 2.5, \mathrm{e}=2.5 \times \frac{175}{266.3}=1.64$

$\mathrm{F}=\frac{0.1}{0.05} \times 0.5 \times 0.01=0.01$

$\mathrm{V}_{u}=1.64 \times\left[0.17 \sqrt{38.7}+10.6 \times 0.0115\left(\frac{175}{266.3}\right)\right]+1.128 \times 0.01=1.87 \mathrm{kN} / \mathrm{mm}^{2}$

$V_{\mathrm{c}}=1.87 \times 100 \times 75=32.7 \mathrm{kN}$

Shear strength based on proposed equations 2.3 by Narayanan and Darwish (1988).

$\mathrm{V}_{u}=\mathrm{e}\left[0.24 \mathrm{f}_{\text {spfc }}+80 \rho\left(\frac{\mathrm{d}}{\mathrm{a}}\right)\right]+0.41 \tau \mathrm{F}$

$\mathrm{F}=\frac{0.1}{0.05} \times 0.5 \times 0.01=0.01$

$\mathrm{f}_{\mathrm{spfc}}=\frac{38.7}{20-\sqrt{0.01}}+0.7+0.1=2.75$

where $\frac{\mathrm{a}}{\mathrm{d}} \leq 2.8, \mathrm{e}=2.8 \times \frac{175}{266.3}=1.68$

$\mathrm{v}_{u}=1.68 \times\left((0.24 \times 2.75)+\left(80 \times 0.0115 \times \frac{175}{266.3}\right)\right)+0.41 \times 4.15 \times 0.01=1.13 \mathrm{kN} / \mathrm{mm}^{2}$

$\mathrm{V}_{\mathrm{c}}=1.13 \times(100 \times 175)=19.8 \mathrm{kN}$

Obtained shear strength based on proposed equation 2.4 by Ashour et al. (1992)

$V_{u}=\left(0.7 \sqrt{f_{c}^{\prime}}+7 F\right) \frac{d}{a}+17.20 \rho \frac{d}{a}$ 
$\mathrm{V}_{\mathrm{u}}=(0.7 \sqrt{38.7}+7 \times 0.01) \frac{175}{266.3}+17.20 \times 0.0115 \frac{175}{266.3}=3.02 \mathrm{kN} / \mathrm{mm}^{2}$

$\mathrm{V}_{\mathrm{c}}=3.02 \times(100 \times 175)=52.8 \mathrm{kN}$

Calculated shear strength based on proposed equation 2.5 by Sharma (1986):

$\mathrm{V}_{\mathrm{u}}=\mathrm{kf}_{\mathrm{t}}^{\prime}\left(\frac{\mathrm{d}}{\mathrm{a}}\right)^{0.25}$

$\mathrm{f}_{\mathrm{t}}^{\prime}=0.3 \times 38.7^{2 / 3}=3.43$

$\mathrm{k}=\frac{4}{9}=0.44$

$\mathrm{V}_{\mathrm{u}}=0.44 \times 3.43 \times\left(\frac{175}{266.3}\right)^{0.25}=1.37$

$\mathrm{V}_{\mathrm{c}}=1.37 \times(100 \times 175)=23.9 \mathrm{kN}$

Obtained shear strength according to proposed equation 2.6 by Khuntia et al. (1992)

$\left.\mathrm{V}_{\mathrm{u}}=(0.167 \propto+0.25 \mathrm{~F}) \sqrt{\mathrm{f}_{\mathrm{c}}^{\prime}}\right)$

where $\frac{\mathrm{a}}{\mathrm{d}}=1.53<2.5, \propto=2.5 \times\left(\frac{175}{266.3}\right)=1.63$

$\left.V_{u}=(0.167 \times 1.63+0.25 \times 0.01) \times \sqrt{38.7}\right)=1.71$

$\mathrm{V}_{\mathrm{c}}=1.71 \times(100 \times 175)=29.7 \mathrm{kN}$

Calculated shear strength according to proposed equation 2.7 by Shin et al. (1996)

$\mathrm{V}_{\mathrm{u}}=0.22 \mathrm{f}_{\mathrm{spfc}}+217 \rho \frac{\mathrm{d}}{\mathrm{a}}+0.834 \mathrm{~F}$, if $\frac{\mathrm{a}}{\mathrm{d}}<3$

$\frac{\mathrm{a}}{\mathrm{d}}=1.53<3$

$\mathrm{F}=\frac{0.1}{0.05} \times 0.5 \times 0.01=0.01$

$\mathrm{f}_{\mathrm{spfc}}=\frac{38.7}{20-\sqrt{0.01}}+0.7+0.1=2.75$

$V_{u}=(0.22 \times 2.75)+\left(217 \times 0.0115 \times \frac{175}{266.3}\right)+(0.834 \times 0.01)=2.24$

$\mathrm{V}_{\mathrm{c}}=2.24 \times(100 \times 175)=39.2 \mathrm{kN}$ 


\section{A.1.2 Theoretical moment of cracking capacity of HDPE-LWSCC-F}

$\mathrm{M}_{\mathrm{cr}}=\frac{\mathrm{f}_{\mathrm{r}} \mathrm{I}_{\mathrm{g}}}{\mathrm{y}_{\mathrm{t}}}$

$\mathrm{f}_{\mathrm{r}}=0.6 \times \sqrt{38.7}=3.73$

$Y_{g}=\frac{\left(\left(\frac{200000}{4500 \times \sqrt{38.7}}-1\right) \times 3 \times 100 \times 200\right)+\left(150 \times 230 \times \frac{230}{2}\right)}{\left(\frac{200000}{4500 \times \sqrt{38.7}}-1\right) \times 3 \times 100+(150 \times 230)}=119.3$

$I_{g}=\left(\frac{150 \times 230^{3}}{12}\right)+\left((150 \times 230) \times\left(119.3-\left(\frac{230}{2}\right)\right)\right)+\left(\frac{200000}{4500 \times \sqrt{38.7}} \times 200\right) \times(174-$

$119.3)=152314377.1 \mathrm{~mm}^{4}$

$\mathrm{M}_{\mathrm{cr}}=\frac{3.73 \times 152314377.1}{(204-119.3) \times 1000000}=6.7 \mathrm{kNm}$

\section{A.1.3 Theoretical moment of resistance capacity of HDPE-LWSCC-F}

$\mathrm{M}_{\mathrm{u}}=\mathrm{f}_{\mathrm{y}} \mathrm{A}_{\mathrm{s}}\left(\mathrm{d}-\frac{\mathrm{a}}{2}\right)$

$\propto_{1}=0.85-0.0015 \times 38.7=0.79$

$\mathrm{a}=\frac{400 \times 300}{0.79 \times 38.7 \times 150}=26.1$

$\mathrm{M}_{\mathrm{u}}=400 \times 300 \times \frac{200-\frac{26.1}{2}}{1000000}=22.43 \mathrm{kNm}$ 


\section{REFERENCES}

ACI Committee 211 (1981). Standard Practice for Selecting Proportions of Structural Lightweight Concrete (ACI 211.2-81). American Concrete Institute, Farmington Hills, USA.

ACI Committee 213 (2003). Guide for Structural Lightweight-Aggregate Concrete (ACI 213R03), American Concrete Institute, Farmington Hills, Farmington Hills, Michigan, pp.38.

ACI Committee 318, (2008), "Building Code Requirements for Structural Concrete", American Concrete Institute, Farmington Hills, Michigan, U.S.A. pp. 151.

ACI Committee (2005). Building Code Requirements for Structural Concrete (ACI 318-05) and Commentary (ACI 318R-05). American Concrete Institute.

Al-Khaiat1, H., \& Haque, N. (1999). Strength and durability of lightweight and normal weight concrete. Journal of materials in civil engineering. 231-235

Al-Ta'an, S. A., and Al-Feel, J. R. (1990). "Evaluation of shear resistance of fiber reinforced concrete beams." Cem. Concr. Compos., 12(2), 87-94.

ASTM C39 (2003). Standard test method for static modulus of elasticity and Poisson's ratio of concrete in compression. American Society for Testing and Materials, West Conshohocken, Pennsylvania, USA, 1-5.

ASTM C330 (2014). Standard specification for lightweight aggregates for structural concrete. American Society for Testing and Materials, West Conshohocken, Pennsylvania, USA, 14.

ASTM C78 / C78M, (2010), "Standard Test Method for Flexural Strength of Concrete (Using Simple Beam with Third-Point Loading)", Cement Standards and Concrete Standards, pp. 1-4.

Ashour, S.A., Sasanian, G.S., \& Wafer, F.F. (1992) Shear Behavior of High Strength Fiber Reinforced Concrete Beams, ACI Structural Journal, 89(2), 176-184.

Aydin, A. C. (2007). "Self compact ability of high volume hybrid fiber reinforced concrete." Constr. Build. Mater. 21(6), 1149-1154.

Bai Y, Ibrahim R. and Muhammed Basheer P. A. M. (2004). Properties of Lightweight Concrete Manufactured with Fly Ash, Furnace Bottom Ash, and Lytag, International Workshop on Sustainable Development and Concrete Technology, Beijing, China, pp.77-88. 
Batayneh, M. K., Marie, I., \& Asi, I. (2008). Promoting the use of crumb rubber concrete in developing countries. Waste Management, 28(11), 2171-2176.

Balendran, R. V. (1995). Estimating the elastic modulus of concrete made with artificially\nmanufactured lightweight aggregates. Structural Survey, 13(2), 16-20.

Bamforth, P. B. (1987). “The properties of high strength lightweight con- crete.” Concrete, 21(4), 8-9.

Bhavi, B. I. K., Reddy, V. V., \& Ullagaddi, P. B. (2012). Effect of Different Percentages of Waste High Density Polyethylene ( HDPE ) Fibres on the Properties of Fibre Reinforced Concrete, , Nature Environment and Pollution Technology, 11(3), 461-468.

Bogas, J. A., De Brito, J., \& Figueiredo, J. M. (2015). Mechanical characterization of concrete produced with recycled lightweight expanded clay aggregate concrete. Journal of Cleaner Production, 89, 187-195.

Bogas, J. A., Ferrer, B., Pontes, J., \& Real, S. (2017). Biphasic compressive behavior of structural lightweight concrete. ACI Materials Journal, 114(1), 49-56.

Bogas, J. A., \& Gomes, T. (2014). Mechanical and Durability Behaviour of Structural Lightweight Concrete Produced with Volcanic Scoria. Arabian Journal for Science and Engineering, 40(3), 705-717.

British Standards Institute. (1997). BS 8110-Part1:1997 Structural Use of Concrete, Code of Practice for Design and Construction, British Standards Institute, London.

Canadian Standards Association. (2004), "Design of Concrete Structures (CSA A23.3-04)," Canadian Standards Association, Rexdale, ON, Canada.

Campione, G. (2014). Flexural and Shear Resistance of Steel Fiber - Reinforced Lightweight Concrete Beams. Journal of Structural Engineering, 140(4), 1-9.

Cheeseman, C. R., Makinde, A., \& Bethanis, S. (2005). Properties of lightweight aggregate produced by rapid sintering of incinerator bottom ash. Resources, Conservation and Recycling, 43(2), 147-162.

Civilexi (2016): http://civilexi.blogspot.com/2016/10/self-compacting-concrete-scc.html 
Corinaldesi, V., \& Moriconi, G. (2015). Use of synthetic fibers in self-compacting lightweight aggregate concretes. Journal of Building Engineering, 4, 247-254.

Curcio, F., Galeota, D., Gallo, A., and Giammatteo, M., (1998), "High-performance Lightweight Concrete for the Precast Prestressed Concrete Industry", Proceeding. 4th International CANMET/ACI/JCI Symposium, To-kushima, Japan, pp. 389 - 406.

Diógenes, H. J. F., Cossolino, L. C., Pereira, A. H. A., Debs, M. K., \& Debs, A. L. H. C. (2011). Determination of modulus elasticity of concrete from acoustic response. Ibracon Structures and Materials Journal, 4(5), 792-813.

Ding, Y., Liu, S., Zhang, Y., and Thomas, A. (2008). "The investigation on the workability of fiber cocktail reinforced self-compacting high performance concrete." Constr. Build. Mater., 22(7), 1462-1470.

Dos Santos, A. C., de Arruda, A. M., da Silva, T. J., Vitor, P. C. P., \& Trautwein, L. M. (2017). Influence of coarse aggregate on concrete's elasticity modulus. Acta Scientiarum Technology, 39(1), 17-25.

Doukakis, J. P. (2013). Lightweight self consolidating fiber reinforced concrete, Master's Thesis, Rutgers, The State University of New Jersey, 43p.

Ehsani Y. A. (2013). Structursal behaivour of reinforcemt high performance concrete ftrames subjected to monotonic lateral loading, MASc Thesis, Ryerson University, Toronto, Canada.

ESCSI (2007). Physical Properties of Structural Lightweight Concrete, Chapter 6, 84117(April), 72, Expanded Shale, Clay \& Slate Institute (ESCSI), Salt Lake City, Utah, USA.

Ferrara, L., Park, Y. D., \& Shah, S. P. (2007). A method for mix-design of fiber-reinforced selfcompacting concrete. Cement and Concrete Research, 37(6), 957-971.

Garg, C., Pilani, B., \& Kumar, M.B.N.S. arg, C. (2014). Experimental Studies on Mechanical Properties of Polypropylene Fibre Based Sustainable Concrete, International Conference on Sustainable Civil Infrastructure, Hyderabad, India.

Gastebled O. J. and May I. M. (2001). Reinforced Concrete Beams Without Stirrups, ACI Structural Journal, Vol.98, No.18. 
Gencel, O., Ozel, C., Brostow, W., \& Martínez-Barrera, G. (2011). Mechanical properties of selfcompacting concrete reinforced with polypropylene fibres. Materials Research Innovations, 15(3), 216-225.

Gerritse, A. (1981). Design considerations for reinforced lightweight concrete. International Journal of Cement Composites and Lightweight Concrete, 3(1), 57-69.

Gonen, T. (2015). Mechanical and fresh properties of ber reinforced self-compacting lightweight concrete, 22, 313-318.

Hamoush, S., Abu-Lebdeh, T., \& Cummins, T. (2010). Deflection behavior of concrete beams reinforced with PVA micro-fibers. Construction and Building Materials, 24(11).

Hassan, A. A. A., Hossain, K. M. A., \& Lachemi, M. (2010). Structural assessment of corroded self-consolidating concrete beams. Engineering Structures, 32(3), 874-885.

Hossain, K. M. A. (2004a). Properties of volcanic pumice based cement and lightweight concrete. Cement and Concrete Research, 34(2), 283-291.

Hossain, K. M. A. (2004b). Properties of volcanic scoria based lightweight concrete. Magazine of Concrete Research, 56(2), 111-120.

Hossain, K. M. A., \& Lachemi, M. (2005). Thermal Conductivity and Acoustic Performance of Volcanic Pumice Based Composites. Materials Science Forum, 480-481, 611-616.

Hossain, K. M. A. (2006). Blended cement and lightweight concrete using scoria: mix design, strength, durability and heat insulation characteristics. International Journal of Physical Sciences, 1(1), 5-16.

Hossain, K. M. A., \& Lachemi, M. (2007a). Characteristics of Self-Consolidating Concrete Characteristics of Self-Consolidating Concrete Incorporating Volcanic Ash.

Hossain, K. M. A., \& Lachemi, M. (2007b). Mixture design, strength, durability, and fire resistance of lightweight pumice concrete. ACI Materials Journal, 104(5), 449-457.

Hossain, K. M. A. (2008). Bond characteristics of plain and deformed bars in lightweight pumice concrete. Construction and Building Materials, 22(7), 1491-1499. 
Hossain, Ahmed, S., \& Lachemi, M. (2011). Lightweight concrete incorporating pumice based blended cement and aggregate: Mechanical and durability characteristics. Construction and Building Materials, 25(3), 1186-1195.

Hossain, K. M. A., Julkarnine K.M.Y., \& Anwar M.S. (2015). Evolution of strength and durability of scoria concrete in sea environment. Evolution of strength and durability of scoria concrete in sea environment. Journal of Multidisciplinary Engineering Science and Technology (JMEST), 2(6), 1268-1275.

Hossain, K. M. A. (2015). Lightweight self-consolidating concrete with volcanic and other natural materials. ICE Journal of Construction Materials, 168(1), 35-44,

Hubertova, M., and Hela, R., (2007), "The Effect of Metakaolin and Silica Fume on the Properties of Lightweight Self-Consolidating Concrete", ACI Materials Journal, American Concrete Institute, Detroit, pp. 35-48.

Hwang, C. L., \& Hung, M. F. (2005). Durability design and performance of self-consolidating lightweight concrete. Construction and Building Materials, 19(8), 619-626.

Issa, C. A., \& Salem, G. (2013). Utilization of recycled crumb rubber as fine aggregates in concrete mix design. Construction and Building Materials, 42, 48-52.

JCI-DFRCC Committee. (2003). DFRCC terminology and application concepts. Journal of Advanced Concrete Technology, 1 (3), 335-340.

Juan K. Y. (2011). Cracking Mode and Shear Strength of Lightweight Concrete Beams, Doctoral Dissertation. Department of Civil and Environmental Engineering, National University of Singapore, Singapore.

Karahan, O., Ozbay, E., Hossain, K. M., Lachemi, M., \& Atis, C. D. (2012, July/August). Fresh, Mechanical, Transport and Durability Properties of Self-Consolidation Rubberized Concrete. ACI Materials Journal, 109(4), 413-420.

Khayat, K. H., and Roussel, Y. (2000). "Testing and performance of fiber-reinforced self consolidating concrete.” Mater. Struct. J., 33(6), 391-397.

Khuntia, M., Stojadinovic, B., \& Goel, S. (1999) Shear Strength of Normal and High-Strength Fiber Reinforced Concrete Beams without Stirrups, ACI Structural Journal, 96(2), 282290. 
Kiliç, A., Atiş, C. D., Yaşar, E., \& Özcan, F. (2003). High-strength lightweight concrete made with scoria aggregate containing mineral admixtures. Cement and Concrete Research, 33(10), 1595-1599.

Kim, H. K., Jeon, J. H., \& Lee, H. K. (2012). Workability, and mechanical, acoustic and thermal properties of lightweight aggregate concrete with a high volume of entrained air. Construction and Building Materials, 29, 193-200.

Kockal, N. U., \& Ozturan, T. (2011). Strength and elastic properties of structural lightweight concretes. Materials and Design, 32(4), 2396-2403.

Lachemi, M., Hossain, K. M. A., Lambros, V., and Bouzoubaâ, N. 2003. "Development of costeffective self-consolidating concrete incorpo- rating fly ash, slag cement or viscosity modifying admixtures.” ACI Mater. J., 419-425.

Li, V. C. (1995). New construction materials proliferate in Japan. Civil Engineering, 65(8), 38.

Li, V. C., Horii, H., Kabele, P., Kanda, T., \& Lim, Y. M. (2000). Repair and retrofit with engineered cementitious composites. Engineering Fracture Mechanics, 65(2-3), 317-334.

Lisantono, A., Praja, B. A., \& Hermawan, B. N. (2017). Flexural strength of self compacting fiber reinforced concrete beams using polypropylene fiber, American Institute of Physics.

Lo, T. Y., \& Cui, H. Z. (2004). Effect of porous lightweight aggregate on strength of concrete. Materials Letters, 58(6), 916-919.

Lotfy, A., Hossain, K. M. A., \& Lachemi, M. (2014). Application of statistical models in proportioning lightweight self-consolidating concrete with expanded clay aggregates Construction and Building Materials, 65(29) 450-469.

Lotfy, A. (2012). Lightweight Self-consolidating Concrete: Statistical Modelling, Mixture Design And Performance Evaluation, PhD Thesis, Ryerson University, Toronto, Canada.

Lotfy, A., Hossain, K. M. A., \& Lachemi, M. (2015a). Lightweight Self-consolidating Concrete with Expanded Shale Aggregates: Modelling and Optimization. International Journal of Concrete Structures and Materials, 9(2), 185-206.

Lotfy, A., Hossain, K. M. A., \& Lachemi, M. (2015b). Statistical models for the development of optimized furnace slag lightweight SCC, Cement and Concrete Composites, 55, 169-185. 
Lotfy, A., Hossain, K. M. A., \& Lachemi, M. (2016a). Durability properties of lightweight selfconsolidating concrete developed with three types of aggregates. Construction and Building Materials, 106 (1), 43-54.

Lotfy, A., Hossain, K. M. A., \& Lachemi, M. (2016b). Mix design and properties of lightweight self-consolidating concretes developed with furnace slag, expanded clay and expanded shale aggregates. Journal Sustainable Cement based Materials, Taylor and Francis, 5(5), 297-323.

Maghsoudi, A. A. (2011). Mix design and mechanical properties of self-compacting light weight concrete, 9(3), 1-7.

Malešev, M., Radonjanin, V., Lukić, I., \& Bulatović, V. (2014). The Effect of Aggregate, Type and Quantity of Cement on Modulus of Elasticity of Lightweight Aggregate Concrete. Arabian Journal for Science and Engineering, 39(2), 705-711

Mazaheripour, H., Ghanbarpour, S., Mirmoradi, S. H., \& Hosseinpour, I. (2011). The effect of polypropylene fibers on the properties of fresh and hardened lightweight self-compacting concrete. Construction and Building Materials, 25(1), 351-358.

Mohammed, B. S., Foo, W. L., Hossain, K. M. a., Abdullahi, M., \& Hossain, K. (2013). Flexural strength of palm oil clinker concrete beams. Materials and Design, 53, 325-331.

Narayanan, R., \& Darwish, IYS. (1988) Fiber Concrete Beams in Shear, ACI Structural Journal, 85(2), 141-149.

Nemati, K. M. (2015). Relationship between the compressive strength and modulus of elasticity of high-strength concrete. CBM-CI International Workshop, (October), 511-526.

Nehdi, M., and Ladanchuk, J. D. (2004). "Fiber synergy in fiber-reinforced self-consolidating concrete.” ACI Mater. J., 101(6), 508-517.

Nehme, S. G., László, R., \& Mir, A. El. (2017). Mechanical Performance of Steel Fiber Reinforced Self-compacting Concrete in Panels. Procedia Engineering, 196(June), 90-96.

Okamura, H., \& Ouchi, M. (2003). Self-Compacting Concrete. Journal of Advanced Concrete Technology, 1(1), 5-15. 
Pelisser, F., Zavarise, N., Longo, T. A., \& Bernardin, A. M. (2011). Concrete made with recycled tire rubber: Effect of alkaline activation and silica fume addition. Journal of Cleaner Production, 19(6-7), 757-763.

Sari, D., \& Pasamehmetoglu, A. G. (2005). The effects of gradation and admixture on the pumice lightweight aggregate concrete. Cement and Concrete Research, 35(5), 936-942.

Sathiyamoorthy, K. (2015), Shear and flexural behaviour of lightweight self-consolidating concrete beams, MASc Thesis, Ryerson University, Toronto, Canada.

Sathiyamoorthy, K., Hossain, K.M.A., \& Lotfy, A. (2016). Shear resistance of lightwieght selfconsolidating, (2015), 1-11.

Sengupta, R., Chakraborty, S., Bandyopadhyay, S., Dasgupta, S., Mukhopadhyay, R., Auddy, K., \& Deuri, a S. (2007). A Short Review on Rubber / Clay Nanocomposites With Emphasis on Mechanical Properties. Engineering, 47, 21-25.

Sereda, P. J., \& Litvan, G. G. (1980). Durability of Building Materials and Components, (1981), 1031.

Sideris, K. K., \& Savva, A. E. (2005). Durability of mixtures containing calcium nitrite based corrosion inhibitor. Cement and Concrete Composites, 27(2), 277-287.

Sharma, A.K. (1986) Shear Strength of Steel Fiber Reinforced Concrete Beams, ACI Structural Journal, 83(4), 624-628.

Shin, S.W., Oh, J.G., \& Ghosh, S.K. (1994) Shear Behavior of Laboratory-sized High Strength Concrete Beams Reinforced with Bars and Steel Fibers. ACI Special Publication 142, 181200.

Sobhan, K., \& Mashnad, M. (2002). Tensile Strength and Toughness of Soil-Cement-Fly-Ash Composite Reinforced with Recycled High-Density Polyethylene Strips. Journal of Materials in Civil Engineering, 14(2), 177-184.

Soroushian, P., Khan, A., \& Hsu, J. (1992). Mechanical Properties of Concrete Materials Reinforced with Polypropylene or Polyethylene Fibers. ACI Materials Journal, (89), 535540 . 
Su, N., Hsu, K.-C., \& Chai, H.-W. (2001). A simple mix design method for self-compacting concrete. Cement and Concrete Research, 31(12), 1799-1807.

Sukontasukkul, P., \& Wiwatpattanapong, S. (2009). Moderate Lightweight Concrete Mixed with Recycled Crumb Rubber. Thammasat Int. J. Sc. Tech., 14(1), 1-9.

Taylor H. P. J. (1970). Investigation of the Forces Carried Across Cracks in Reinforced Concrete Beams in Shear by Interlock of Aggregate (No. TR 42.447 Tech. Rpt.).

Topcu, I.B., (1997), "Semi-Lightweight Concretes Produced by Volcanic Ash", Cement and Concrete Research, Vol. 27, Issue. 1, pp. 15-21.

Vakhshouri, B., \& Nejadi, S. (2016). Mix design of light-weight self-compacting concrete. Case Studies in Construction Materials, 4, 1-14.

Wang, H. Y. (2009). Durability of self-consolidating lightweight aggregate concrete using dredged silt. Construction and Building Materials, 23(6), 2332-2337.

Wight J.K. and Macgregor J.G. (1997). Reinforced Concrete Mechanics and Design, Sixth Edition Upper Saddle River, NJ, Prentice Hall, U.S.A, pp.1143.

Yasar, E., Atis, C. D., Kilic, A., \& Gulsen, H. (2003). Strength properties of lightweight concrete made with basaltic pumice and fly ash. Materials Letters, 57(15), 2267-2270.

Yehia, S., Douba, A. E., Abdullahi, O., \& Farrag, S. (2016). Mechanical and durability evaluation of fiber-reinforced self-compacting concrete. Construction and Building Materials, 121(2), $120-133$. 